Portland State University

PDXScholar

\title{
The Dynamic Returns of Descriptive Representation: A Study of Race, Politics and Policy in Urban Governments
}

Stephanie Taylor Hawke Portland State University

Follow this and additional works at: https://pdxscholar.library.pdx.edu/open_access_etds

Part of the Public Affairs Commons, and the Public Policy Commons Let us know how access to this document benefits you.

\section{Recommended Citation}

Hawke, Stephanie Taylor, "The Dynamic Returns of Descriptive Representation: A Study of Race, Politics and Policy in Urban Governments" (2018). Dissertations and Theses. Paper 4399.

https://doi.org/10.15760/etd.6283

This Dissertation is brought to you for free and open access. It has been accepted for inclusion in Dissertations and Theses by an authorized administrator of PDXScholar. Please contact us if we can make this document more accessible: pdxscholar@pdx.edu. 
The Dynamic Returns of Descriptive Representation:

A Study of Race, Politics, and Policy in Urban Governments

by

Stephanie Taylor Hawke

A dissertation submitted in partial fulfillment of the requirements for the degree of

Doctor of Philosophy

in

Public Affairs and Policy

Dissertation Committee:

Melody Ellis Valdini, Chair

Masami Nishishiba

Kim Williams

Marisa Zapata

Portland State University

2018 
(C) 2018 Stephanie Taylor Hawke 


\begin{abstract}
In $2015,78 \%$ of Detroit's city council was African American - the highest percentage in the country. For decades, there had been an assumption in the academic and activist fields that a legislative body with such a high percentage of minority presence would produce incredible policy gains for that group (i.e. African American Detroiters). Instead, the council passed no Black racial policy. In a city where there were ostensibly no barriers for passing racial policy -- there were no subsequent policy gains. Though running contrary to existing scholarship, Detroit is not an anomaly; it is an indicator of the larger trend.

Using a mixed methods approach, I consider the impact of descriptive representation (i.e. presence of a minority group) on representation in policy (i.e. policy outcomes). The thesis that emerges from my examination is that the relationship between descriptive representation and representation in policy is not static, as has been suggested, but dynamic. The amount of representation in policy that a group achieves is a function of descriptive representation, but the relationship is not linear. More descriptive representation does not always predict more representation in policy. And indeed, cities with the most descriptive representation often have relatively low levels of representation in policy. This work challenges the current body of literature and calls for substantial revision of seminal theory.
\end{abstract}




\section{Dedication}

To Oakland - My home and my heart.

To Theo - With the hope of a more equitable tomorrow.

And to Tony - Thank you. For Everything. Always. 


\section{Acknowledgements}

I am grateful to those who have supported the creation and writing of this dissertation. Over many years, Dr. Melody Valdini has provided endless time and support, help and feedback. For this, and so much more, I will be forever grateful. Dr. Masami Nishishiba's wise counsel and strategic advice has helped me discover my career path. Dr. Kim Williams has the ability to find an interesting puzzle in any research question and provide invaluable, immediate insight. Finally, Dr. Marisa Zapata truly came through in a moment of need. Without any of these individuals, my project would have suffered immensely. Thank you all.

And thank you to my family and friends. You are all so dear to me; I could not have done any of this without you. 


\section{Table of Contents}

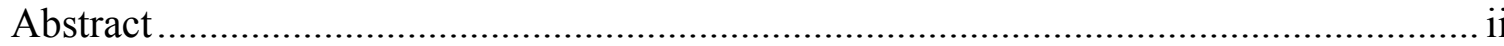

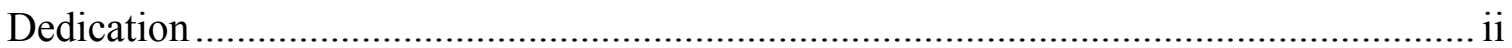

Acknowledgements ............................................................................................. ii

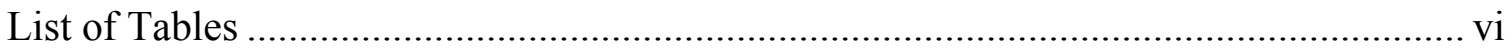

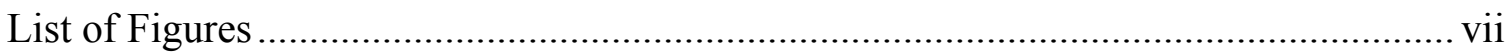

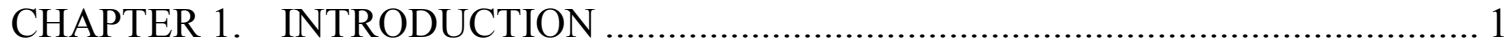

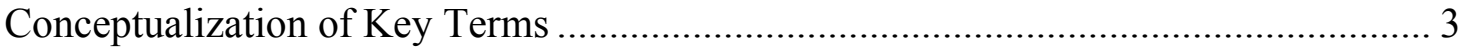

Conceptual Framework for the Study ................................................................... 8

Research Questions and Logic Models .............................................................. 10

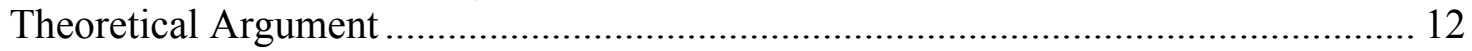

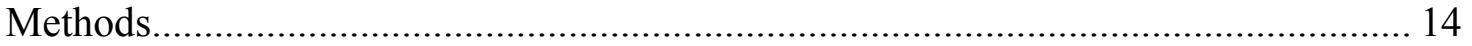

Significance of the Study ..................................................................................... 15

Limitations of the Study....................................................................................... 17

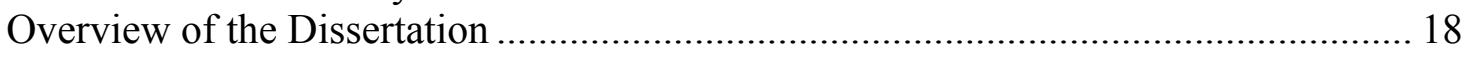

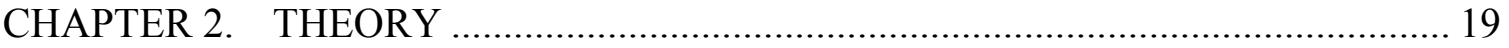

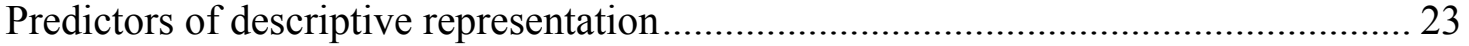

Descriptive Representation's effect on Representation in Policy - and a discussion of

Substantive Representation.................................................................................. 25

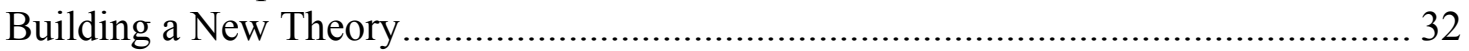

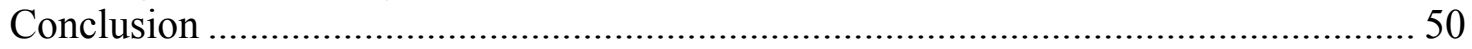

CHAPTER 3. QUANTIATIVE METHODS AND RESULTS …........................... 51

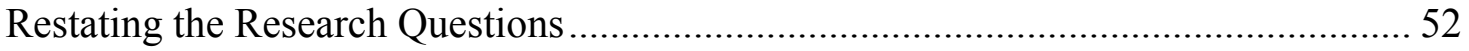

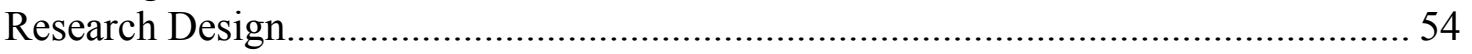

Key variable operationalization and data collection ................................................ 56

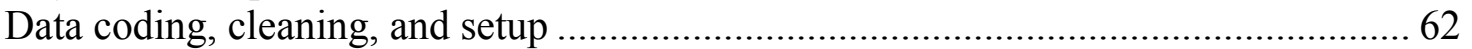

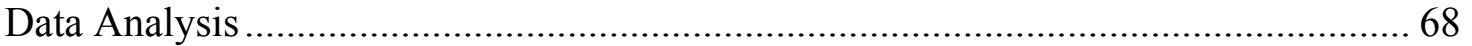

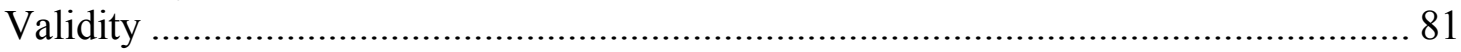

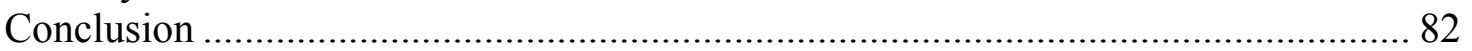

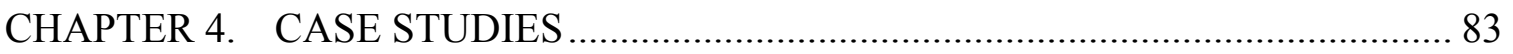

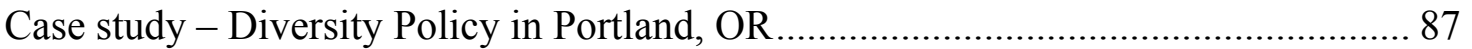

Case study - Asian Racial Policy in Minneapolis, MN ........................................... 93

Case Study - Diversity Policy in Albuquerque ......................................................... 97

Case study - Black Racial Policy in New Orleans, LA .......................................... 102

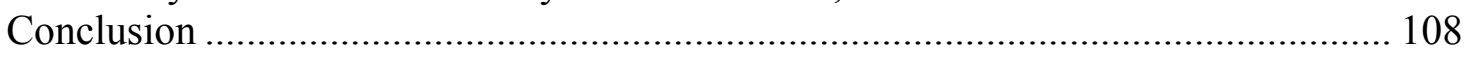

CHAPTER 5. DISCUSSION, IMPLICATIONS AND FUTURE RESEARCH......... 111

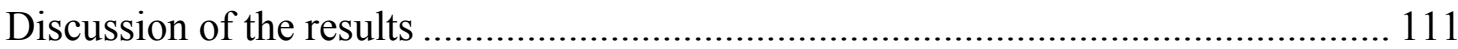

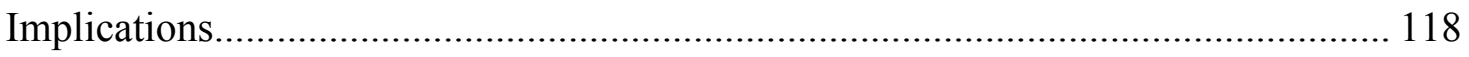




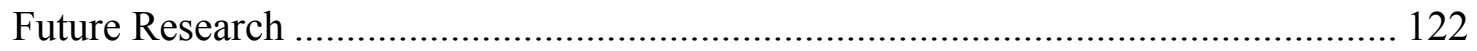

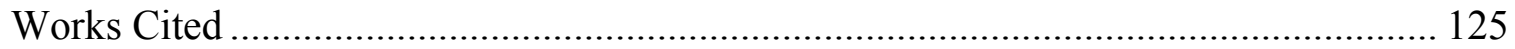

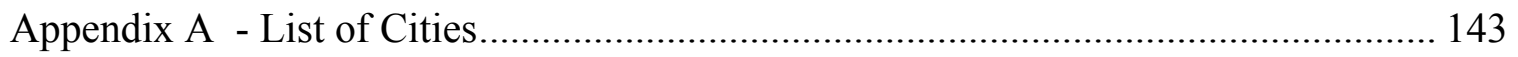

Appendix B - Indicators of Racial and Diversity policies ......................................... 146

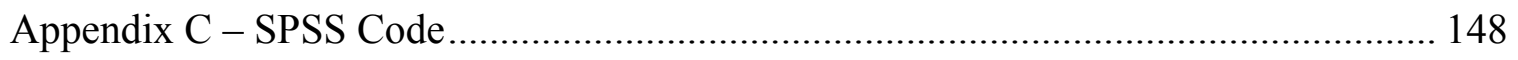

Appendix D - Explanation of creating the dataset ................................................. 155

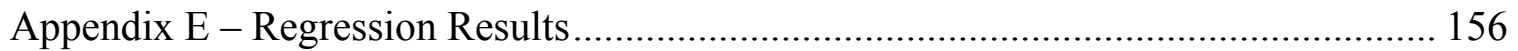

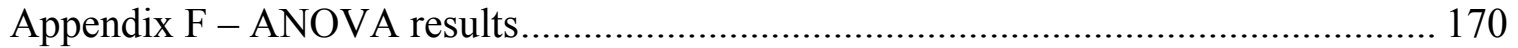




\section{List of Tables}

Table 1.1 Black Representation - highest descriptive representation in the country ......... 2

Table 1.2 Asian Representation - highest descriptive representation in the country .......... 2

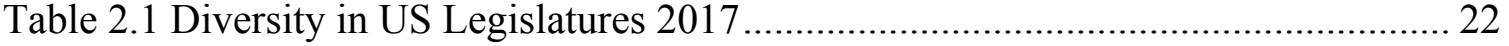

Table 3.1 Linear Regression Results, Racial Policy ........................................................ 70

Table 3.2 Cubic Regression Results, Racial Policy ..................................................... 71

Table 3.3 Linear Regression Results, Diversity Policy .............................................. 74

Table 3.4 Cubic Regression Results, Diversity Policy ................................................ 74

Table 3.5 ANOVA results, African American Descriptive Representation and Racial

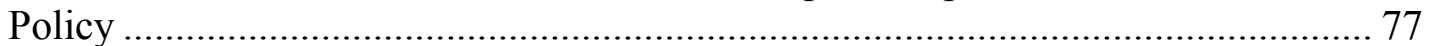

Table 3.6 ANOVA results, Latino Descriptive Representation and Racial Policy .......... 78

Table 3.7 ANOVA Results, General Descriptive Representation and Diversity Policy .. 80 


\section{List of Figures}

Figure 1.1 US Senate Racial Composition, 1990 - 2015 ............................................... 6

Figure 1.2 US House of Representatives Racial Composition, 1990 - 2015 ..................... 7

Figure 1.3 Theorized Curvilinear Relationship between Descriptive Representation and

Representation in Policy

Figure 2.1 City Variables affecting Descriptive Representation ..................................... 25

Figure 2.2 Traditional Understanding of Representation in Policy .................................. 35

Figure 2.3 Applying the Traditional Approach to Representation in Policy .................... 36

Figure 2.4 Theorized Curvilinear Relationship between Descriptive Representation and

Representation in Policy ................................................................................... 37

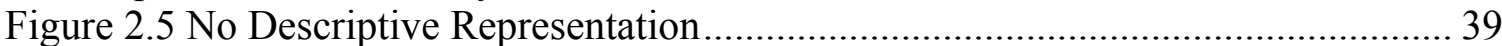

Figure 2.6 Hypothesized Relationship, No Descriptive Representation and Policy

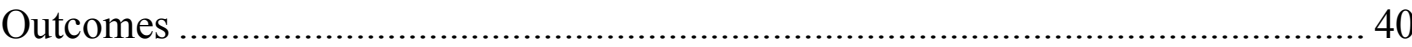

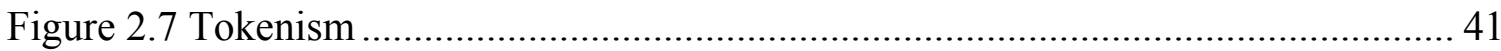

Figure 2.8 Hypothesized Relationship, Tokenism and Policy Outcomes......................... 42

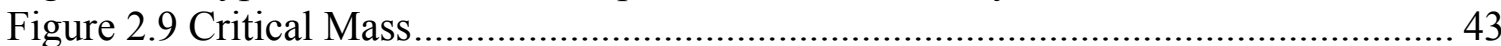

Figure 2.10 Hypothesized Relationship, Critical Mass and Policy Outcomes ................ 44

Figure 2.11 Majority Descriptive Representation......................................................... 49

Figure 2.12 Hypothesized Relationship, Majority Descriptive Representation and Policy

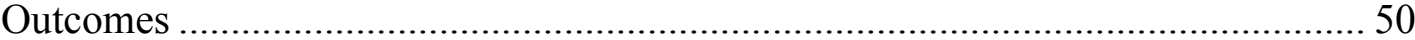

Figure 3.1 Plot of ANOVA results, African American Descriptive Representation and

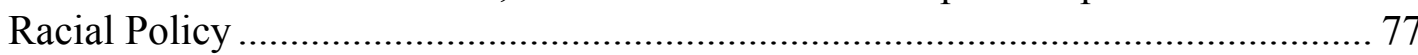

Figure 3.2 Plot of ANOVA results, Latino Descriptive Representation and Racial Policy

Figure 3.3 Plot of ANOVA Results, General Descriptive Representation and Diversity

Policy

79

Figure 4.1 Illustration of Portland's General Descriptive Representation .annento 91

Figure 4.2 General Descriptive Representation in Policy, Portland as Compared to the

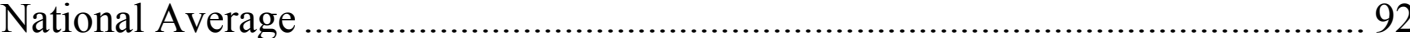

Figure 4.3 Illustration of Minneapolis' Asian Descriptive Representation....................... 96

Figure 4.4 Asian Representation in Policy, Minneapolis as Compared to National

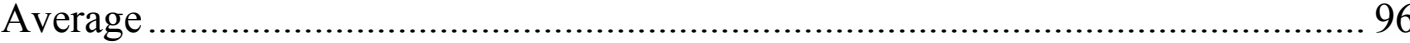

Figure 4.5 Illustration of Albuquerque's General Descriptive Representation ............... 102

Figure 4.6 General Representation in Policy, Albuquerque as Compared to National

Average 102

Figure 4.7 Illustration of New Orleans' Black Descriptive Representation.................... 107

Figure 4.8 Black Representation in Policy, New Orleans as Compared to National

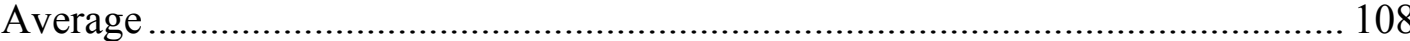

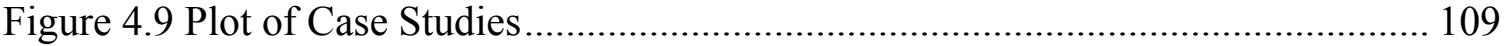




\section{CHAPTER 1. INTRODUCTION}

Representation is the foundation of modern democracy. As citizens of a democratic state, we agree to abdicate our right to vote on every piece of legislation, in favor of a less frequent vote for a representative. We believe that a representative will convey our policy preferences within the political arena. We believe that representatives are important, serving as both a conduit of our preferences and a reflection of our ideals.

With such an important role in democratic society, it is not surprising that representation has been studied with commitment and vigor. Starting perhaps with Hobbes' Leviathan, modern political scholars have spent considerable time, energy, and text exploring the mechanisms at work in representation. From the purely philosophical exploration (i.e. this is how representation should work, e.g. Pitkin (1967), Brown (2006), Tate (2001)), to the wholly practical (e.g. Epstein and O'Halloran's quantitative study aligning roll call votes and constituent surveys (1999b)) -much of the representation question has been answered. However, a gap remains in the field's understanding. My mission in this dissertation is to add clarity to an unanswered question in representation: how does presence affect policy outcomes? Representation is too important a topic, too foundational an issue, to leave parts of it in the shadows of murky understanding. My goal is to bring another corner of representation into the light.

Consider this example of a previously unanswered question: in $2015,78 \%$ of Detroit's city council was Black - the highest percentage in the country. For decades, there had been an assumption in the academic and activist fields that a legislative body 
with such a high percentage of minority presence would produce incredible policy gains for that group (i.e. Black Detroiters). Instead, no Black racial policy was passed. In a city where there were ostensibly no barriers for passing racial policy -- there were no subsequent policy gains. Though running contrary to existing scholarship, Detroit is not an anomaly; it is an indicator of the larger trend.

In the first iterations of this project, I devised a small-scale project that tested the existing representation theory in cities. My preliminary findings were not explained by the literature. As in Detroit, I found evidence of relatively high levels of representation in policy in cities with all white councils, and relatively low levels of representation in policy in cities with very diverse councils. The gains in presence were not mirrored in policy outcomes. Consider the data below, from the cities with the highest levels of Black and Asian descriptive representation in the country.

Table 1.1 Black Representation - highest descriptive representation in the country

City

Detroit

Atlanta

Birmingham
Descriptive Representation

$78 \%$

$69 \%$

$78 \%$ Representation in Policy* $0 \%$ $.08 \%$ $.12 \%$

* The average Black representation in policy in 2015 is $.29 \%$

Table 1.2 Asian Representation - highest descriptive representation in the country

City

Honolulu

Fremont, CA

San Francisco
Descriptive Representation

$89 \%$

$50 \%$

$45 \%$
Representation in

Policy**

$.5 \%$

$0 \%$

$.12 \%$ 
**Average Asian representation in policy is $.209 \%$

Previous literature has suggested that after a minority group achieves a certain level of presence on a legislative body, its policy shortfalls will be solved. Suddenly, minority groups will have the political power and capital to pursue a policy agenda that is geared almost exclusively towards their racial group. If that is not the case, as my work suggests, then there is considerable room for new theory, models and data to substantiate a new perspectives about representation.

This introductory chapter is organized as follows. I first discuss the conceptualization of key terms. Next, I present the problem statement - a summary of my perspective on what is missing from the literature and how my work rectifies this. Third, I present the conceptual framework that undergirds my study; this is a brief summary of the most pertinent theory and literature from the field. Fourth, I discuss my research questions and logic models. Fifth, I present my basic theoretical argument. Sixth, I review my methods, describing both the quantitative and qualitative approaches to answer the research questions. Finally, I lay out the limitations of my research, as well as an outline for the remainder of the dissertation.

\section{Conceptualization of Key Terms}

It is essential to establish a set of shared definitions and conceptualizations. In this section, I define the main concepts in the project. There are two main variables in the project: descriptive representation (the main independent variable) and representation in policy (the dependent variable). 
Descriptive representation is conceptualized in two ways - specific and general. Specific is belonging to a particular racial group (e.g. African American members of a council). General is belonging to any racial minority (e.g. minority members of council). Throughout this project, I refer both to the concept as a whole and, when appropriate, the bifurcated conceptualization into specific and general.

Throughout this dissertation, I use the phrases "representation in policy" or "policy outcomes" to describe the dependent variable in my models. Those familiar with the field may ask why I am not using the phrase "substantive representation", as it is common in the literature. I argue that the literature has mutated the original conception of substantive representation, bending and twisting the idea into something that is easy to measure but theoretically unrecognizable from Pitkin's original work. See Chapter 2 for a full discussion.

Representation in policy is also conceptualized in two ways: a) racial policy and b) diversity and equity policy. Racial policy is explicit about its racial nature, naming the racial group that it aims to affect. This idea emanates from David Canon's work Race, Redistricting, and Representation (1999). Canon writes, "Bills dealing with civil rights, discrimination, minority businesses, and historically black colleges; the racial justice act; the anti-redlining in insurance disclosure act; and dozens of pieces of commemorative legislation... are coded as racial" (D. Canon, 1999, p. 166). I use the same tactic, as have others (e.g. Epstein \& O’Halloran, 1999b; Weir, 2007).

Diversity and equity policy promotes diversity, equity and inclusion goals explicitly. To conceptualize diversity policy, I developed a definition parallel to that of 
Canon's racial policy. I defined diversity policy as policies that explicitly state their equity and diversity goals. This definition is supported by the field (e.g. Fassinger, 2008; M. N. Htun, 2003; Nishishiba, 2003; Tolbert \& Hero, 2001).

\section{Problem Statement}

I argue that the research setting of previous studies has had an incalculably large effect on the results and conclusions of the field. Despite the large body of research about descriptive representation and policy outcomes; there is no consensus. Stalwarts of the field are posed at opposing sides of the argument. Some say that descriptive representation leads to more representation in policy (e.g. Childs, 2001; Dahlerup, 1988; Mansbridge, 1999; Matsubayashi \& Rocha, 2012; Tate, 2001; Whitby \& Krause, 2001). Others argue that there is no link between the two variables, and that the evidence supporting a positive link between descriptive representation and policy outcomes is tenuous at best (e.g. Beckwith \& Cowell-Meyers, 2007; Z. L. Hajnal, 2001; Hero \& Tolbert, 1995; Lublin, 1997; Tausanovitch \& Warshaw, 2014). The reason for this disconnect is that the research setting has biased the results. The scholars are looking at only pieces of the picture, and missing the true nature of the relationship.

The majority of scholarship considers only state and regional legislatures - where descriptive representation is always low (see Figures 1.1 and 1.2 below) (Manning, 2016; Ornstein, 2014). 
Figure 1.1 US Senate Racial Composition, 1990 - 2015

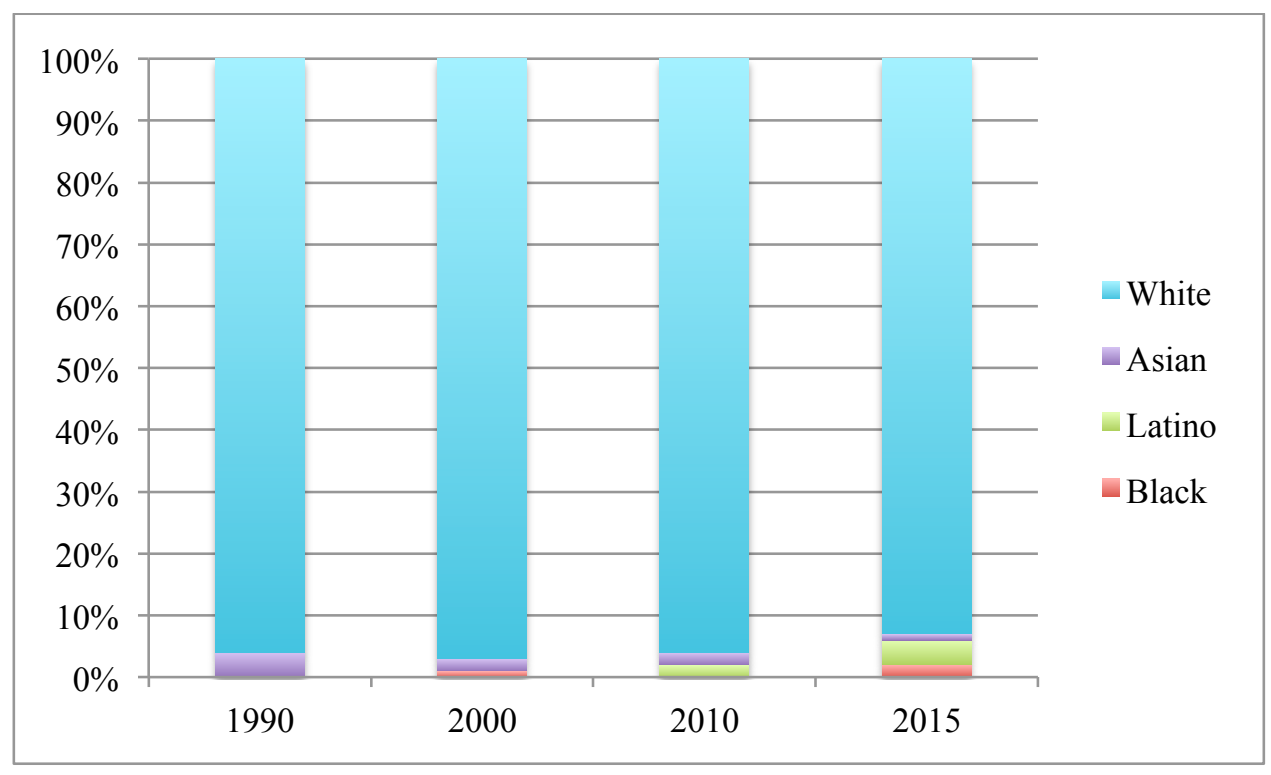


Figure 1.2 US House of Representatives Racial Composition, 1990 - 2015

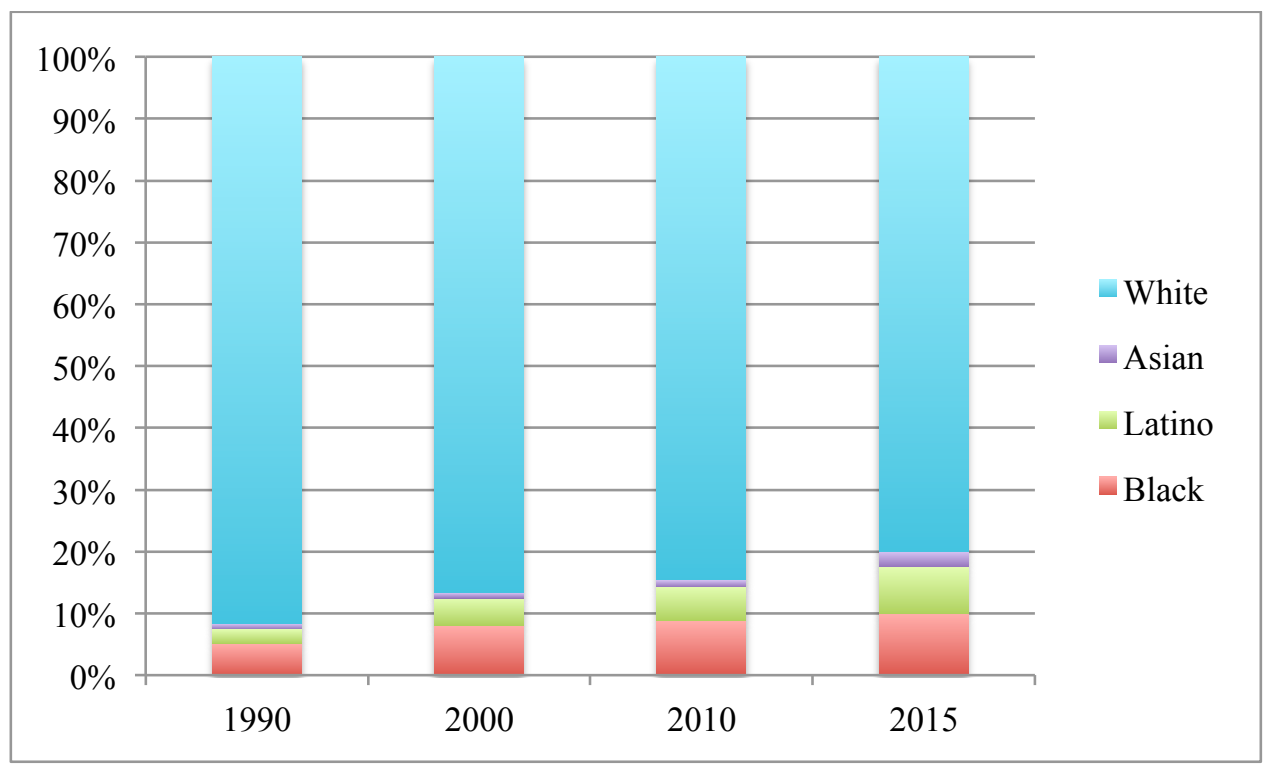

By choosing this frame of study, scholars have limited themselves; they have fallen into the fallacy of a restricted range of data. They are only seeing part of the real effect of descriptive representation, and thus, all sweeping claims about it should be considered suspect. My work here is part of that requisite further inquiry.

I test the impact of descriptive representation on policy outcomes. By looking at the local level, I circumvent the restricted range fallacy, including cases of very high and very low descriptive representation. The thesis that emerges from my examination is that the relationships are not static, as has been suggested, but dynamic. The amount of representation in policy that a group achieves is a function of the level of descriptive representation achieved, but it is not a linear relationship. More descriptive representation does not always predict more representation in policy. And indeed, cities with the most descriptive representation often have relatively low levels of representation in policy. 


\section{Conceptual Framework for the Study}

The conceptual framework of a study is the scaffolding that readers climb, making their way upwards to the author's final new argument. It provides the intellectual shortcuts for the reader, ensuring a shared foundation of knowledge upon which to place a new argument. My conceptual framework begins with Pitkin, moves to Kanter's, Dahlerup's and Mansbridge's critical mass theories, finally touching on Kanthak and Krause's tokenism theory. Though discussed in detail in Chapter 2, this section serves as grounding for the reader, ensuring common reference points.

A conversation about political representation must start with Hana Pitkin. She changed the field's understanding of representation in the modern context. Furthermore, she engendered one of the paramount concepts in my dissertation: descriptive representation. In her seminal book, The Concept of Representation (1967), Pitkin introduces four ways to discuss political representation, two of which are relevant to my study. Substantive representation is a key idea in this work but, as I discuss in detail below, it impossible to operationalize the concept; I therefore use 'representation in policy' in its place. Descriptive representation is the main independent variable across my models.

According to Pitkin, descriptive representation occurs when constituents share their primary identifying characteristic with their representative. The brilliance of Pitkin's definition of descriptive representation is that it both captures the important idea in its 
entirety ${ }^{1}$, and simultaneously is simple to measure. This has led to a robust body of literature about the causes and effects of varying levels of descriptive representation.

Roseabeth Moss Kanter's (1977) contribution to political representation conversations is somewhat unexpected. Unlike the other giants in the field that make up my conceptual framework, Kanter does not come from a political science background, but from a public and business administration lens. Her perspective on critical mass in the corporate world takes on the form of a typology about group dynamics - some with more and some with less representation of minority groups. Despite coming from a different research setting, one can, as I do, draw a straight line from Pitkin to Kanter to the researchers of today.

Drude Dahlerup was the next in line to make groundbreaking discoveries in terms of critical mass. Focusing on political representation, Dahlerup (1988) streamlines Kanter's four-part typology into two: large and small minority groups. In her 1999 article, Jane Mansbridge took the work previously done engendered the modern application of critical mass. Previous scholarship, looking for a link between descriptive representation and policy outcomes, had been flummoxed. There was an ostensibly logical connection: more women in the legislature (as was the focus of the study at the time) should lead to more policies for women. However, there was paltry evidence to support this claim. Counterintuitive quantitative results had stymied the field, until Mansbridge's addition: Critical mass. Simply, she writes that there have to be enough

\footnotetext{
${ }^{1}$ A relatively recent addition to the field is intersectionality in primary identities. For example, scholars have looked at Black representatives and women representatives, but far less attention was paid to Black women representatives. Though there is considerably more research on intersectional identities now, squaring that literature with that of Pitkin's descriptive representation has not yet happened in a convincing way. It is certainly an area of scholarship that should, and will, receive more attention in the years to come.
} 
women, or as she later extends it enough people of color, to see a measurable increase in representation in policy. When there are very few women in the legislature, their ability to coalesce and advocate for policy is limited. She finds that more women in the legislature leads to more policy favored by women -- but only after there are enough women as to affect policy outcomes.

Considering Pitkin, Dahlerup and Mansbridge together, the scaffolding for my dissertation starts to come together. I am exploring the interplay of representation and policy, with the wrinkle that different levels of descriptive representation have different effects on policy outcomes. Essentially, this is an extension of Dahlerup's and Mansbridge's logic. If pre-critical mass descriptive representation has a different effect on policy outcomes than post-critical mass - why stop there? Why not study the difference between no descriptive representation and tokenism? Why not explore the difference between critical mass and majority descriptive representation? Using the conceptual framework developed by these giants, and paired with the work on tokenism by Kanthak and Krause (2012), and my own theoretical work on no descriptive representation and majority descriptive representation, I start to develop a more complete understanding of how representation works - across all levels.

\section{Research Questions and Logic Models}

RQ1. In US cities with more than 200,000 residents, what is the relationship between specific descriptive representation and racial policy in 2015, holding relevant variables constant? (Model 1) 
RQ2. In US cities with more than 200,000 residents, what is the relationship between general descriptive representation and diversity and equity policy in 2015, holding relevant variables constant? (Model 2)

To illustrate these research questions and the hypothesized relationships, I devised two theoretical equations. These equations capture the key components of my theory. I used two conceptions of descriptive representation: specific and general. These two conceptions are paired with two conceptions of representation in policy: racial policy and diversity policy.

MODEL 1 representation in policy racial policy

$$
\begin{aligned}
& =\text { descriptive representation }{ }_{\text {specific }}{ }^{z}+\text { strength of mayor } \\
& + \text { mayor party }+ \text { mayor race }+ \text { city partisan ideology } \\
& + \text { one }_{\text {minority }}+\varepsilon
\end{aligned}
$$

MODEL 2 representation in policy diversity policy

$$
\begin{aligned}
& =\text { descriptive representation }{ }_{\text {general }}^{z}+\text { strength of mayor } \\
& + \text { mayor party }+ \text { mayor race }+ \text { city partisan ideology } \\
& + \text { one }_{\text {minority }}+\varepsilon
\end{aligned}
$$

I included five covariates in the models - a full discussion is in Chapter 3. They represent the elements that, according to the literature, also affect representation in policy. Therefore, they must be held constant - by including them in the model - to observe the true effect of descriptive representation on representation in policy. The 
covariates represent: the city's party ideology, the strength of the mayor, the mayor's party ideology, the mayor's race, and if there was only one minority member of the council.

An essential element of my model is the power to which descriptive representation is raised (i.e. the ${ }^{\wedge} \mathrm{z}$ notation in the models above). It represents that $\mathrm{I}$ am refuting the field's assertion that this is a linear relationship (i.e. $\mathrm{z}=1$ ), and that $\mathrm{I}$ believe that it is curvilinear (i.e. $z>3$ ). I test the curved nature of the relationships by running the model once as linear, then as quadratic, then cubic, and finally quartic.

\section{Theoretical Argument}

I argue that the racial composition of the legislature affects policy outcomes in differing ways. When the level of descriptive representation changes, the policy outcomes change as well. The political and electoral strategies of councilors change with changing levels of descriptive representation. Figure 1.3 below is a graphic representation of my hypothesized curvilinear relationship between the two variables. I expect to find this relationship both in terms of specific and general descriptive representation. 
Figure 1.3 Theorized Curvilinear Relationship between Descriptive Representation and Representation in Policy

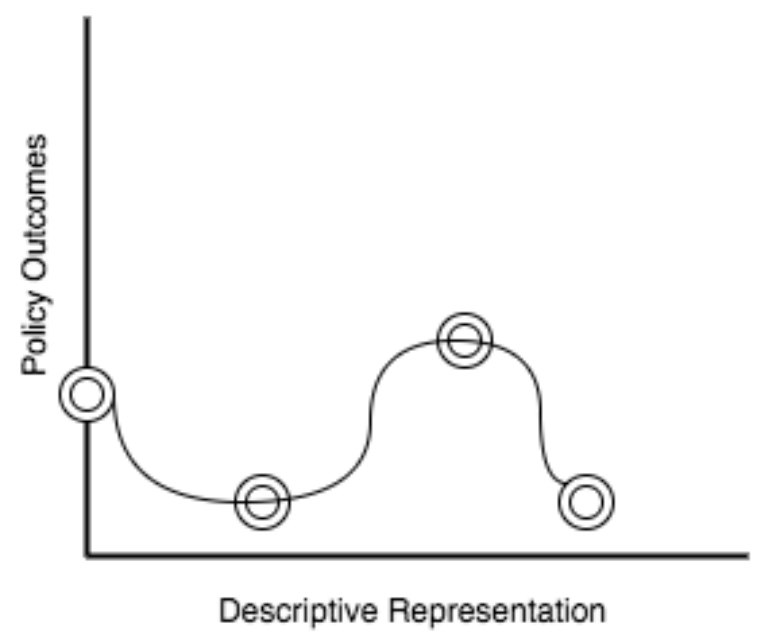

Explicitly, I argue that policy outcomes will change in the following ways. When there is no descriptive representation, I posit that there will be mid-level representation in policy, which can be attributed to politicians trying to stave off a descriptively representative challenger. When there is very low descriptive representation (i.e. tokenism), there will very little representation in policy for the group, attributed to "white backlash" (Abrajano \& Hajnal, 2015; Wilson, 2009). When there is mid-level descriptive representation (i.e. critical mass), there will be many policies passed for the group in question (see Mansbridge, 1999). When there is very high descriptive representation (i.e. majority descriptive representation), I expect to find a distinct drop in representation in policy. A racially defined bloc can only elect so many candidates before tapping its electoral power. To keep winning seats, descriptively representative candidates must pivot, and attract the support of other, issue-oriented voting blocs. Therefore, though the 
number of descriptively representative legislators has increased, fewer legislators are electorally reliant on the racial voting bloc. Instead they pursue policies that are favored by the voting blocs that did elect them. Thus, in majority descriptive representation descriptively representative legislators will predict less representation in policy.

\section{Methods}

I use a mixed-methods approach - pairing quantitative, big-n analysis with nuanced case studies. I developed criteria for selecting the cases, in accordance with the literature: mid-sized, liberal cities with similar institutions and political trends. For the quantitative piece, all cities in the US with populations greater than 200,000 $(n=116)$ were included. Eight of these cities were eventually excluded from the final analysis; see Chapter 3 for details. I look at a cross-section of data from $2015^{2}$ and identify policies of interest, coding them as (a) racial policy, (b) diversity policy, or (c) irrelevant to this study. The data collection process has simultaneously created a database for future research projects. Data analysis consisted of a series of regression models and ANOVA tests. Each iteration of the model tested specifications, like the effect of conflating variables and polynomials formats to test elements of my theory. This flexible approach is appropriate because of the exploratory nature of my project.

The qualitative piece of my project consists of four case studies. I developed criteria for selecting the cases: mid-sized liberal cities, with similar institutions and political trends, in different regions of the country. Using these criteria, informed by the literature, I chose: Albuquerque, NM; Minneapolis, MN; New Orleans, LA; and Portland,

\footnotetext{
${ }^{2}$ Or 2014 , if 2015 is an election year.
} 
OR. The results from these cases follow my theoretical and hypothesized relationships well. In addition to providing support for my theoretical contributions, the case studies are essential in that they provide incredible richness and depth of understanding in terms of the mechanism at work. They illustrate the political context and constraints facing councilors and help explain why, given those factors, variable levels of representative policy are passed.

\section{Significance of the Study}

My project contributes to the current state of knowledge in a few key ways. First, it marks a contribution to the theoretical field. I a look at the whole picture of representation, how representation works at all levels - from no descriptive representation to very high (i.e. majority descriptive representation). In addition to the theoretical contribution, there are important practical implications to this research. My argument is essentially that minority racial groups must choose between presence and political power. They can either shoot for the highest possible level of descriptive representation, or they can aim to wield the most power over policy. Currently, the data suggests that they cannot pursue both aims simultaneously.

This is, if nothing else, pessimistic. And the implications are grave for those who care about political representation as a normative good. But I argue that, with a perspective shift, this finding is more useful than worrisome. It calls for a new political strategy to leverage both presence and a political agenda. In addition to the theoretical 
contributions, my approach to this question is new in two other ways: (1) level of analysis, and (2) scope. These deviations from the field are described below.

\section{Level of analysis}

Considerable research has been done on representation at the state and regional levels. However, relatively few projects have considered representation at the local level (e.g. Meier, Stewart, \& England, 1991). Additionally, the scholarship that does exist was conducted between 1990 and 2005. My work adds to the studies that seriously focus on local representation politics. I contend that this addition to the field will help flesh out our understanding of the representative mechanisms, political incentives, and institutions at work in cities.

There is another reason why the level of analysis in my project is important: very high levels of descriptive representation have not yet been observed in the state or regional legislatures. These levels have occurred at the local level. This means that the studies that consider state and regional legislatures only consider cases with mid-level descriptive representation and thus are operating with a restricted range of data. The trends and conclusions that have been identified at the state and regional levels may only apply to mid-level descriptive representation. As legislatures, at any level, become more racially diverse then the applicability of previous studies will wane. 


\section{Scope: number of policies, number of cities, number of councilors}

Quantitative analyses are data-driven; the more quality data that one has access to, the more robust the results. The scope of my project is large. I comb through a vast number of policies. Over the 108 cities included in the study, I analyzed approximately 125,000 policies. I also collected and coded the racial identification data for 1,028 city councilors. I have not seen another study of this magnitude. The scope of this project allows for robust comparison and conclusions. Further, by collecting data from so many cities, I circumvent the need for a longitudinal study to increase the sample size.

\section{Limitations of the Study}

There are limitations to any study and mine is no exception. One possible critique is that my conception of representation in policy is too narrow. My choice to use racial policy and diversity and equity policy was thoughtful, and is described in Chapter 2. But there still may be those who claim that my definition of representation in policy is too limited. My work does not include policy that is not explicitly about race or diversity, but still disproportionately affects racial minority groups. I argue that it would be exceedingly difficult to capture these types of policies in a systematic quantitative way. These policies may be identified in a qualitative way, with thorough understanding of the context in which they are made. But to identify this type of policy across more than 100 city legislative contexts may be impossible - and is certainly outside of the scope of this project.

Another limitation to this study arises from data availability. I planned to include all cities with more than 200,000 residents in the US - 116 cities, based on the 2010 census. 
However, eight cities did not share their data in a usable format (see Chapter 3 for a thorough discussion). This is a limitation that was out of my control. Similarly, I had envisioned this study to test the relationships between three racial groups and related policy. However, there were so few cities with Asian representatives across the dataset that it was not feasible to test specific Asian descriptive representation's effect on policy outcomes through regression analysis. These two limitations were due to data availability.

\section{Overview of the Dissertation}

There are five chapters in my dissertation. The first, here, is an introduction to the key ideas, themes, concepts, arguments, and conclusions that will be addressed in the subsequent materials. The second chapter presents a thorough treatment of my theory; I summarize and build upon the literature to show that by coupling together related but distinct concepts, I discover theoretical answers to my research questions. The third chapter is a discussion of my methods choices and subsequent results from testing. I present my research procedure in detail, so that my results can be simply replicated in the future. The fourth chapter presents four case studies: Albuquerque, Minneapolis, New Orleans, and Portland, OR. Finally, the fifth chapter of my dissertation brings all elements of my study together. I discuss what the key conclusions from the research are, and the implications of this work for both scholars and political activists. 


\section{CHAPTER 2. THEORY}

Political representation is a tenet of political science and is best understood as a transaction between the elected official and his constituency (Anderson, 2000; Mansbridge, 2003; Przeworski, 2004). A constituency elects a representative who, in exchange, advocates for his constituency's preferred policies in the legislative arena. This transaction - votes for a voice in the political landscape - is understood by democratic participants; it is why we vote. Though the theory of transactional (or "economic", as termed by Anderson, 2000) democracy holds across cases, how this theory manifests in the real world can often produce surprising results.

The theory that I advance rests on the theoretical building blocks of rational choice and representational accountability. I argue the following: city-level institutional and structural variables consistently predict descriptive representation, but the relationship between descriptive representation and representation in policy is dynamic, varying in response to the amount of descriptive representation present.

Rational politicians act in a way to increase the likelihood of being reelected and retain political power (Downs, 1957). They calculate which groups are most likely to support them in the next election, and use their political power to pursue policies that are ostensibly aligned with that group's interests (Stone, 1993). To identify which groups will support the candidate in the next election, candidates use a variety of indicators including partisan support (e.g. running as a Democrat predicts Democratic electoral support) (Mcdermott, 2005), historical support (e.g. running as a labor candidate predicts union electoral support) (Popkin, 1995), and descriptive representation support (e.g. 
leveraging racial voting bloc support) (Mcdermott, 1998). For all, it is a rational calculation about which group will best serve their interests of maintaining political power (Downs, 1957; Stone, 1993).

With different racial compositions of the city council, a politician's rational calculation about which group will support them in the next election are different, and subsequently the politician's policy priorities are different. I argue that the effect of descriptive representation on representation in policy is neither constant nor always positive, contrary to the expectations of the majority of the literature (e.g. Banducci, Donovan, \& Karp, 2004; Dahlerup, 1988; Mansbridge, 1999; Swiss, Fallon, \& Burgos, 2012). Though many scholars have added nuance and subtlety to the hypothesized relationship between descriptive representation and representation in policy, none have yet taken these claims to their natural conclusions: there $i$ a predictable relationship between these two variables, across all levels, but that it is curvilinear and thus not captured by current theory. Specifically, this curvilinear relationship implies that more descriptive representation can predict less representation in policy, even when holding the relevant variables constant.

The local level differs from the regional and state governments in two ways that are relevant to this study and affect the application of previous literature to the questions at hand. First, the institutional constraints at the local level are different. Non-partisan elections, for example, have no corollary in US upper level institutions. The literature shows that non-partisan elections have a significant effect on descriptive representation at the local level (Pantoja \& Segura, 2003; Tausanovitch \& Warshaw, 2014; Uslaner \& 
Weber, 1983; Wängnerud, 2009). Therefore, superimposing theory that was created for upper level politics onto the local level is problematic, as the theory will not address key institutional variables. Additional institutions that do not have a corollary in upper level US politics: non-presidential forms of government (i.e. weak mayors or council-manager governments), variation in electoral system (i.e. partisan versus nonpartisan elections), and district versus at-large constituencies. These institutions are not addressed in the bulk of representation literature, but tangential research has shown that they are significant predictors of representation. Weak mayor systems predict more representation in policy (Egner \& Heinelt, 2008). Non-partisan elections predict more descriptive representation (Pantoja \& Segura, 2003; Tausanovitch \& Warshaw, 2014; Uslaner \& Weber, 1983; Wängnerud, 2009). District elections predict more descriptive representation (Davidson \& Korbel, 1981; Engstrom \& Mcdonald, 1981; Karnig \& Welch, 1980; Leal, MartinezEbers, \& Meier, 2004; Robinson \& Dye, 1978; Tausanovitch \& Warshaw, 2014; Trounstine \& Valdini, 2008; S. Welch, 1990). Institutions matter in representation, and to apply national theories to the local level is to erase the importance of key local institutional variables.

The second key difference between local politics in the US and state or regional politics in the US is the level of racial diversity. That is, local governments are markedly (and significantly) more racially diverse than their regional and state counterparts. Many scholars who discuss descriptive representation at the regional or state levels have cited low descriptive representation as a pitfall in their research. Grey (2006), for example, writes that the research setting of most studies rarely has $30 \%$ descriptive representation, 
let alone anything higher. And she notes that this is a real hindrance for theory creation.

Though this problem is recognized, it has not spawned a surfeit of studies on local

representation. There is a dramatic difference in racial diversity at the regional and state

levels versus at the local levels, as illustrated in Table 2.1 below. Values are for 2017.

Table 2.1 Diversity in US Legislatures 2017

\begin{tabular}{|c|c|c|c|c|c|}
\hline Legislature & $\begin{array}{l}\text { Percent } \\
\text { Asian }^{3}\end{array}$ & $\begin{array}{l}\text { Percent } \\
\text { Black }\end{array}$ & $\begin{array}{l}\text { Percent } \\
\text { Latino }^{4}\end{array}$ & $\begin{array}{l}\text { Percent } \\
\text { Native } \\
\text { American }\end{array}$ & $\begin{array}{l}\text { Percent } \\
\text { white }\end{array}$ \\
\hline US Senate $^{5}$ & $3 \%$ & $3 \%$ & $4 \%$ & $0 \%$ & $90 \%$ \\
\hline US House $^{6}$ & $3.4 \%$ & $10.6 \%$ & $9 \%$ & $.5 \%$ & $77.1 \%$ \\
\hline HI* & $57 \%$ & $1 \%$ & $1 \%$ & $0 \%$ & $22 \%$ \\
\hline $\mathrm{CA}^{*}$ & $10 \%$ & $9 \%$ & $19 \%$ & $0 \%$ & $62 \%$ \\
\hline Santa Ana, CA $\dagger$ & $0 \%$ & $0 \%$ & $100 \%$ & $0 \%$ & $0 \%$ \\
\hline Detroit, MI $\dagger$ & $0 \%$ & $78 \%$ & $11 \%$ & $0 \%$ & $11 \%$ \\
\hline
\end{tabular}

* Most diverse state legislatures in 2017

$\dagger$ Most diverse city councils in study

In this chapter, I provide an overview of existing theory and literature. I begin

with a discussion of the predictors of descriptive representation. In the second section, I discuss the current literature on descriptive representation's effect on representation in policy. In the third section, I provide evidence that a new theory is required, and in the fourth section, I present my theoretical contribution.

\footnotetext{
${ }^{3}$ Latino is a rollup category that I use throughout this study. Though the use of panethnic categories are supported by the literature (see Lopez \& Espiritu, 1990), this practice erases the ethnic differences between Latino groups in the US (e.g. the difference between Mexican Americans and Cuban Americans). It is problematic but it is also the best method that we have to conduct quantitative analyses across cities. New methods and further research are called for in the future.

${ }^{4}$ Asian, too, is a rollup category. See Footnote 3 for discussion.

${ }^{5} \mathrm{https}$ ://www.senate.gov/artandhistory/history/common/briefing/minority_senators.htm

${ }^{6} \mathrm{http}$ ://www.pewresearch.org/fact-tank/2017/01/24/115th-congress-sets-new-high-for-racial-ethnicdiversity/
} 


\section{Predictors of descriptive representation}

A review of the literature indicates that there are four key predictors of descriptive representation. They are: city demographics, electoral system, if a city has partisan elections, and the city's "partisan composition" (the term used by Reingold and Harrold 2010 , p. 281 to describe the party affiliation of city residents). Throughout this review, I pull from both the gender representation and racial representation bodies of literature. These fields are complementary, and it is exceedingly common to draw from both literatures. The most potent predictor of racial descriptive representation is demographics (Cameron, Epstein, \& O’Halloran, 1996; Kanthak \& Krause, 2012; Lublin, 1997). The predictors of racial descriptive representation markedly differ from the predictors of gender descriptive representation in this respect. The other three predictors - electoral system, partisan elections, and partisan affiliation - are prominent in both literatures.

The impact of district elections on descriptive representation outcomes has been extensively researched. Results from the research suggest a consensus: minority candidates tend to do better in district elections (Davidson \& Korbel, 1981; Engstrom \& Mcdonald, 1981; Karnig \& Welch, 1980; Leal et al., 2004; Robinson \& Dye, 1978; Tausanovitch \& Warshaw, 2014; Trounstine \& Valdini, 2008; S. Welch, 1990). Though the field agrees on the direction of the relationship, many scholars have had added to this theory. Trounstine and Valdini (2008) for example, write that the effect of district elections on the election of African American candidates is larger, and stronger, than for Latino candidates. Others take an inverse approach, arguing not that district elections are 
better for minority candidates, but that at-large elections are so much worse (Engstrom \& Mcdonald, 1981).

The second predictor in the descriptive representation literature is the presence of partisan elections. Nonpartisan elections predict that incumbents win (Pantoja \& Segura, 2003; Tausanovitch \& Warshaw, 2014; Uslaner \& Weber, 1983; Wängnerud, 2009). Voters have less information in nonpartisan elections (in that they do not know which party the candidate belongs to). Voters base their decisions on the information they $d o$ have. Incumbency, for example, has an outsized influence on voter decisions in nonpartisan elections (Krebs, 1998). Voters choose incumbents when they have little information, and thus incumbents do far better in nonpartisan elections (Wright, Schaffner, Streb, \& Wright, 2001).

Party matters. In terms of this dissertation, a city's partisan composition matters. Party predicts institutions, outcomes and, related to this discussion, descriptive representation. If a city consistently votes Democrat, it is more likely to elect representatives of color (Cameron et al., 1996; Gay, 2002; Pantoja \& Segura, 2003; Preuhs, 2007; Reingold, 2000). The mass of evidence is further substantiated by Hajnal (2001), who finds a causal mechanism: cities that vote consistently for Democrats are more politically liberal, and cities that are more liberal tend to elect more minorities.

Finally, the most consistent and powerful predictor of racial descriptive representation: city demographics. Large populations of racial minorities predict high levels of descriptive representation (Karnig \& Welch, 1980; Lublin, 1997; Tate, 2001). This connection has been investigated at all levels of government - from regional and 
state to local bodies -- and the results are the same. Results are consistent whether one studies majority-minority voting districts for US Congress (Cameron et al., 1996; Lublin, 1999) or school board elections (Browning, Marshall, \& Tabb, 1997; Meier \& England, 1984). More racial diversity in the constituency predicts more racial diversity in the legislature.

Considered in concert these four variables create a robust predictive theoretical model for descriptive representation. If there are more members of a minority group in the city, expect more descriptive representation. If there is a district type election in the city, expect more descriptive representation. If there are partisan elections, expect more descriptive representation. And, finally, if the city tends to vote Democrat, expect more descriptive representation.

Figure 2.1 City Variables affecting Descriptive Representation

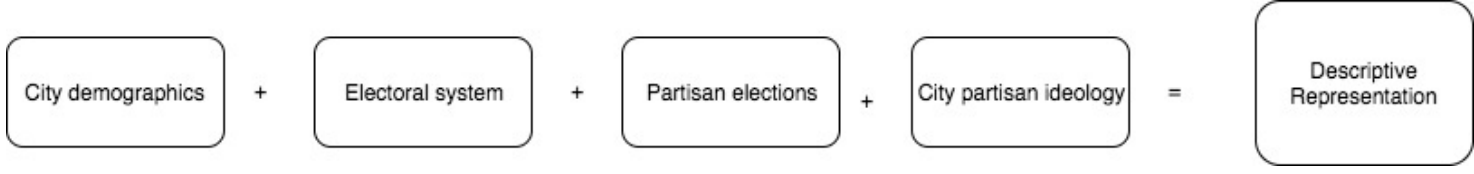

\section{Descriptive Representation's effect on Representation in Policy - and a discussion of Substantive Representation}

There may be consensus about what factors predict descriptive representation; the field is much more divided when the discussion turns to how descriptive representation affects representation in policy. Though it feels intuitively like there should be a link between the two, the evidence is tenuous and the fight is contentious. 
The most prominent theme in the substantive representation literature ${ }^{7}$ is an exploration of whether descriptive representation is, or is not, a significant predictor of substantive representation. Nearly all articles about substantive representation are looking for some sort of causal relationship - testing sets of variables and covariates to determine an explanation for changes in substantive representation. There are countless studies about descriptive representation alone (Google Scholar returns 743,000 results to the query "political AND descriptive representation"), whereas there are far fewer that discuss substantive representation without descriptive (the parallel search returns 308,000 articles).

There are divergent findings when considering if, and when, descriptive representation predicts substantive representation. There are scholars who argue that there is a strong, substantiated link between the two, that they are "linked in significant ways" (Gerber, Morton, \& Rietz, 1998, p. 127) (e.g. Bratton \& Haynie, 1999; Leal et al., 2004; Matsubayashi \& Rocha, 2012; Swiss et al., 2012; Tate, 2001; Taylor-Robinson \& Heath, 2003; Thomas, 1991; Whitby \& Krause, 2001). Many have added nuance to the relationship, like finding support only when socioeconomic and institutional variables are held constant (e.g. Matsubayashi \& Rocha, 2012) or when substantive representation is defined in terms of policies with concentrated - as opposed to diffuse - benefits (Whitby \& Krause, 2001).

For every scholar who argues that descriptive representation leads to more substantive representation, there is someone who argues that there is no evidence of the

\footnotetext{
${ }^{7}$ Though previous researchers have used substantive representation as an operationalized variable - an approach that I disagree with -they have made substantial contributions to the way we understand political representation
} 
link (Vega \& Firestone, 1995) (e.g. Banducci et al., 2004; Dovi, 2002). Others write that though the theory is compelling, the empirical evidence of substantive representation following descriptive representation is inconclusive (Childs \& Krook, 2008; Vega \& Firestone, 1995). Some find that more descriptive representation leads to less support of minority-sponsored legislation (Cameron et al., 1996) and a decrease in effective policy making (Carroll, 2001). Some say that this is because minority members of congress sponsor fewer bills and are less politically active than their white counterparts (Rocca \& Sanchez, 2007). Others have found simply no evidence of the link at all both in the US (Z. L. Hajnal, 2001; Hero \& Tolbert, 1995) and in international contexts (Johnson III, 1998). "If the presumption is that all women or all black people share the same preferences and goals, this is clearly - and dangerously - erroneous" (Phillips, 1995, p. 157).

And there are many studies that corroborate Phillips' normative argument. Though most scholars acknowledge the logical appeal of the descriptive representationsubstantive representation link, they point to a dearth of empirical evidence (e.g. Childs \& Krook, 2008). There are those whose results show, explicitly, that descriptive representation has not led to increased substantive representation for Latinos (Hero \& Tolbert, 1995), African Americans (Z. L. Hajnal, 2001; Lublin, 1997; Shotts, 2003) or women (Childs \& Krook, 2009). Finally, there are scholars who argue that there are far more important predictors of substantive representation. Institutions, for example, are cited as the most important indicator of policy outcomes (Peterson, 1995; Tausanovitch \& Warshaw, 2014; Trounstine \& Valdini, 2008). 
In addition to those who categorically argue in favor or against a link, there are those who add a wrinkle to the argument. Far and away, the most cogent nuance added to this theory is critical mass. Critical mass theorists argue that there is a positive relationship between the two variables - after descriptive representation has reached a certain point. This idea was championed first by Dahlerup $(1988,2006)$ and then turned into a full fledged theory by Mansbridge (1999). They argue that minority groups (i.e. racial minorities or women) must gain a certain percentage of the legislature before they can effectively influence policy. Kanter and Dahlerup both argue that once critical mass is achieved, once a large minority is gained, the increase in policy outcomes is not a simple, steady linear slope - it is exponential. Representation in policy is not a constant function of descriptive representation; when descriptive representation achieves a certain magnitude, the returns in representation in policy are vast.

The problem with critical mass is that, despite decades of research, there is no consensus within the field as to the level of descriptive representation that must be achieved before subsequent policy gains come to fruition. Where Dahlerup defined critical mass (or "large minority" to use her phrase from the 1988 article) as more than $20 \%$, Mansbridge argues that $30 \%$ is the actual threshold, and Epstein and O'Halloran (1999) argue that $45 \%$ is more likely to be correct. This infighting has led some scholars to argue that while critical mass is an appealing theory, the inability to substantiate it with evidence is problematic - and perhaps implies that the theory itself is flawed (Beckwith \& Cowell-Meyers, 2007). 
Since the publication of these seminal works, the argument about the exact value of critical mass has become stauncher, and more important to subsequent research (Vega \& Firestone, 1995). Some say critical mass can be observed when the minority population reaches just $20 \%$ (e.g. Swiss et al., 2012); others directly dispute that claim (Beckwith \& Cowell-Meyers, 2007). Others complicate it by saying, for example, $45 \%$ is the critical mass cut point, but only when the city's demographics are $45 \%$ minority, too (Epstein \& O'Halloran, 1998). For most, these divergences do not negate the importance of critical mass as a theory ${ }^{8}$, however. As stated, critical mass has been developed in the theoretical realm; researchers have found a theoretical grounding to be sufficient for their research. My project, however, requires an actual critical mass value; that is, my research design requires the testing of explicit values. Fortunately, the research design also provides ample opportunity to test the theoretical cut points that have been previously suggested by the literature; see Chapter 3 for a thorough discussion. Though the theoretical base of critical mass is solid, the practical, applicable definition is not.

In this project, I test an applied critical mass in an appropriately diverse setting. As Grey et al. (2006) writes, this undertaking is relatively rare and therefore this is a main contribution of my work. When there has been applied research, the field is marked with stark divergences about the predictive power of critical mass. Perhaps some of this conflict arises from a striking gap in the theoretical literature: an agreed upon definitive value of critical mass. Indeed, the foundation of the field is based on this rift: Kanter writes that critical mass is defined as $40 \%$ of a legislature; Dahlerup writes that it is

\footnotetext{
${ }^{8}$ Some say that critical mass theory is under-theorized. They argue that because there is no agreed-upon value for critical mass, so it is impossible to systematically study (Beckwith \& Cowell-Meyers, 2007).
} 
defined as $30 \%$ of the legislature. Theoretically, this difference may be unimportant. When it comes to testing the theory, however, it is critical.

In summary, there are decades of research about substantive representation and its causes. Yet the field has not reached consensus. There are powerful arguments and evidence supporting that descriptive representation leads to substantive representation. But there are equally powerful arguments and evidence claiming that there is no causal relationship. This split in the field is not unique, but it is troubling. I argue that the relationship between descriptive representation and substantive representation is much more complex than the scholarship presented here and that, when thinking of it as a multi-dimensional, curvilinear relationship, many of these arguments are not actually atodds, but part of a larger picture.

\section{The argument against 'Substantive Representation'}

Pitkin defines substantive representation as when a legislator acts in the best interest of a group. Theoretically, this is clear. But identifying examples of this is difficult, she writes; it is very hard identify the best interests of a group (Phillips, 1995; Pitkin, 1967). Pitkin concludes that substantive representation may never be measurable in a quantitative sense.

Pitkin was explicit in her skepticism of an operationalized, quantitative substantive representation. Despite the warning, countless scholars have done exactly this. Most have used substantive representation as a tool for talking about policy outcomes, for identifying when a legislator is acting for a stated group. Those scholars who have tried to thoroughly understand and measure operationalized substantive 
representation wind up tangled in complex strains of logic and methods. For example, Bratton and Haynie (1999) try to operationalize substantive representation in terms of Black interest bills writing,

Black interest legislation includes those bills that may decrease racial discrimination or alleviate the effects of such discrimination, and those that are intended to improve the socioeconomic status of African Americans. Some specific examples are: a bill that requires school integration and a bill that increases funding of sickle-cell anemia research... Bills that, in the judgment of the authors, hindered the social, economic or political advancement of African Americans or women were not included in these categories. For example, bills that attempted to preserve school segregation or end affirmative action were not considered black interest bills

(Bratton \& Haynie, 1999)

This definition relies almost entirely on the discretion of the researcher. Scholars must judge, case-by-case, whether the legislation supports Black interests. The possibilities for Type I and II errors are staggering, never mind that the idea of "Black interests" is an inherently subjective criterion. Ask 10 different scholars - or politicians, or community members - what is in the best interest of the Black community and you will have 10 different answers. As a rubric for identifying representative policy - the crucial dependent variable - relying only on the "judgment of the authors" is, at best, impossible to replicate. At worst, it is entirely unscientific.

This is not my only problem with the treatment of substantive representation. Even if a researcher were to overcome the issue of systematically identifying the supposed substantive representation bills, there is another major hurdle. The definition of substantive representation requires assumptions about the mindset of the legislator. The method that is used frequently assumes that the researcher and the legislator have the 
same beliefs about what benefits a group. Further, it implies that the legislator and the researcher both have perfect information - or at least both have the exact same information. Both the legislator and the researcher have to have the same understanding of the context of the bill, the impacts of the bill, and the politics of the bill. These pieces of information are the only way to determine whether legislation is in the best interest of a group. To say that a legislator is actively substantively representing a group would mean that the researcher knows exactly what the legislator knows about bill and have made the same determinations.

In summary, substantive representation should not be operationalized. It is too nebulous a term. It is subjective; to measure it, a researcher has to rely too heavily on his judgment. Further, identifying supposed cases of substantive representation implies that the researcher and the legislator have exactly the same information. They both know exactly the impact of the bill - including unintended short and long term consequences, the politics of the bill and the context in which the bill came to be. It is simply not possible, nor scientific, to use an operationalized substantive representation variable in a quantitative study.

\section{Building a New Theory}

Briefly, the literature says that there are three steps in the relationship between descriptive representation and representation in policy. First, voters use descriptive representation as an information shortcut and, using stereotypes, make assumptions about 
the policy preferences of candidates and vote accordingly. Second, councilors know this, and will pursue policies that ostensibly align with the largest voting bloc(s), which are sometimes defined along racial lines. Third, a descriptively representative legislator will pursue the policies preferred by a racial group in attempts to secure electoral support in the next election. Below, I discuss each of the steps in the mechanism. I summarize the literature, and identify gaps.

Candidates run, and the voters use information shortcuts to better understand the policy preferences of the candidates (Bartels, 1996; Carey, 2009; Chang \& Golden, 2007; Lau \& Redlawsk, 2001; Lupia, 1994; Mcdermott, 1998; Shugart, Valdini, \& Suominen, 2005). It is neither feasible nor efficient for voters to learn about the policy preferences of all candidates. The most salient information shortcut is political party; voters read a candidate's political party affiliation as an indicator of policy preferences. There are many cases, however, when political party is either not a pertinent factor (e.g. competition between candidates of the same party), or is not known (e.g. non-partisan elections). Voters then take cues from candidates' biographical information to gauge policy preferences. Pertinent biographical information includes place of birth or gender (Shugart et al., 2005), and race (Mcdermott, 1998). Voters use these cues to determine which candidate most likely shares their view on policies, and cast their ballots accordingly.

Many voters vote in a bloc. Blocs can be delimitated on party lines, on occupation lines (e.g. unions), and on racial lines (Collet, 2005; Z. Hajnal \& Trounstine, 2005). In many ways, winning over voting blocs or cohorts is a safe way to win an election; it is 
the relative guarantee of electoral support. Voting blocs support a candidate because of policy preferences, both stated and assumed. That is, the candidate may explicitly address the concerns of a voting bloc, or use other cues to signal policy preferences. Either way, the votes of the bloc are secured when the bloc believes that its preferred policies are the preferred policies of the candidate.

Consider the hypothetical Voting Bloc A and Candidate A, where Bloc A makes up a substantial portion of the votes cast for Candidate A. Candidate A wins his election, thanks in large part to Bloc A, and begins to govern. In addition to governing, nowLegislator A starts the process of retaining power. Every decision that a legislator makes is both about policy and about positioning. Legislator A needs to retain the support that got him into office. To lose that support while in office could mean losing his seat in the next election. One of the few things that political scientists agree on is that those who have power want to retain their power. The rational Legislator A will act in a way to retain power.

Legislator A is making decisions based on both his appraisal of good policy as well as favorable political positioning in terms of those who elected him. He knows that Bloc A was responsible, in part, for his electoral success. And so, to retain those votes in the next election, he will skew his policy preferences towards Bloc A. Skewing his policy preferences is a form of responsiveness (Przeworski, Stokes, \& Manin, 1999). He does this for two reasons, both of which aim to secure him future legislative power. First, he is aware of the mandate of his constituency. Candidate A made promises during the election, skewing himself towards Bloc A to win its support. Now that he is a legislator, 
he knows that Bloc A expects a policy agenda that reflects those campaign positions.

Following through on those promises is upholding the mandate and appeasing his base.

Second, Legislator A is afraid of being sanctioned by his constituency; that is, he is afraid that if the constituency does not like what he has done in office, they will use the accountability mechanisms available to them (i.e. their vote) and elect a different candidate (Przeworski et al., 1999). The responsiveness, mandate, and desire to avoid being sanctioned coalesce to ensure that a) Bloc A supports Legislator A in the next election, and b) Bloc A's policy preferences are translated into a policy agenda.

Figure 2.2 Traditional Understanding of Representation in Policy

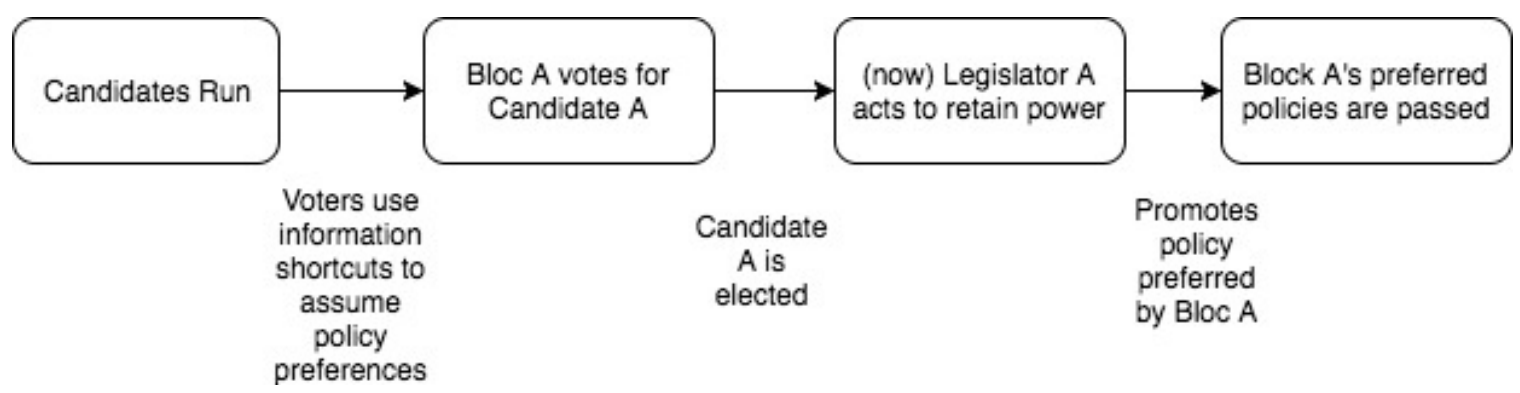

Now, in place of Bloc A, consider African American voters. In place of Candidate A, consider an African American candidate. The hypothetical logic above, when applied, perfectly illustrates why people assume a link between descriptive and substantive representations. Politicians must act to retain their electoral support if they want to win the next election - and thus they promote the political agenda of the group that won them the election. See Figure 2.3 below. My argument, however, is that this relationship works only to a point. 
Figure 2.3 Applying the Traditional Approach to Representation in Policy

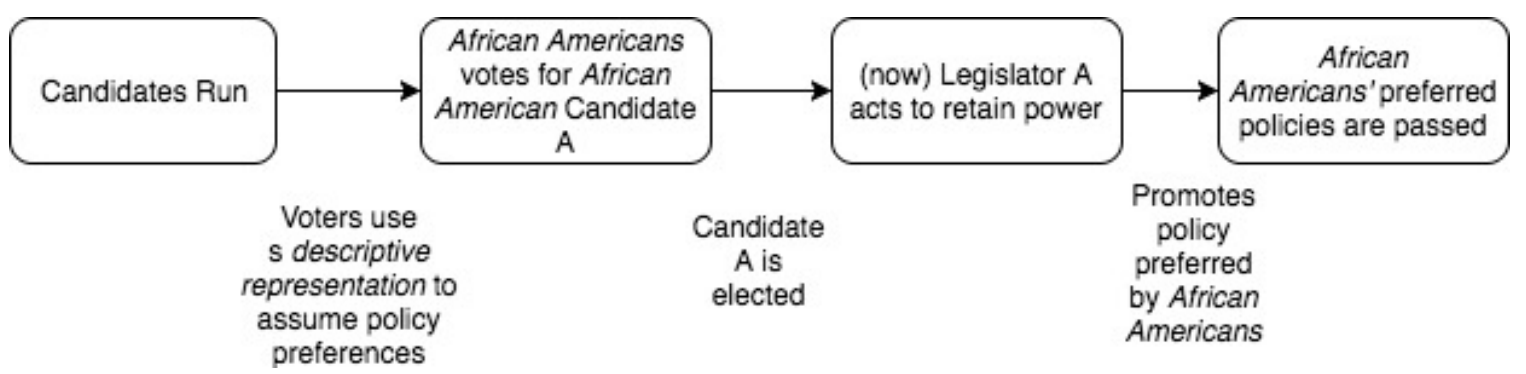

However, I argue that this only works to a point. The political positioning of representatives will change in accordance with the racial composition of the council. The beginning of this new understanding is illustrated in Figure 2.4 below, a graphic representation of the hypothesized relationship between descriptive representation and representation in policy. I argue that there are four stages of descriptive representation: no descriptive representation, tokenism, critical mass, and majority descriptive representation. Each of these stages predicts a different level of representation in policy, some of which has been covered by existing theory, some of which is wholly new. The following section details the theoretical rationale for the predicted values of representation in policy. 
Figure 2.4 Theorized Curvilinear Relationship between Descriptive Representation and Representation in Policy

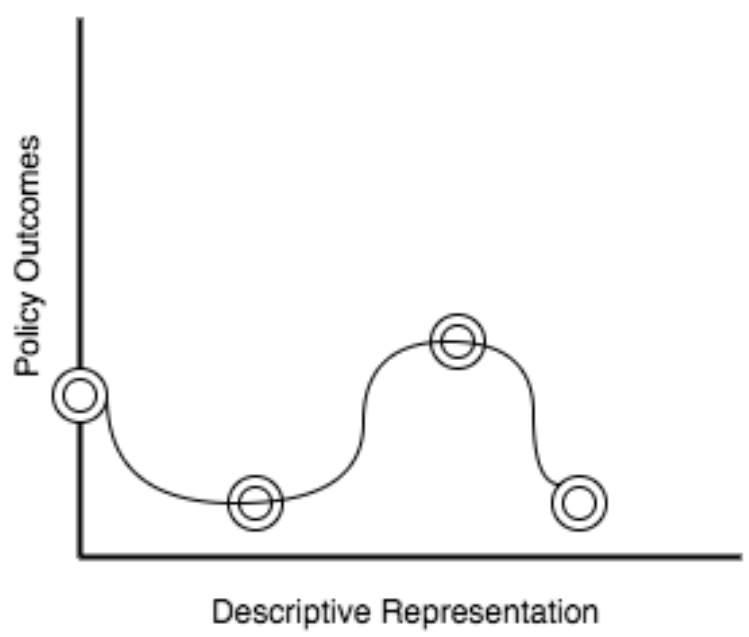

No descriptive representation

A council with no African Americans councilors has no African American descriptive representation. In a council with no descriptive representation, I argue that we will see a mid-level amount of representation in policy. This hypothesis - that no descriptive representation predicts mid-level policy outcomes - is contrary to the logic in much of the current research. Current research suggests that a linear, positive relationship describes the interaction between descriptive representation and representation in policy. The logic underpinning these models is that more descriptive representation means more representation in policy, and the inverse logic is that less descriptive representation means less representation in policy. To hypothesize mid-level policy outcomes when there is no descriptive representation contradicts the basic assumption that the only way to have more representation in policy is to have more descriptive representation. 
However, my argument for this hypothesis comes straight from the theoretical foundations of political science. Politicians in power want - and act - to retain power (Downs, 1957). Politicians who are not descriptively representative of the population are vulnerable to a challenger. Politicians know that in the future, they may be vulnerable to a challenge by someone who is descriptively representative (Epstein \& O’Halloran, 1999a; Nelson, 2007). Logically, it follows that they will act to preempt a challenge through representation in policy.

White councilors that sense a gap in representation will act to fill that gap, and thus avoid a challenger from a descriptively representative candidate. White council members can appear representative by pursuing a policy agenda that is reflective of the under-represented group. They will promote policies that are representative of other community groups so as to prevent a challenge by a non-white candidate.

However, there is a limit to the amount of representative policy that white councilors will pursue. The councilors will pass enough legislation to stave off a challenge; but there is no need to go beyond the minimum. Pursuing policy - any policy - takes political capital (Kjaer, 2015; Stone, 1993). To pursue representative policy means jeopardizing the success of other policy platforms. Strategically, an all white council will pass enough policies to prevent a challenge from minority candidates - but no more.

Literature suggests that white and minority legislators promote different policy agendas when in office (Juenke \& Preuhs, 2012), and thus it follows that white councilors would not promote the same representation in policy as minority councilors. In other 
words, in accordance with the logic of current literature, an all white council would predict essentially no representative policy for minority constituencies. My theory differs from this underpinning logic, but I argue that this is because of the dearth of empirical studies of representative policy with no descriptive representation. The rationale for a councilor functioning in a no-descriptive-representation situation will look like Figure 2.5 below.

Figure 2.5 No Descriptive Representation

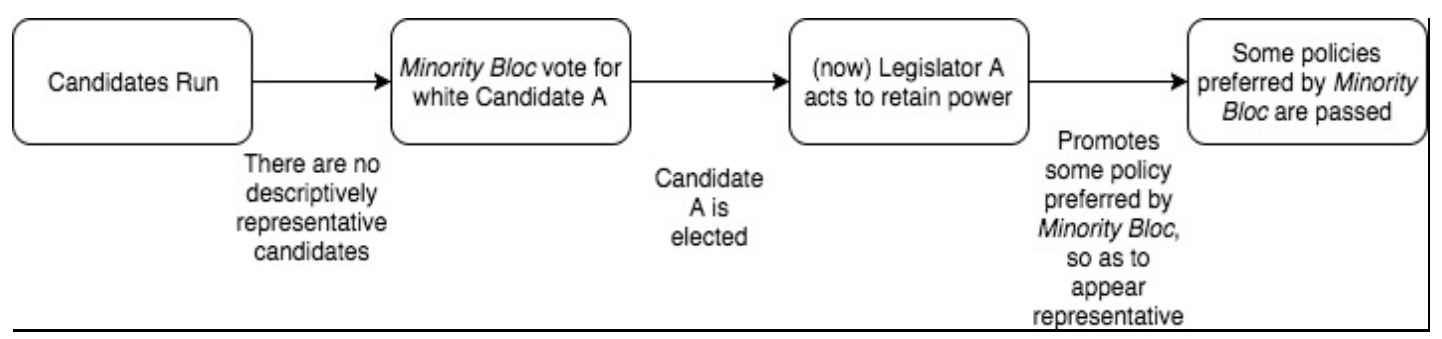

For example, there are no Black councilors on the Seattle city council in 2015 (there are seven white councilors and two Asian councilors). Based on previous literature, one might assume that this means very little substantive representation for Black residents. However, Seattle aligns with the theory presented here. An example of Black policy in Seattle was Resolution 31578, which reaffirmed support for Somali communities in Seattle. This policy passed unanimously, meaning that all council members voted in support of a racial policy without any related descriptive representation. Even though there were no Black councilors, $.259 \%$ of policies passed were Black racial policies. This value is close to the average amount of Black policy passed across cases $(.294 \%)$ - and thus Seattle is the very picture of mid-level policy outcomes. 


\section{Figure 2.6 Hypothesized Relationship, No Descriptive Representation and Policy}

Outcomes

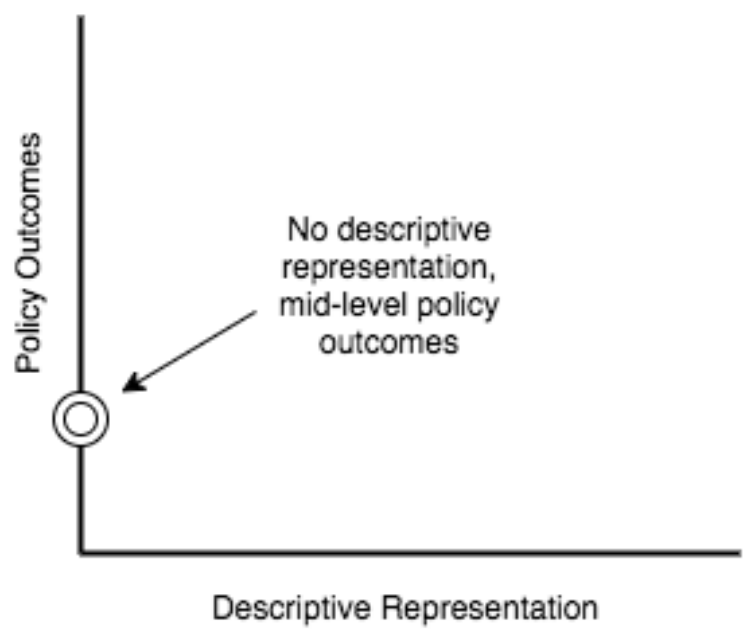

\section{Tokenism}

Tokenism is the period of very low descriptive representation, indicated by either a very small percentage and/or a single representative in a legislature. This is when I expect to see the worst policy outcomes for represented groups. The literature provides compelling support of this hypothesis; there are various theoretical explanations in the literature, and I develop a composite theoretical explanation here.

Kanthak and Krause (2012) write that tokenism is a powerful and encumbering phenomenon. The token councilor must hold the entire mantle of representation in policy. This translates into undue pressure upon the councilor and stagnation in terms of the policy outcomes of represented group. One person cannot pass legislation by himself; and yet that is exactly what is expected of the token minority council member. This understanding of the effects of tokenism underpins the logic of councilors in the low 
descriptive representation stage. It, in part, explains why such low representation in policy occurs in this type.

In addition to the negative effects of tokenism on policy outcomes, Kanthak and Krause highlight that backlash from the majority group can be expected during the tokenism period. Backlash - the idea that the majority group will act to undercut the efforts of the minority group - can forestall the policy efforts of a minority group. The idea of white backlash is present in politics at every level. William Julius Wilson (1998, 2009) discusses white backlash extensively in his work, citing it as one reason that the urban African American population's progressive political efforts are have been stymied by white hegemons. Though Wilson's concept was not developed to talk about descriptive representation, other scholars have applied it explicitly to racial and representation politics (Cameron et al., 1996; Crowley, 2014; Epstein \& O’Halloran, 1999a). In the tokenism period, white backlash is one explanation for low representation in policy.

\section{Figure 2.7 Tokenism}

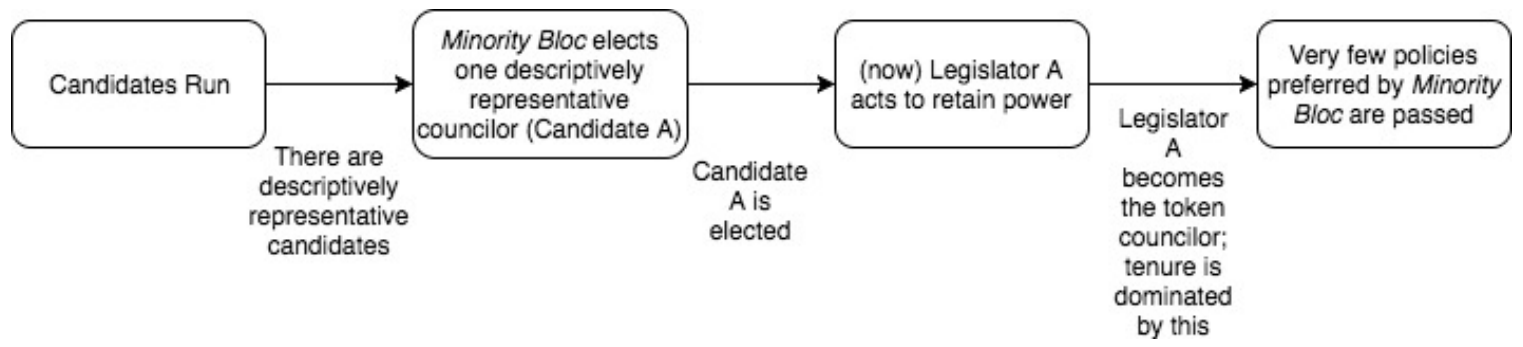

To illustrate low representation in policy during the tokenism period, consider Philadelphia. During 2014, Philadelphia had one Latino councilor on a council of 17, 
translating to about $6 \%$ of the council. A sole member of a racial group indicates the tokenism period. During the study year, only .12\% of the policies passed were Latino racial policies. This is a low value, particularly when compared to the average amount of Latino racial policy passed across all cases (.20\%). Further, the one Latina councilor (Councilor Quiñones-Sánchez) sponsored every piece of Latino policy that was passed by the council. This, at least, speaks to Kanthak and Krause's point about tokenism: that the few members of the group are responsible for spearheading all representation in policy.

\section{Figure 2.8 Hypothesized Relationship, Tokenism and Policy Outcomes}

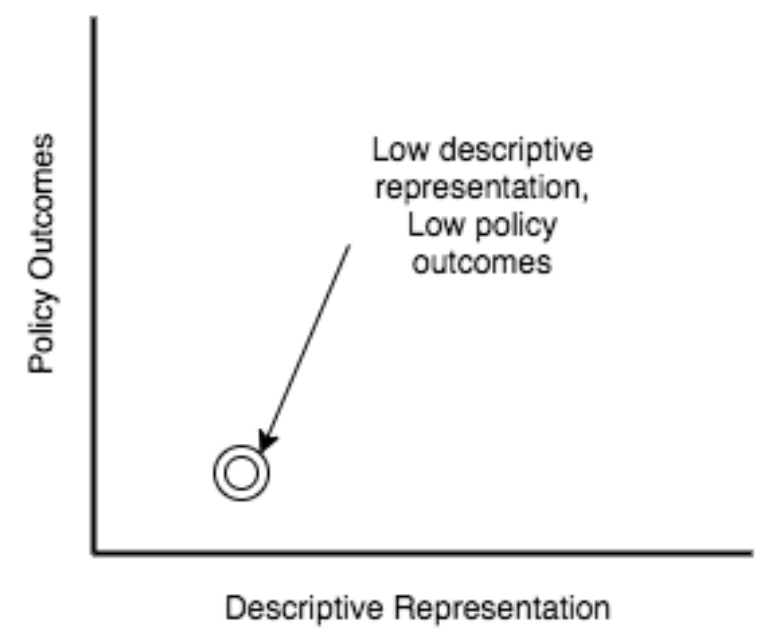

Critical Mass

Critical mass theory is truly a theoretical touchstone in the field. If Pitkin engendered the modern study of political representation, Kanter (1977) engendered the discussion of representation in policy for minority groups. She explores what it means for women to be tokens, and when we can expect that tokenism to subside. She wrote about a 
type of representation in which women moved from tokens to real, powerful decision makers. This idea - that a minority group can gain decision-making power - is incredibly powerful. It reshaped the field's understanding of minority politics.

In the critical mass period, I expect to see a lot of representation in policy. There is sufficient momentum and collegial support to pursue the policy agenda of minority group (Dahlerup, 1988; Kanter, 1977; Mansbridge, 1999). Additionally, the voting bloc power of the minority constituency has not been split across too many descriptively representative councilors, as will happen in majority descriptive representation. Minority councilors can pursue policy agendas without experiencing white backlash, and have sufficient strategic motivation to pursue representation in policy for racial groups. Racial policy and diversity policy will be buffeted because there is no strategic reason to impede them. The resulting logic (presented below in Figure 2.9) predicts high representation in policy.

Figure 2.9 Critical Mass

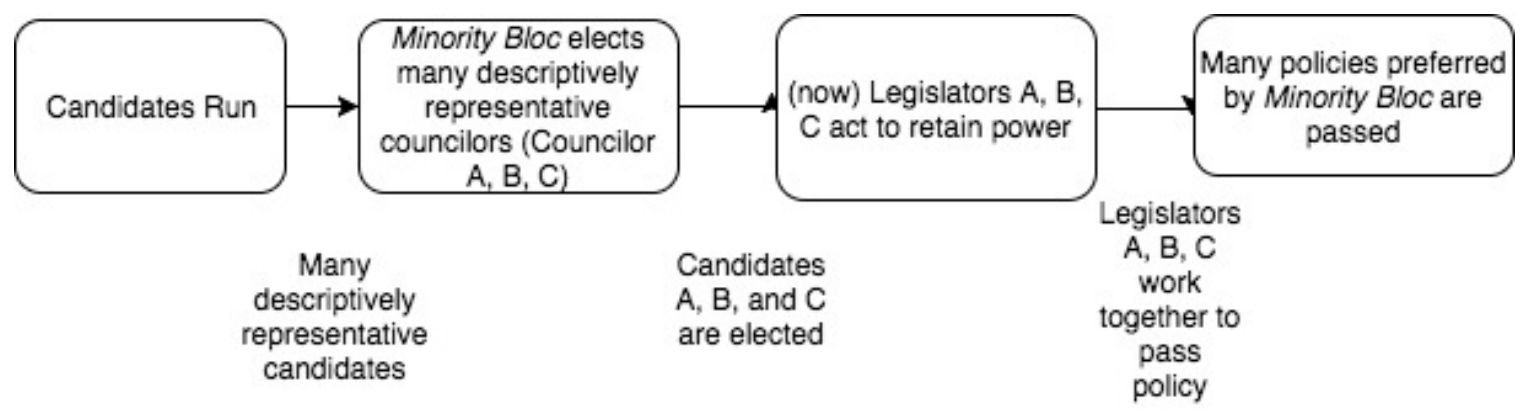


Critical mass occurs in the dataset in many places, including in Austin. Latino councilors make up $30 \%{ }^{9}$ of the council during the study year. I argue that in the critical mass period, representation in policy will be quite high. In Austin, . $51 \%$ of the policies passed during the study year were Latino racial policies. This is more than twice the average across cases (mean equals $.20 \%$ ).

\section{Figure 2.10 Hypothesized Relationship, Critical Mass and Policy Outcomes}

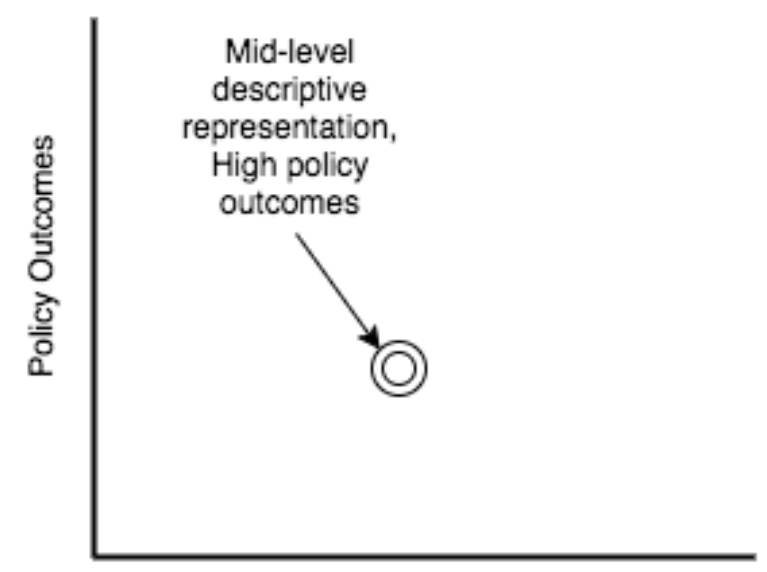

Descriptive Representation

\section{Majority Descriptive Representation}

Majority descriptive representation is chronically under-researched in the field. I hypothesize that the high descriptive representation that defines this period predicts low representation in policy outcomes. This may seem contrary to logic; it certainly runs contrary to much of the literature. However, I argue that low representation in policy will

\footnotetext{
${ }^{9}$ I discuss this more in the Methods and Results chapter, for my purposes $30 \%$ is in the critical mass period.
} 
occur because the electoral strategy of councilors has changed in response to a diverse council makeup. In short, intra-racial competition forces candidates to differentiate themselves by aligning themselves with voting blocs outside the racial group.

Descriptive representation functions as an effective information shortcut in other types, but its impact in the majority descriptive representation type is different. When there is considerable competition between minority candidates (i.e. intra-racial competition), the positive effect of descriptive representation is negated. No longer can voters rely on the information shortcuts that descriptive representation provides - because descriptive representation connotes the same thing for all candidates involved. The information gleaned from the information shortcut provides the same information for all descriptively representative candidates. Therefore the power of descriptive representation wanes.

Though majority descriptive representation is understudied in the traditional political context, it has been considered in other ways. The closest parallel is the study of electoral structures that promote racial and ethnic diversity in legislatures. Racially based quotas are one context in which scholars have studied intra-racial electoral competition. For example, in New Zealand, there is a separate electoral roll comprised entirely of Maori candidates ${ }^{10}$; this roll serves to populate reserved seats in the national legislature and only the Maori constituency can vote for these candidates (Banducci et al., 2004; Braswell, 2010). Studies have used this perfect natural experiment on intra-racial political competition to better understand minority participation (Banducci et al., 2004), a constituency's satisfaction with government (Banducci et al., 2004), how race aligns with

\footnotetext{
${ }^{10}$ The Maori population is the largest racial minority in the country, and the Indigenous population.
} 
party affiliation (M. Htun, 2004), and how government defines race and ethnicity (Kukutai, 2004). Yet no one is using it to explain intra-racial political competition. That is, there is still a dearth of literature that explores how candidates position themselves when in direct competition with other descriptively representative candidates.

In the American context, the closest studies of majority descriptive representation focus on the impact of majority-minority national electoral districts drawn in the 1990s. Canon et al. (1996), in particular, study the electoral strategy of Black politicians in majority-minority districts. Their findings run contrary to the literature of the time, which had suggested that majority-minority districts would lead to the extreme representation in policy for Black constituencies. The study suggests that Black candidates skew their political strategy away from extremes, instead adopting a median voter (Downs, 1957) type approach. That is, Black politicians in majority-minority districts adopt the "politics of commonality" (D. T. Canon et al., 1996, p. 846) and promote policies that are not racially motivated. Instead, they promote policies that have a broad, biracial consensus in the constituency. Though Canon et al. stop short of theorizing about the political motivations in intra-racial competition outside of majority-minority contexts, his logic holds. As opposed to appealing only to one's racial base, candidates must pursue a policy agenda that attracts support from a diverse set of voters. In terms of my work, this means less representation in policy.

Majority descriptive representation of an identity group is not unique to racial descriptive representation. Gender descriptive representation has a similar type. When there are many women competing for the same thing, the power of gender as an 
information shortcut is null. For instance, consider the women-only ballots in Rwanda. Voters have a number of women candidates to choose from, but gender is no longer a distinction between the candidates. Other information is used to make a choice (Dahlerup \& Freidenvall, 2005)

Similarly, party affiliation is considered the most salient information shortcut (Popkin, 1995). When there are multiple candidates running with the same party affiliation, in the same race, the power of party affiliation wanes (Shugart et al., 2005; Valdini, 2006). For example, in a proportional representation open list electoral system, voters can vote for a party and an individual within the party. In this case, party affiliation does not serve as a differentiator between candidates, and thus provides no additional information to the voter (Shugart et al., 2005; Valdini, 2006). Similarly, the effect of party is mitigated in the US in primary competitions. Presidential primary competitions in the US intraparty competitions; that is, candidates are, by design, only competing against those with the same party affiliation. Therefore, just as in the PR list ballot, the competition is intraparty and voters must use other cues to read the candidates (Branton, 2009).

When there is considerable intra-racial competition (i.e. majority descriptive representation), I expect the outcomes to be markedly different from the critical mass period. Additional minority representatives do not predict more representative policy. Instead, more descriptive representation predicts lower representation in policy, because the appropriate electoral strategy is to cultivate electoral support from other voting blocs. When political strategy becomes about something other than race, political motivations 
become more akin to traditional (i.e. a-racial) political posturing. Political candidates make policy promises to voting blocs that are not defined on racial lines. Candidates will reach out to the business community, to education interests, to those concerned about criminal justice. They will position themselves differently to attract the votes needed to win. In other words, a Black candidate cannot expect to win based on descriptive representation when he is running against another Black candidate (D. T. Canon et al., 1996). He has to distinguish himself in the field. He has to be the business candidate that is Black - and to attract the support of the business community, he has to skew his policy agenda during the campaign. Successful candidates who will seek reelection must keep in mind their constituency when they are in office. This is the accountability theory of democracy: candidates make promises during the campaign, and carry them out when in office (Przeworski et al., 1999).

This theory applies to all politicians, not just those who are looking to cultivate the minority vote. All candidates look for voting blocs (Collet, 2005; Gormley \& Murphy, 2008). All candidates try to woo blocs with policy promises (Butler, 2009; Z. L. Hajnal, 2009). If the promises woo enough votes, the candidate wins the seat. If the councilor wants to maintain the electoral support that he gained during the election, he needs to appear like he is fulfilling his promises (Aragones, Palfrey, \& Postlewaite, 2007; Przeworski et al., 1999). A candidate who has distinguished himself from other Black candidates has made promises to other voting blocs. When in office, he must pursue their preferred policies. To not, to pursue policies preferred by others, would risk alienation of 
the voters and the loss of electoral support and mandate (Aragones et al., 2007;

Przeworski et al., 1999).

This explains why a candidate may advocate for interests outside minority constituency. I am not arguing that the minority councilor will wholly abandon the minority constituency and only advocate for the other voting blocs. Instead, I am arguing that the councilor's priority has become the other voting blocs. During the critical mass period, the rationale to pursue representation in policy is much stronger than in the majority descriptive representation period. Thus, the predicted value of representation in policy in the majority descriptive representation period is significantly less than in the critical mass period (see Figure 2.11).

Figure 2.11 Majority Descriptive Representation

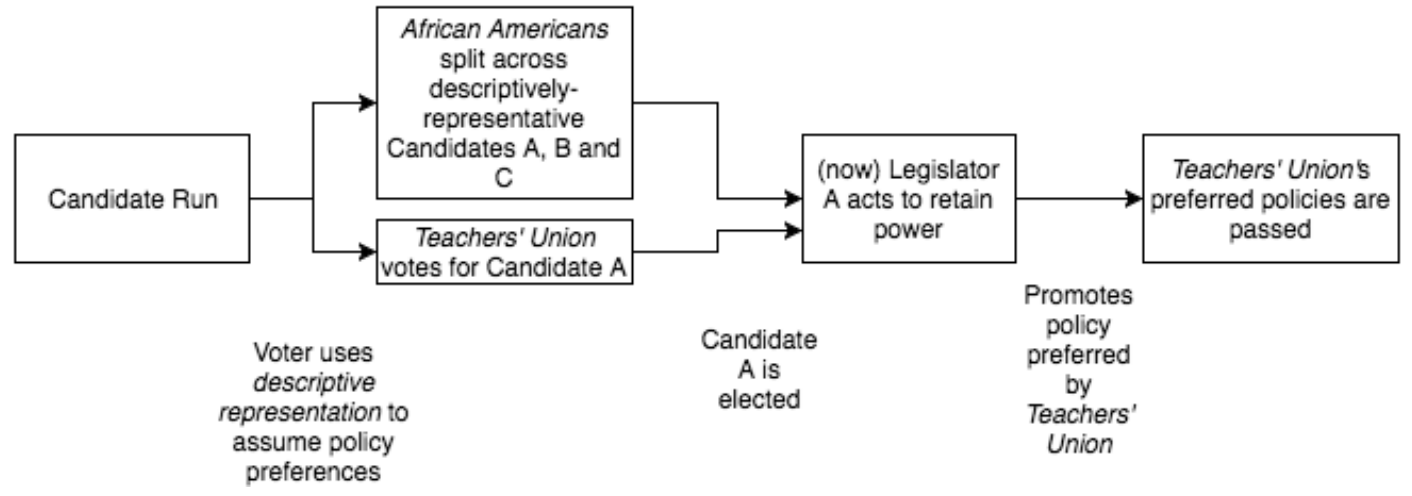

Atlanta is a ready example of majority descriptive representation aligning with low representation in policy. Black councilors make up $69 \%$ of the council during the study period. Yet, in terms of representation in policy, the Black constituency does not fair well. Across all cases, Black racial policy made up .294\% of all policies passed. In 
Atlanta, however, Black racial policy constituted .089\% -- nearly 2.5 times less than the national average.

Figure 2.12 Hypothesized Relationship, Majority Descriptive Representation and Policy Outcomes

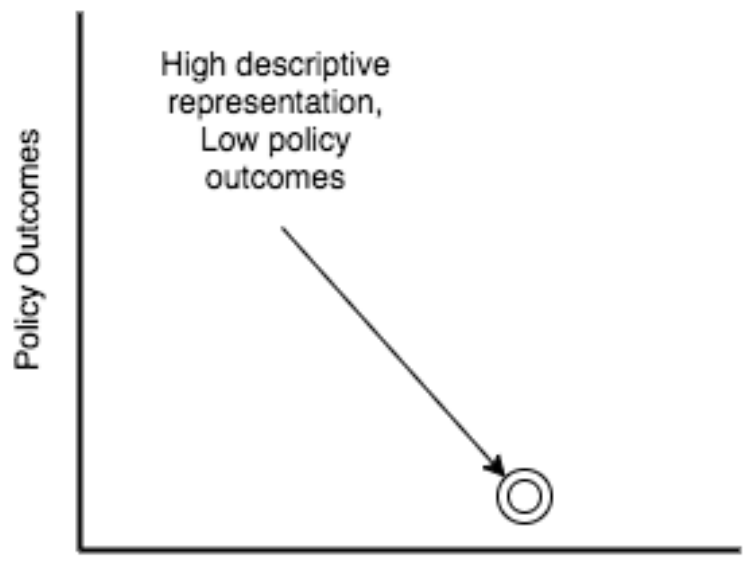

Descriptive Representation

\section{Conclusion}

In order to better understand the relationship between descriptive representation and representation in policy, I conducted a sweeping review of the relevant literature. The results of this review indicated that a new theory was required to better explain the latter link (i.e. how descriptive representation predicts policy outcomes). I therefore have developed a new theory, by pulling theoretical elements form disparate bodies of literature. This new theory predicts that the relationship in question is curvilinear in nature and, perhaps most surprisingly, it suggests that when descriptive representation is very high, representation in policy will be low. 


\section{CHAPTER 3. QUANTIATIVE METHODS AND RESULTS}

I have developed a multi-pronged, extensive approach to nearly every element of the project. The data collection, for example, has resulted in a very large database - larger than any other I have seen in the field. In my approach to data analysis, too, I took great pains to be complete. I used not just regression analysis but ANOVAs as well - so as to better understand and illustrate the true nature of the relationship at play. I then paired the quantitative analyses with case studies, rounding out my understanding of the mechanisms at work. I took care at each juncture of the project and this has created an epic project with compelling results.

In this chapter, I outline the quantitative methods and results. I find support for the main argument. Overall, I find compelling evidence that the theory that I have advanced in the previous chapters of this dissertation has merit. The organization of this chapter is as follows. I first restate the research questions and the related hypotheses. I then discuss the foundation of the research design, including the research setting (case selection and target year) and the operationalization of the target policies. Then I describe the extensive data collection process. Next, I describe the data coding and cleaning procedures that ensured validity of the study, as well as describing covariates and the construction of the database. I then describe the data analysis procedures and results from each set of tests. Finally, I discuss the validity and reliability of the methods choices I have used. 


\section{Restating the Research Questions}

To explain my methods choices, and formally outline my hypotheses, here I restate my research questions. After each question, I list the related hypotheses. After that, I explain my methodological and methods choices emanating from the questions. The methodological choices that I made were explicitly related to the research questions and the fundamental motivation of the study. To better explain these choices, I have restated the questions below. In this section, I tie the research questions to my hypotheses and then explain each testing method that I used.

Research Question 1. In US cities with more than 200,000 residents, what is the relationship between specific descriptive representation and racial policy in 2015, holding relevant variables constant?

Hypothesis 1: In the linear model, specific descriptive representation will not be a significant positive predictor of racial policy.

Hypothesis 2: The best fit model will be when $z$ (that is, the power to which descriptive representation is raised) is more than two, indicating that the nature of the relationship is not linear (where $z$ would be equal to 1) and not quadratic (where $z$ would equal 2), but curvilinear.

I was interested in knowing how the theoretically curvilinear relationship between descriptive representation and representation in policy is best modeled as a polynomial. Hypotheses 1 and 2 get at that question. They provide operationalized and testable approaches to determining the correct functional form. To determine if these hypotheses 
were substantiated by the data, I conducted a series of regressions. Each iteration of the regression equation was identical, except for the functional form of descriptive representation. I tested the models using descriptive representation as a straight percentage, as well as quadratic, cubic, and quartic functional forms.

There are six covariates in the model, in addition to the polynomial expression of specific descriptive representation. I tested four models - from linear to quartic - to gauge goodness of fit and test my hypotheses. I did not use robust standard errors, as the number of cases was not large enough to justify such a strain on statistical power (Kezdi, 2003; Wooldridge, 2003). I did not cluster by region, or other variable. Instead, I included the pertinent variables in the model.

Research Question 2. In US cities with more than 200,000 residents, what is the relationship between general descriptive representation and diversity and equity policy in 2015, holding constant other relevant variables?

Hypothesis 3: In the linear model, general descriptive representation will not be a significant positive predictor of diversity policy.

Hypothesis 4: The best fit model will be when $z$ (that is, the power to which descriptive representation is raised) is more than two, indicating that the nature of the relationship is not linear (where $z$ would be equal to 1) and not quadratic (where $z$ would equal 2), but curvilinear. 
I performed a parallel process to test general descriptive representation's affect on diversity policy. I tested multiple iterations of the regression equation - identical save for the power to which general descriptive representation was raised. I gauged goodness of fit of each model, comparing them to ascertain which model had the most explanatory power.

\section{Research Design}

I designed this aspect of the research project to quantitatively assess the hypotheses and theoretical models introduced in the previous chapter. I set parameters of the study, collected the intended data, initiated a procedure of cleaning, coding and setting up the data for analysis, and proceeded with a data analysis procedure that is substantiated by the literature. These elements are described in this subsection.

\section{Case selection, Sampling}

The population of this study is city councils in all US cities with more than 200,000 residents, as indicated by the 2010 US Census. According to the Census, 116 cities fit this criterion (see Appendix A for list of cities included in the study). Using the entire population of city councils presents a number of distinct benefits. First, studies of the population circumvent issues of sampling integrity (Kumar, 2011). Sampling always allows for the possibility that the sample does not mirror the target population (Ethridge, 2002); studying the population in its entirety removes this risk. The second benefit is that there is no need for a complex sampling strategy that incorporates and weighs different variables for inclusion. The process without sampling is streamlined and efficient and 
easily replicable. Though including the entire population required more data collection, it simplified the procedures overall.

\section{Target year of the data}

My study is temporally cross sectional as I am most interested in the interplay of race and policy, and less interested in the change of this relationship over time. Cross sectional data provides a snapshot of the world in one point in time. The addition of a temporal element would require that I include confounding variables that are associated with time. By using cross-sectional data, I am able to hold time-dependent variables constant. This not only streamlines the study and aligns it with trends in the current literature (e.g. Bueno \& Dunning, 2017; Tausanovitch \& Warshaw, 2014), but also allows me to focus on the relationships between the primary independent and dependent variables. There is substantially less statistical noise when a cross-sectional approach is used (Bailey, 2008).

The main target year for this study is 2015 . However, my study requires that there were no changes to the council during the study period (i.e. the representatives who served at the beginning of the year must be the same as those who served at the end of the year). If there was a change in council, I could not attribute the year's policy outcomes to one set of councilors, because this would undermine my thesis, that the composition of the council predicts policy outcomes. Therefore, when there was a change in representation in 2015, I used 2014 as the study year. A complete list of cities for which 2014 was used is included in Appendix A. 


\section{Key variable operationalization and data collection}

\section{Descriptive Representation -- Conceptualization and Operationalization}

Descriptive representation is the idea that there is import in being represented by an individual who shares the same primary characteristic. In this study, I have conceptualized descriptive representation in two ways: specific and general. Specific descriptive representation is the percent of councilmembers who identify as a specific racial group (i.e. for this study, the percent of the council that identifies as Black, Asian and Latino). General descriptive representation is the percent of councilmembers who identify as any racial minority group.

\section{Data collection and Coding Processes}

The data collection process for descriptive representation mirrors the information processing of voters. I examined photographs, newspaper articles, biographical data, and organization memberships to find a councilor's racial identity. This process aligns with the literature (Barrett \& Barrington, 2005; Druckman, 2004). Unlike, US mayors ${ }^{11}$, there is no repository for the race of city councilors. Therefore, all data on descriptive representation was collected by manually coding racial identification data (described below). After identifying the appropriate year (i.e. 2015 or 2014) to draw the data from, I checked the current city council website. Many of the councilors who currently serve were also serving in 2015 . Using this as a starting place, I looked at the current council, identified all of the councilors who served in 2015, and recorded their names and race.

\footnotetext{
${ }^{11}$ Found at www.usmayors.org
} 
Next, I identified the councilors who had served in 2015 but were no longer in office. I used a two-pronged approach to find these former councilors. One tine of my approach was to search through archived newspapers for articles about former councilors. The other approach was to check Internet Archive's "Wayback Machine"12 to see a cached snapshot of the council website during the study year. These two approaches provided the name and photos of the councilors that were not on the current city council website.

After I found the names of the councilors who served in 2015, I looked for the racial identification of each councilor. I developed a process that mimics that of the voters, and is supported in the literature (e.g. A. W. Barrett \& Barrington, 2005; Druckman, 2004). I looked at photographs of the councilors, read biographical information for explicitly racial cues, considered organizational membership (e.g. a councilor who is a member of the city's Asian Chamber of Commerce or who leads the Hispanic Caucus), and perused newspaper articles for racial information. This approach approximates how the voter learns about candidates, and therefore how the public reads the racial identification of the councilors (A. W. Barrett \& Barrington, 2005; Druckman, 2004).

After collecting the racial data on all councilors in the study, I coded the data in two ways. To test my theory concerning specific descriptive representation, I used three racial categories: Black, Latino/Hispanic, and Asian. These categories were chosen for

\footnotetext{
${ }^{12}$ Internet Archive is non-profit organization that, in addition to maintaining an archival resource of traditional media, catalogs iterations of webpages. It functions by taking snapshots of webpages, as they are, at different points over the years that the website exists. Find more information here: https://archive.org/about/faqs.php
} 
two reasons: 1) streamlining the review of existing theory by conforming to current trends in the literature ${ }^{13}$, and 2) in accordance with methods literature, these categories have a sufficiently large $\mathrm{N}$ in the dataset for quantitative analysis (Ethridge, 2002;

Kumar, 2011; Myers, Well, \& Jr., Lorch, 2010).

In this study, I use Asian and Latino as categories. In reality, those are both ethnic roll up categories - that is, they are sweeping overarching categories that encompass a vast, diverse set of ethnicities. Though it is common in the field to collapse these ethnicities into broader categories - and indeed it is necessary in a large-N study such as this - this process erases the important and vast differences between ethnic groups. I made this choice thoughtfully, aware of the tradeoffs. For a thorough discussion of panethnic categories, see Lopez and Espiritu (1990).

In total, across the 116 cities initially included in the study, there were 1,028 city councilors. I collected racial data on each of these individuals. Across all cases, 32 of the city councilors were Asian, approximately 3.1\%. Compare this to the national population of $4.8 \%$ (US Census 2010). Black councilors make up 24\% of the councils, across all cities studied $(\mathrm{n}=247)$, as compared to $13.1 \%$ of the national population. There were 111 Latino councilors serving in 2015 across all cases, which constituted approximately $11 \%$ of all councilors in the study. The national Latino population is approximately $16.3 \%$, according to the US Census.

For models that use general descriptive representation as the independent variable, a parallel coding process was used. Conceptually, general descriptive

\footnotetext{
${ }^{13}$ That is, the vast majority of literature is about Black and Latino representation and, to a lesser extent, Asian representation. There is a marked dearth of scholarship regarding other racial groups.
} 
representation is an indicator of whether a councilor is, or is not, a racial minority.

General descriptive representation is a binary category; councilors were coded as minority representatives (1) or white representatives (0). Approximately $39.5 \%$ (407 of 1028) of all councilors were coded as a minority representative in this study, as compared to $27.6 \%$ of the nation ${ }^{14}$.

\section{Representation in Policy -- Conceptualization and Operationalization}

My understanding of representation in policy has two distinct categories of policy. The first category is racial policy, and comes from Canon's seminal book (1999). Racial policy explicitly names the group it seeks to affect. For example, in San Diego, CA the following passed policy was coded as Asian racial policy: “Authorizing a Community Projects, Programs, and Services funding allocation agreement to the Union of Pan Asian Communities for the purpose of high-risk Asian/Pacific Islander mentorship program." This policy clearly names the group that it is targeting and is therefore considered racial policy.

To identify racial policy, I have compiled a collection of indicator terms associated with racial policy (informed by Canon, see Appendix B for full list). For example, to identify Asian racial policy, the following words are searched for: "Asian", “Asian American”, “Chinese”, “Japanese”, “Korean”, “Thai”, and "Cambodian”. My

\footnotetext{
${ }^{14}$ There may be some surprise about the overrepresentation of minority councilors generally, and Black councilors specifically, as compared to national demographics. However, the urban-rural divide can explain the ostensible overrepresentation. That is, studies of population shifts, migration and settlement patterns have found that racial minority populations in the US are disproportionately in cities (Massey \& Denton, 1993; Wilson, 2009)Because my study focuses on US urban environments, it is not surprising that the councils have higher-than-average minority representation. Indeed, as compared to the average demographics for the cities in the study (48.46\% minority, 20.72\% Black) the descriptive representation of these groups in cities is markedly low.
} 
search procedure included searching for all iterations of these root terms (e.g. not just searching for "Asian” but also "asian”, “Asia”, “Asian-“, etc.). To identify Black and Latino racial policy, I searched for a different but parallel group of words and terms. See Appendix B for full list of identifying terms and phrases for each racial group.

After identifying and coding Black, Asian and Latino racial policy, I operationalized these groups into usable variables for the quantitative model. Conceptually as a variable, 'Black racial policy' is the amount of Black racial policy passed in the city in 2015 , as compared to all policy passed in the city in 2015 . There is considerable variation in the amount of policy that a council passes (ranging from 24 policies passed by Columbus, GA to 15,982 in Cleveland, $\mathrm{OH}$ ), and therefore a straight number (as opposed to a ratio) of racial policies passed would be useless. I operationalize racial policy as a compound variable; it is calculated by dividing the number of racial policies for a group by the total number of policies passed in 2015 for each city. To continue the above example, Columbus, GA passed one Black racial policy in 2015; Cleveland passed six. But as a proportion of the total policies passed, Columbus was actually far more representative, with $4 \%$ of all policies considered Black racial policies compared to $.04 \%$ in Cleveland.

The second conceptualization of policy is diversity and equity policy. Diversity policy is legislation that explicitly names diversity and equity goals in the text of the legislation. To identify diversity policy, I compiled a second collection of indicator terms. I compiled these terms through a review of the current literature (e.g. Fassinger, 2008; Ferner, Almond, \& Colling, 2005). Examples of the terms include: diversity, equity, 
inclusion, multiculturalism, pluralism, and equality. See complete list in Appendix B. Across all cities, approximately .4\% of all policies in 2015 were related to diversity and equity ( $\mathrm{n}=537)$.

Similar to racial policy, the diversity policy variable must be operationalized as a proportion. Just as it was illogical to compare the number of racial policies passed, it is illogical to compare the number of diversity policies. Therefore, diversity policy is operationalized as a compound variable; it is calculated as the number of diversity and equity policies passed divided by the total number of policies passed in each city in 2015 .

\section{Data Collection and Coding Processes}

To collect data on racial and diversity policies, I examined legislative records. All city councils keep records. However, the format of these records varies dramatically between cities. Approximately half of the cities in the study use an online data repository, such as Legistar. This software stores legislation, agendas, meeting dates and more in an accessible format for public records.

I needed to identify which office maintained the legislative records to gain access, ask follow up questions, or find relevant links. However, the office charged with maintaining these records varies between cities, too. In many cities the City Clerk's Office plays this role. In others, the City Secretary's Office or the council itself maintains records. Identifying which office is maintains records was an important step in data collection, as many times I had to contact the office directly to ask for record access or clarification. 
Archives vary substantially between cities; I devised a three-type approach to examine the records. First, I collected all legislation passed in the study year that was readily available (i.e. downloadable from a web-based source). I define legislation as ordinances, resolutions, and proclamations. Second, I issued records requests to cities that did not have accessible information. These requests produced mixed results; some cities provided exactly what I sought, whereas others were confused as to why I wanted the information and thus there was a delay in information sharing (e.g. New Orleans). Other cities, like Memphis, TN (which was eventually excluded from the study because of lack of data), refused to turn over archives to an out-of-state resident.

When the first two approaches did not work, I collected all legislative information that was available. This includes meeting minutes, legislative agendas, and voting records. All legislative information - regardless of what process I used to find it made available directly by the city, not a third-party like newspapers. This ensured that all of the policies passed in the year, without bias, were included in the study.

\section{Data coding, cleaning, and setup}

In terms of the legislative data, the coding process focused on identifying policy that fit into the two policy groups: racial policy and diversity policy. Racial policy was broken down further, by racial group. I used the same criteria (i.e. contains the words, "Asian", "Asia", "China" etc.) that were used to conceptually identify racial policy. An exactly parallel procedure was used to code diversity policy. A set of terms, informed by the literature, was established and searched for. If the title information of a bill included 
reference to these terms, the bill was coded as diversity policy, and pulled into its own dataset for further examination. The initial coding of legislation was done automatically. I wrote SPSS syntax (in Appendix C) to search through the titles and descriptions of the bills in the data set. The syntax searched through the legislation for the key terms. When the program found a piece of legislation that contained one of the key terms, it coded the bill accordingly.

After the initial coding process, I conducted a coding verification process. I read through all policies that had been coded as either racial or diversity policy, looking for errors in the automatic coding process. There were many policies that were initially collected and eventually excluded. For example, a piece of legislation about construction on Blackstone Road in Philadelphia was initially coded as African American racial policy. Clearly, it is not. The secondary coding verification process was essential to ensure the integrity of the database.

Across all cities, I collected and sifted through 124,202 policies. Approximately $.16 \%$ of all policies were Black racial policy ( $\mathrm{n}=197), .15 \%$ of policies were Latino racial policy ( $\mathrm{n}=183$ ), and $.19 \%$ of policies were Asian racial policy $(\mathrm{n}=245)$. Across all cities, $.43 \%$ of the policies were related to diversity and equity $(\mathrm{n}=537)$.

\section{Covariates - Operationalization and Data Collection}

There are five covariates in the model: city partisan composition, strength of mayor, mayor party ideology, mayor race, and one minority variable. They are described here, as are the processes for data collection. The city partisan composition variable 
captures the Democratic or Republican voting tendency of the city. Individual-level party affiliation of councilors is not included in this analysis. Though much of the literature considers the importance of an individual's party affiliation in predicting a councilor's voting record (e.g. Cameron et al., 1996; Gay, 2002; Z. L. Hajnal, 2001; Pantoja \& Segura, 2003; Preuhs, 2007; Reingold, 2000), there is strong rationale for why party affiliation in aggregate, as opposed to individual-level, is most appropriate for this study.

First, research suggests that party affiliation is closely aligned with race, implying that an individual's party affiliation is oftentimes assumed by voters by reading the race of the candidates (M. Htun, 2004). Second, the majority of large US cities have nonpartisan elections (see the National League of Cities for a full discussion). In these cities, the party affiliation of the candidates and subsequent councilors is not known to voters, and does not play a role in politics. In my data set of 116 cities, only 22 have partisan elections. This also means that the data point is missing for 94 of the cities in my study; clearly the inclusion of party data for just 22 cases in the study would seriously jeopardize the project's internal validity. Thus, the concept of party affiliation is operationalized in aggregate.

To capture party affiliation in aggregate, I created an index variable that models the predictive power of party at the city level. A city's partisan ideology or affiliation, captured sometimes by a measure of its conservative or liberal nature, has extensive predictive power in terms of what policies are passed (Z. L. Hajnal, 2001). In terms of operationalization, researchers have approached this in different ways. My study follows 
the example of Reingold and Harrold (2010): city partisan composition variable that captures the city's recent voting record (i.e. did the city vote Democrat or Republican in the last presidential election?). If a city's partisan composition is Democrat, I expect an increase in representation in policy (Tausanovitch \& Warshaw, 2014).

The strength of mayor variable indicates if the city has a strong or weak mayoral system. There is a vast body of literature on the effect of mayors, particularly on policy outcomes, beginning in the 1970's with Kotter and Lawrence's work (1974), who developed five approaches to being mayor mayors take to their positions. This work has been refined, and the typology of strong mayor versus weak mayor eventually came to dominate the literature (Baqir, 2002; Cheyne, 2004; Egner \& Heinelt, 2008; Kjaer, 2015; Mouritzen \& Svara, 2002). Baqir (2002), for example, writes that this duality - strong mayor versus weak mayor - is the most common types of mayor in the US. Additionally, he writes that this captures the most important variable to understanding the mayor's role in policy, particularly vis-à-vis the council. Mayor-council governments are coded as strong mayor cities. Weak mayor cities tend to have city managers, and the mayor has a seat on the city council (Egner \& Heinelt, 2008). Weak mayors tend to have ceremonial, as opposed to executive, duties (Cheyne, 2004) and tend towards a collaborative decision making model (Kjaer, 2015).

The predicted effect of a strong mayor government structure is less representation in policy. The underpinning logic of this relationship, as presented in Morgan and Watson (1992), is akin to comparative political science theory about collaborative (i.e. parliamentary) versus adversarial (i.e. presidential) executive structures. Adversarial 
executives exercise power over the legislature, through vetoes (or the threat thereof), agenda setting, and a concurrent legitimacy (Linz, 1990). The resulting relationship slows momentum in policy efforts (Linz, 1990; Mainwaring \& Shugart, 1997). In parliamentary systems, the prime minister is chosen from the political party that has won the majority (or plurality) of seats in the legislature; the resulting relationship is pursuing a common agenda. Without an institutionalized adversary, parliamentary systems are able to pass more policy (Mainwaring \& Shugart, 1997; Moe \& Caldwell, 1994; Strøm, 2000).

The mayor party ideology variable indicates city partisan composition. I dummy coded the democratic mayor variable, so that a democratic mayor is coded as 1. I expect a positive relationship between democratic mayors and representation in policy, as suggested by the literature (Tausanovitch \& Warshaw, 2014).

I collected data on the mayor's race for each city - referred to in the model as mayor's race. The operationalization of this concept is a bit complicated, though. I operationalize the mayor's race as a dummy variable, indicating if the mayor is the same race as the group being represented. In other words, when analyzing African American racial policy, this indicator captures if the mayor is African American. When looking at diversity and equity policy, this variable indicates if the mayor is a minority. I expect the relationship between mayor race and representation in policy to be positive.

Finally, there is a one minority variable. This is a dummy variable. If the value is one, it signals that there is a sole councilor in the category being tested. For the specific descriptive representation models, this means that there is only one Black, Latino or Asian councilor - depending on the model being tested. For the general descriptive 
representation models, a value of one signals that there is only one minority councilor. I included this variable because it is an additional signal of tokenism. The size of councils varies considerably - from 51 councilors in New York to 4 councilors in Chula Vista, CA. The tokenism percentages are defined through the literature - but because there are such variety in the number of councilors on each council the percentages are not always good indicators. For example, one minority councilor in New York would constitute about $2 \%$ of the council; one minority councilor in Chula Vista would constitute $25 \%$. In New York, this would clearly be categorized as tokenism; in Chula Vista, the percentage would be mis-categorized as critical mass. And clearly, the hypothesized relationships at tokenism versus critical mass are starkly different. To account for this, I use the one minority councilor variable. If there is only one councilor in the category, it automatically triggers tokenism, regardless of percentage.

\section{Data Setup}

To set up the data, I first examined it for outliers. As outlined in the literature, outliers were identified as data points that were either a) spurious, and/or b) more than two standard deviations from the mean (Ethridge, 2002; Kumar, 2011; Myers et al., 2010). I identified one outlier: Toledo, Ohio. Toledo had much higher levels of representation in policy than all other cities in the dataset. $6.25 \%$ of policy passed in 2015 was Black racial policy - a true outlier (the average amount of Black policy passed across all cities was .29\%). Upon further inspection Toledo's data was not directly comparable to the other data points in the set. The format of the data was such that the values of representation in policy for all categories were artificially high. 
An additional seven cases were eliminated because of missing or unavailable data. Baton Rouge, for example, could not be convinced to share the data with an out of state resident. St. Petersburg, FL, on the other hand, maintains its records using hand written annotations and mark ups on scanned documents. This is impossible to search automatically, and because of the immense size of the records (tens of thousands of records) not feasible to search by hand. These cases, as well as four others, were eliminated. There are 116 cities with more than 200,000 residents in the US; after eliminating cases, 108 made up the complete study sample. The eight cities that were excluded from the study, listed alphabetically, are: Anaheim, CA; Arlington, TX; Baton Rouge, LA; Memphis, TN; St. Petersburg, FL; Tampa, FL; Toledo, OH; Virginia Beach, VA; Yonkers, NY.

When creating the dataset, I used a method that took each relationship (i.e. a racial group as compared to its related racial policy) as its own data point. Explained in detail in Appendix D, the result of this process was to create a dataset that was three times the size of the original data. This increased the statistical power of my models and allowed me to test relationships that may have been too infrequent to test in the previous dataset construction (King, Keohane, \& Verba, 1994). The dataset was sufficiently large to test most of the models that I was interested in $(\mathrm{N}=324)$.

\section{Data Analysis}

My data analysis approach consisted of two sets of quantitative tests: multiple regressions and a series of one-way ANOVAs. This two-pronged approach allows for a thorough understanding to be developed. Because ANOVA and linear regression are 
based on similar foundations - the same assumptions about the data, the same basis of inquiry - they can be used in conjunction to paint a vivid picture (King, 1986). Further, using ANOVA to augment linear regression models removes any constraints in the data (King et al., 1994), and allows for the relationship between independent and dependent variables to be the sole focus, without the control variables (Schrodt, 2014). As Schrodt (2014) points out, the inclusion of control variables can sometimes muddy the analysis of the primary relationship. Therefore using this two-step approach, including the controls in the regression analysis and removing them in the ANOVAs, allows me to more fully understand the relationships in question.

First, I conducted a series of regression analyses to better understand the direction, strength and significance of the relationships under this study. I looked at the predictive power of specific descriptive representation on racial policy (Model 1) for each racial group. Next, I tested the predictive power of general descriptive representation on diversity and equity policy (Model 2).

\section{RQ1. In US cities with more than 200,000 residents, what is the relationship between specific descriptive representation and racial policy in 2015 , holding relevant variables constant?}

H1: In the linear model, specific descriptive representation will not be a significant positive predictor of racial policy.

$\mathrm{H} 2$ : The best fit model will be when $z$ (that is, the power to which descriptive representation is raised) is more than two, indicating that the nature of the relationship is 
not linear (where $\mathrm{z}$ would be equal to 1 ) and not quadratic (where $\mathrm{z}$ would equal 2), but curvilinear.

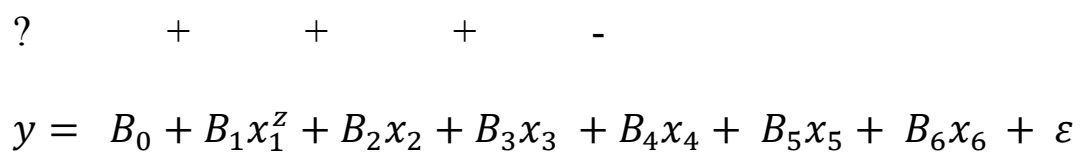

Where

$\mathrm{y}=$ racial policy

$x_{1}=$ percent of the council that identifies as the racial minority

$x_{2}=$ city has a strong mayor (dummy coded, $1=\mathrm{y}, 0=\mathrm{n}$ )

$x_{3}=$ district election (dummy coded, $1=\mathrm{y}, 0=\mathrm{n}$ )

$x_{4}=$ mayor is also the racial minority (dummy coded, $1=\mathrm{y}, 0=\mathrm{n}$ )

$x_{5}=$ city partisan ideology (dummy coded, $1=$ democrat, $0=$ republican $)$

$x_{6}=$ council has only one member of the race (dummy coded, $1=\mathrm{y}, 0=\mathrm{n}$ )

The results from the analysis of this data supported my hypotheses. Where the literature promises a continual positive relationship, I find evidence that the relationship is not constant. In the linear model, contrary to suggestions from the literature, specific descriptive representation is not a significant predictor of racial policy $(p=.226)$. See Table 3.1 below for full linear regression results.

Table 3.1 Linear Regression Results, Racial Policy

\begin{tabular}{lcc}
\multicolumn{3}{c}{ Racial Policy } \\
\hline & Coefficient & St Error \\
\cline { 2 - 3 } Specific descriptive representation & .364 & .300 \\
District election & $-.129^{*}$ & .068
\end{tabular}


Strong mayor

This finding supports Hypothesis 1. The importance of this finding, discussed below, cannot be overstated. A relationship that has previously been taken for granted by scholars finds no supported in this data. I also find evidence that the there is a significant relationship between specific descriptive representation and racial policy in the cubic model. That is, the relationships that were hypothesized to be significant (Hypothesis 2) were, in fact, significant. This is the most important conclusion from this test.

In terms of the covariates, I find interesting conclusions as well. In all models, three of the covariates were significant. District elections predict less racial policy; approximately .15\% less racial policy occurred in cities that use a district election system $(p=.033)$. Strong mayor cities produce approximately $.17 \%$ more racial policy when compared with weak mayor cities $(\mathrm{p}=.014)$. Democratic cities predict about $.14 \%$ less racial policy across all models $(\mathrm{p}=.061)$. That is, district elections, strong mayors, and democratic cities all have significant impacts on the amount of racial policy passed by the council.

Table 3.2 Cubic Regression Results, Racial Policy

\begin{tabular}{lcc}
\multicolumn{3}{c}{ Racial Policy } \\
\hline & Coefficient & St Error \\
\cline { 2 - 3 } Specific descriptive representation & $1.774^{*}$ & .938
\end{tabular}


Specific descriptive representation ${ }^{\wedge} 2$

Specific descriptive representation ${ }^{\wedge} 3$

District election

Strong mayor

Mayor race

Multiple councilors (no)

.063

.072

Democratic city $-.136 *$

RQ2. In US cities with more than 200,000 residents, what is the relationship between general descriptive representation and diversity and equity policy in 2015, holding constant other relevant variables?

H3: In the linear model, general descriptive representation will not be a significant positive predictor of diversity policy.

H4: The best fit model will be when $z$ (that is, the power to which descriptive representation is raised) is more than two, indicating that the nature of the relationship is not linear (where z would be equal to 1) and not quadratic (where z would equal 2), but curvilinear.

$?+\frac{+}{+}+-$
$y=B_{0}+B_{1} x_{1}^{z}+B_{2} x_{2}+B_{3} x_{3}+B_{4} x_{4}+B_{5} x_{5}+B_{6} x_{6}+\varepsilon$

Where

$\mathrm{y}=$ diversity policy

$x_{1}=$ percent of the council that identifies as racial minority

$x_{2}=$ city has a strong mayor (dummy coded, $1=\mathrm{y}, 0=\mathrm{n}$ ) 
$x_{3}=$ mayor is a democrat (dummy coded, $1=\mathrm{y}, 0=\mathrm{n}$ )

$x_{4}=$ mayor is a racial minority (dummy coded, $1=\mathrm{y}, 0=\mathrm{n}$ )

$x_{5}=$ city partisan ideology $($ dummy coded, $1=$ democrat, $0=$ republican $)$

$x_{6}=$ council has only one minority member (dummy coded, $1=\mathrm{y}, 0=\mathrm{n}$ )

My hypotheses claim that the general descriptive representation will be a significant predictor of diversity policy only in the curvilinear models. General descriptive representation was not a significant predictor of diversity policy in any of the models that were tested, regardless of functional form (i.e. from linear to quartic). Additionally, the majority of the covariates that were suggested by the literature, were not significant predictors of diversity policy. The two variables that were consistently significant, across the models, were a) the indicators of a strong mayor system, and b) the Democrat mayor variable. I predicted that the strong mayor variable would have a negative effect on policy outcomes, but here it has consistently a positive coefficient $(\mathrm{b}=$ .003). The Democrat mayor variable aligns with hypotheses, with a consistently positive coefficient $(b=.003)$, meaning that Democratic mayors predict more diversity policy. See Table 3.3 for full linear results; see Table 3.4 for cubic results. Additional results can be found in Appendix E. 
Table 3.3 Linear Regression Results, Diversity Policy

Diversity Policy

Specific descriptive representation

District election

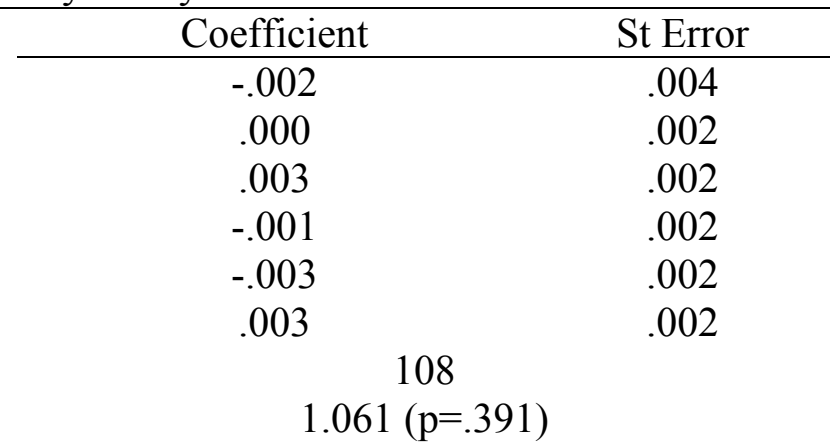

Table 3.4 Cubic Regression Results, Diversity Policy

Diversity Policy

Specific descriptive representation

Specific descriptive representation ${ }^{\wedge} 2$

\begin{tabular}{|c|c|}
\hline Coefficient & St Error \\
\hline-.024 & .022 \\
\hline .040 & .058 \\
\hline-.018 & .042 \\
\hline .000 & .002 \\
\hline .003 & .002 \\
\hline-.001 & .002 \\
\hline-.003 & .002 \\
\hline .003 & .002 \\
\hline \multicolumn{2}{|c|}{108} \\
\hline
\end{tabular}

It is my interpretation that the diversity regression models are spurious. As noted above, general descriptive representation was not a significant predictor of diversity policy, in any of its polynomial expressions. When a strong mayor was running a city, the model predicts . $3 \%$ more diversity policy than a weak mayor city, holding all other things constant. Similarly, when a city is Democratic, the model predicts .3\% more diversity policy than when a city is Republican, holding all other variables constant. The direction of the Democratic city indicator is aligned with theory and hypotheses. This evidence 
seems suspect. Further research is required to determine the magnitude and direction of the relationship in question. As it stands, there is not evidence of a significant predictive relationship as hypothesized.

\section{ANOVA Explanation and Results}

To better understand the relationship between specific descriptive representation of African American, Latino, and Asian populations and racial policy I conducted a series of ANOVA tests. I considered each of the racial groups on its own. This approach allowed me to test the theorized cut points in the data. I used the ANOVAs to better understand what the tokenism period looks like for Latino representation, for example. As discussed above, this approach is supported by the literature in that it provides insight into the relationships, additional to that of regression analysis. I wanted to determine what kind of representation in policy could be expected in the no descriptive representation, tokenism, critical mass, and majority descriptive representation periods. I looked at these by group (i.e. African American, Latino, Asian) as it related to racial policy.

Results of an ANOVA test indicate if there is a significant difference between the means for different groups. The way I set up the data, the ANOCAs tested means in policy outcomes for different types in descriptive representation. I expect the means to be significantly different when the cut points are aligned correctly.

My approach to ANOVA testing was standard, as outlined by Myers, Well and Lorch (2010). I set the significance level at .05. I produced both the tabular and graphic 
results, for a visual indicator of how each model fit with my theory. To choose which cut points best explain the variance in the data (i.e. goodness of fit), I used the significance between difference, alignment with theoretical expectations, and the F-statistic.

\section{Specific Descriptive Representation and Racial Policy by Group}

To deep dive into each racial group separately I used ANOVAs, which use the same analytic framework as regressions while providing a more qualitative look at the data excluding the effect of covariates (King et al., 1994; Schrodt, 2014). I tested African American representation and Latino representation. There was not significant variance in the amount of Asian descriptive representation to perform an ANOVA $^{15}$ (King et al., 1994). The results from African American and Latino tests are presented in tabular, graphic, and descriptive form and interpreted below. The binned data showed a significant difference in the mean racial policy passed at different intervals of descriptive representation. The models support my hypotheses of a curvilinear hypothesized relationship. I ran six different configurations of ANOVAs. Of the six models tested, three sets of results were both statistically significant and theoretically hypothesized. Results of the best-fit model (determined by looking at the F-score) are presented below. Full results can be found in Appendix F.

\footnotetext{
${ }^{15}$ The variation around the independent variable (i.e. specific descriptive representation) was so little that there was not much variance to analyze. For example, 90 of the 107 cities included in the study had no Asian councilors at all. This extreme lack of diversity in the data points means that any analysis on just the Asian population would be difficult to interpret as compared to the black or Latino populations. Asian data was included in the overarching analyses.
} 
Table 3.5 ANOVA results, African American Descriptive Representation and Racial Policy

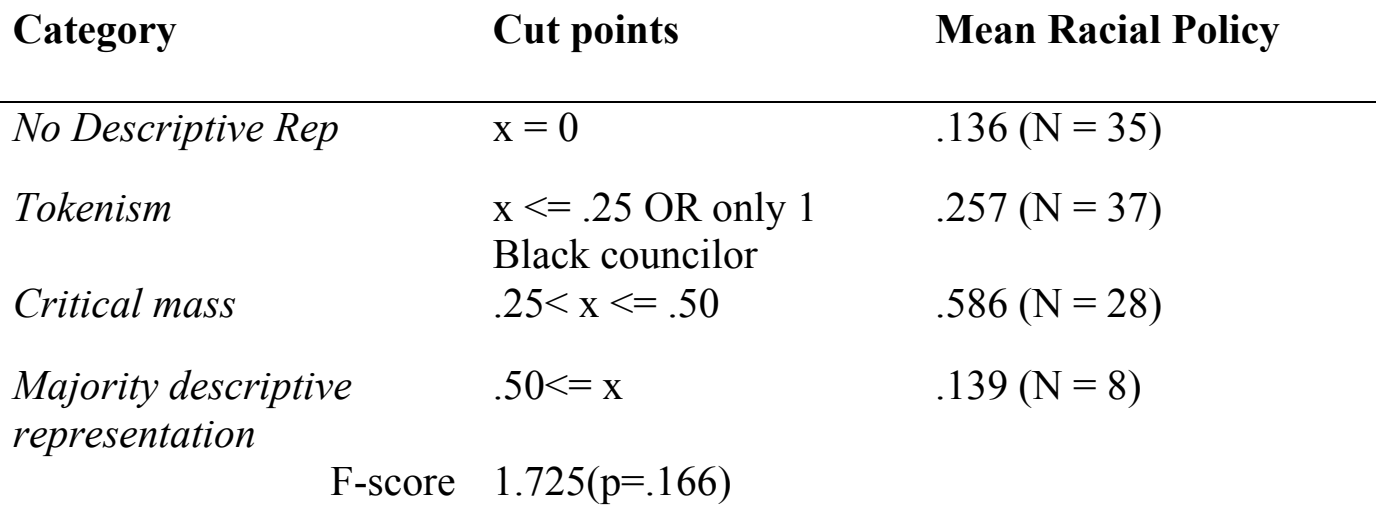

Figure 3.1 Plot of ANOVA results, African American Descriptive Representation and Racial Policy

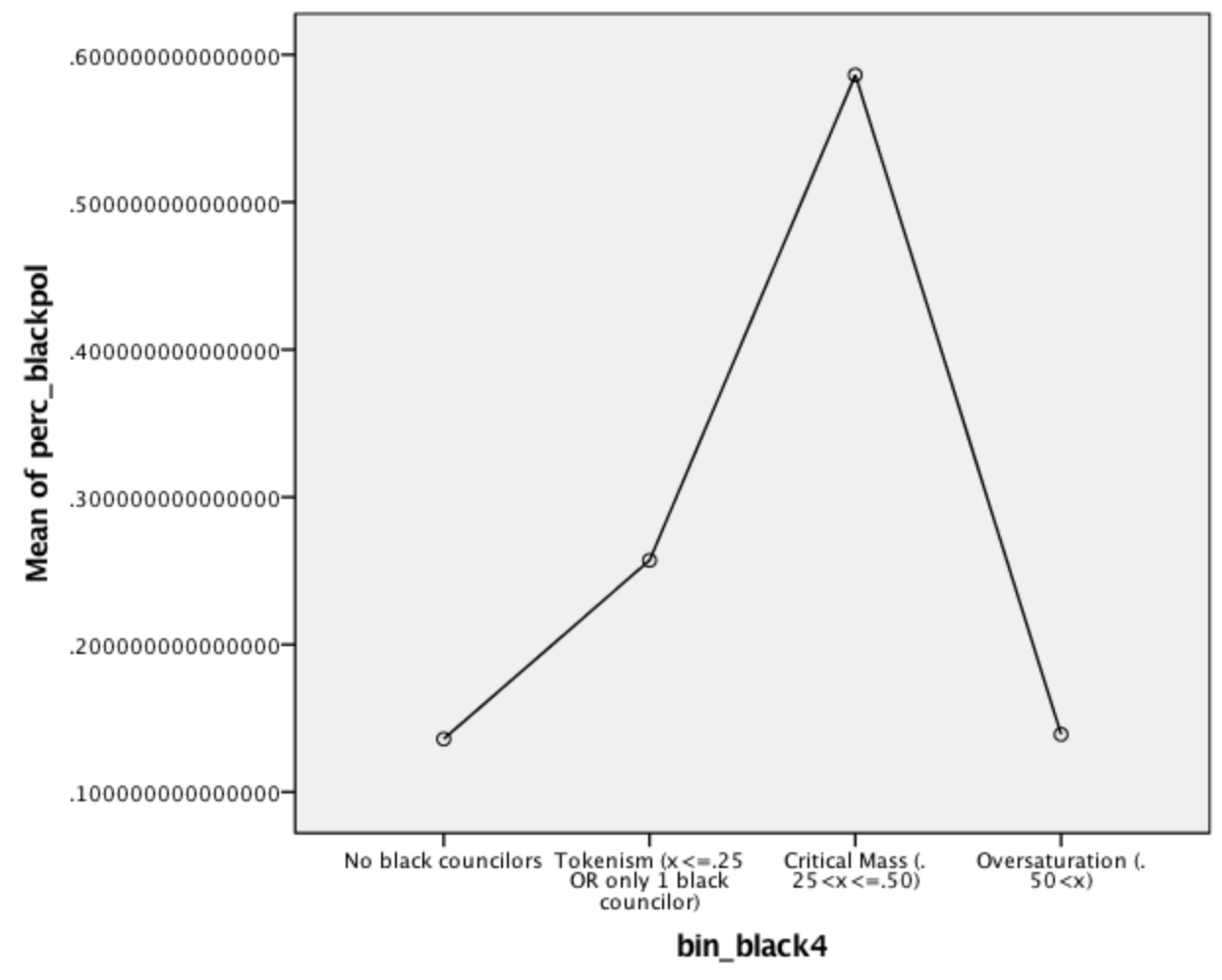


The model presented above is approaching significance $(p=.116)$. The shape of the plot, Figure 3.1, aligns perfectly with my theoretical model. There is a distinct peak in the amount of racial policy passed in the critical mass period - as I argued. And there is an equally distinct drop off in the amount of racial policy passed in the Majority descriptive representation period. This supports my claim that councilors focus on passing other types of policies in periods of majority descriptive representation.

The ANOVA tests of the Latino data produced markedly different results. First, the results were significant $(\mathrm{p}=.018)$ indicating a significant difference between group means. Second, the shape of the data was different from my theoretical model, and from the results from the African American ANOVA. See results below.

Table 3.6 ANOVA results, Latino Descriptive Representation and Racial Policy

\begin{tabular}{|c|c|c|}
\hline Category & Cut points & Mean Racial Policy \\
\hline No Descriptive Rep & $\mathrm{x}=0$ & $.113(\mathrm{~N}=55)$ \\
\hline Tokenism & $\begin{array}{l}\mathrm{x}<=.25 \text { AND only } 1 \\
\text { Latino councilor }\end{array}$ & $.231(\mathrm{~N}=38)$ \\
\hline Critical mass & $.25<x<=.50$ & $.312(\mathrm{~N}=10)$ \\
\hline $\begin{array}{l}\text { Majority descriptive } \\
\text { representation }\end{array}$ & $.50<=x$ & $.638(\mathrm{~N}=5)$ \\
\hline & $3.149(\mathrm{p}=.028)$ & \\
\hline
\end{tabular}


Figure 3.2 Plot of ANOVA results, Latino Descriptive Representation and Racial Policy

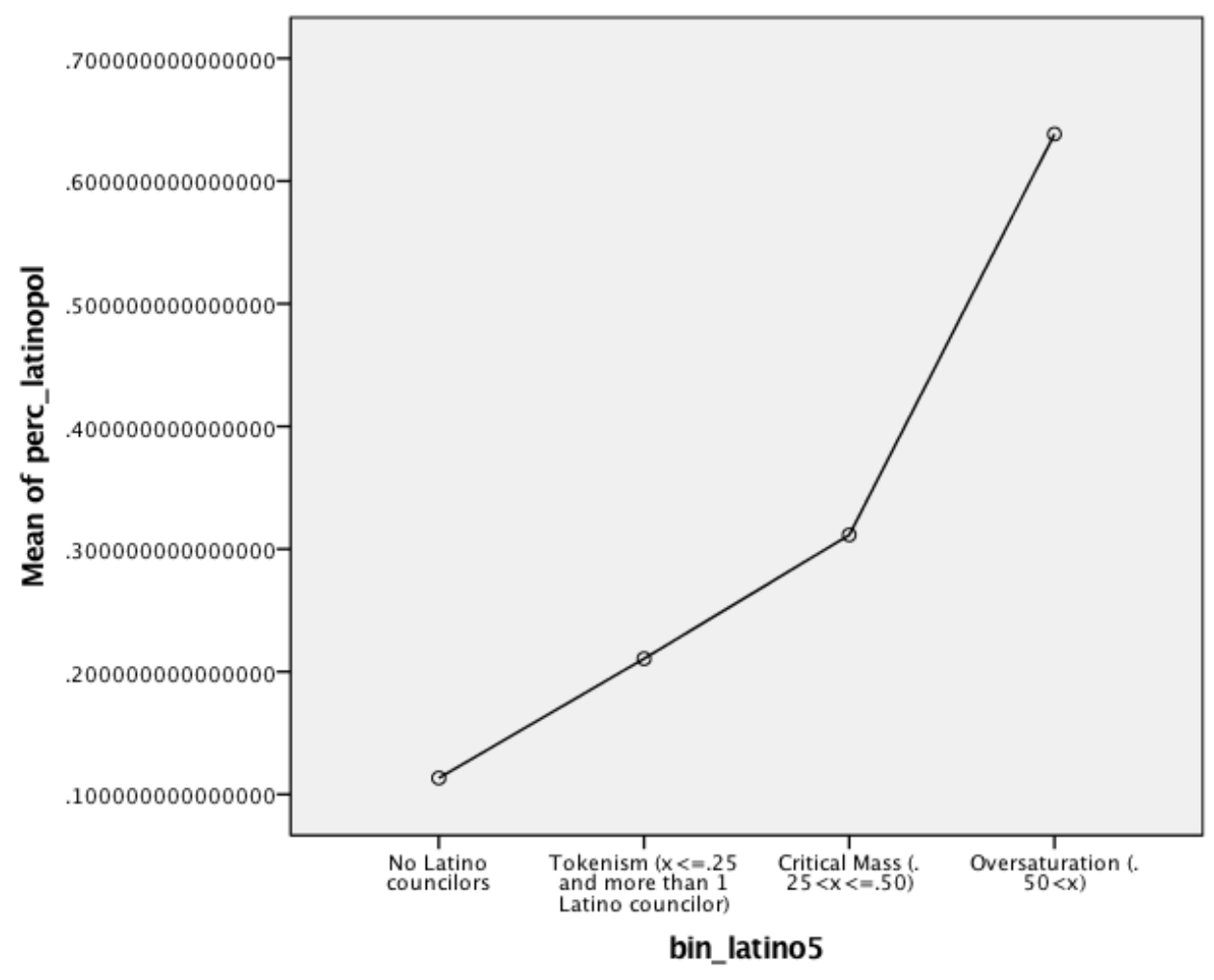

The data supports my argument that there are significant differences in racial policy output based on the level of descriptive representation. However, the direction of these differences runs contrary to my argument. There is a nearly-constant rate of increase in racial policy as descriptive representation increases in the first three stages. When we enter the stage of Majority descriptive representation, I expected to see a sharp decrease in racial policy. Instead there is a drastic increase in the amount of racial policy passed

\section{General Descriptive Representation and Diversity Policy}

Like the results from the regression analysis of this relationship, the ANOVA results were not significant. The model that is approaching significance is shown below. 
The p-value associated with this test suggests that there is not a significant different between the means of the types of general descriptive representation. Further, the plot of these results is contrary to the hypotheses presented earlier in the chapter.

Table 3.7 ANOVA Results, General Descriptive Representation and Diversity Policy

\begin{tabular}{lll} 
Category & Cut points & Mean \\
\hline No minority councilors & $\mathrm{x}=0$ & $.797(\mathrm{~N}=12)$ \\
Tokenism1 & 1 minority councilor & $.228(\mathrm{~N}=12)$ \\
Tokenism2 & $\begin{array}{l}\mathrm{x}<=.30 \text { AND more than } \\
\text { one minority councilor }\end{array}$ & $.793(\mathrm{~N}=23)$ \\
$\begin{array}{l}.30<\mathrm{x}<=.50 \\
\text { Critical mass }\end{array}$ & $.418(\mathrm{~N}=37)$ \\
$\begin{array}{l}\text { Majority descriptive } \\
\text { representation }\end{array}$ & F-score & $1.547(\mathrm{p}=.194)$
\end{tabular}


Figure 3.3 Plot of ANOVA Results, General Descriptive Representation and Diversity Policy

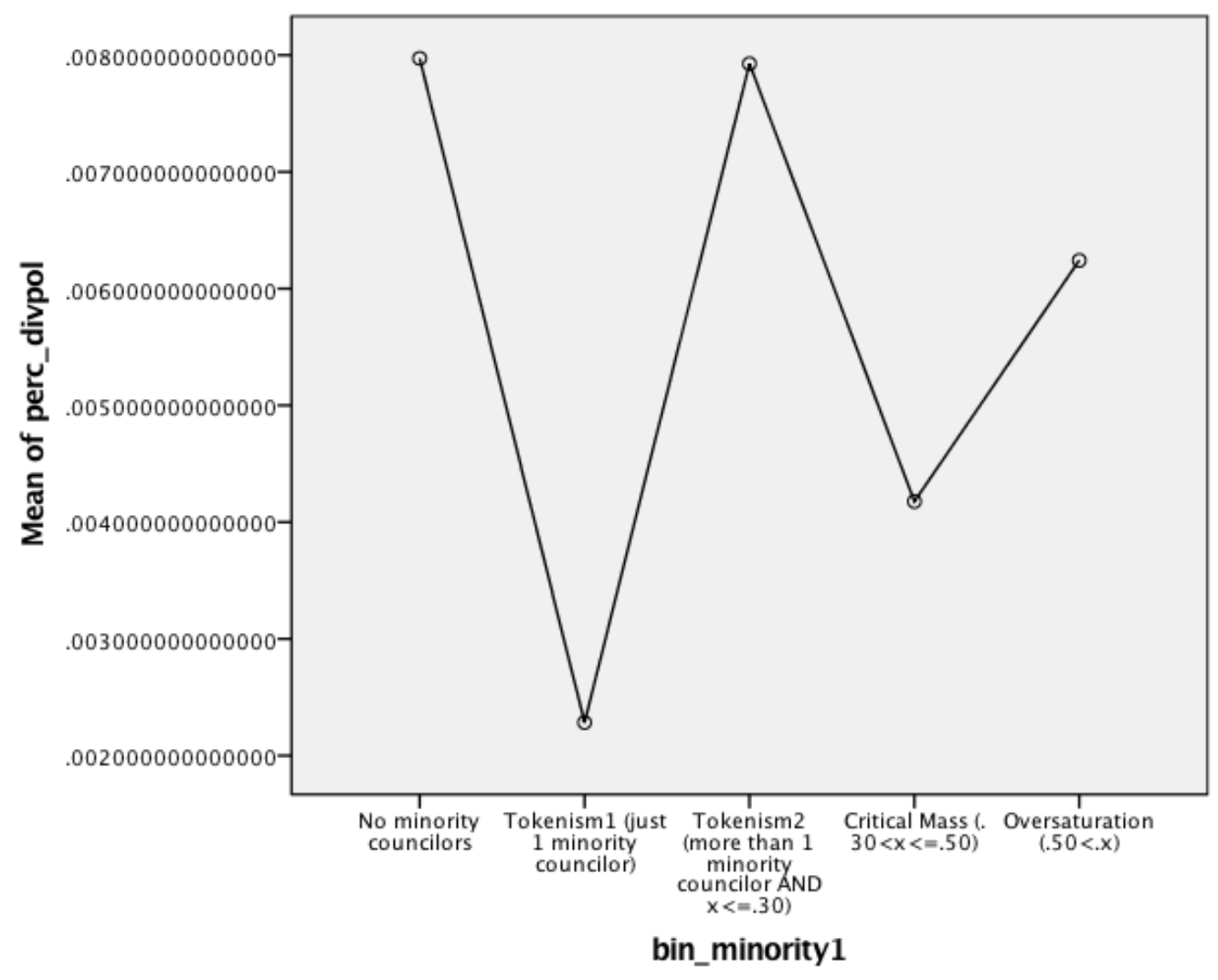

Validity

In accordance with the literature (Ethridge, 2002; Myers et al., 2010) this project has internal validity. The components of the project are logically linked. The racial composition of a council affects the dynamics of the group, thus affecting which policies are proposed and championed, and by whom. Additionally, the racial composition of the council affects the perceptions of the constituency, altering the electoral math and 
strategy pursued by councilors. This intuitive link lends credibility to the internal validity of my project.

\section{Conclusion}

To test my theory and hypotheses, I devised two strategies. These approaches are outlined in this chapter. In this chapter, I first restated the research questions and hypotheses, including hypothesized effects of covariates. In the second section, I discuss the research design and the operationalization of all variables included in the study. Then I describe my data collection process. Next, I discussed how I use two main methods for testing my hypotheses: regression analysis and ANOVA testing. I explain my rationale for these choices, and then described how I conduct these tests. I then presented my findings, highlighting which results supported, and which detracted from, hypothesized results. Finally, I conclude the chapter by discussing challenges to validity and reliability. 


\section{CHAPTER 4. CASE STUDIES}

"There is much to be gained from recognizing the deep epistemological differences between qualitative and quantitative approaches to the pursuit of knowledge" (D. L. Morgan, 1998, p. 363). A mixed methods approach allows for the inclusion of these epistemological differences in a real, robust way. The combination of these methods means that the author can make broad generalizations about the nature of the relationship in question, while simultaneously making deep inquiries about the mechanisms at work in particular cases.

Armed with the assurance that qualitative research provides a different kind of insight and understanding than quantitative, I began a qualitative venture. I conducted four case studies, focusing on liberal cities with similar institutions in different regions of the US. The results highlight that there are differing rationales at play in different levels of descriptive representation. That is, by conducting a qualitative, subset analysis, I was able to better understand and illustrate the political posturing and positioning that is going on at the ground level.

Case selection is paramount for a successful set of case studies; my description of the case selection process is the first section below. The second section focuses on the qualitative methods I used. I describe my process for understanding each case and how I replicated the data gathering for each case. I then present the case studies, beginning with Diversity Policy in Portland, OR, then moving to Asian Racial Policy in Minneapolis, Diversity Policy in Albuquerque, and finally Black Racial Policy in New Orleans. I conclude the chapter by bringing these case studies together and looking at the entire 
picture. The thesis that emerges from this exercise is that there is qualitative support for my theories, and that the curvilinear relationship described in previous chapters can be observed in these case studies.

\section{Case Selection}

Case selection is the foundation for case study. As described by Gerring (2008), I used the 'typical method' of selection, coupled with the 'diverse method.' That is, I sought cases with key similarities (in this case, population values and city partisanship), as well as essential differences (regional and demographic). This hybrid technique allows for the most compelling, complete picture of the qualitative data.

The four cities included as case studies are (listed alphabetically): Albuquerque, NM; Minneapolis, MN: New Orleans, LA; and Portland, OR. All cities are mid-sized, with populations ranging from nearly 400,000 (New Orleans' population is approximately 390,000) to around 600,000 (Portland's population is approximately $630,000)$. In addition to similar population sizes, all four cities are politically liberal. All voted Democratic in the last presidential election, and all are run by a Democratic (or non partisan) mayor. The liberal political views indicate that the city is more open to passing representative policy (Abrajano \& Hajnal, 2015; Z. L. Hajnal, 2001). By using only liberal cities, I am in effect holding this variable constant so that I can focus on the effect of descriptive representation on policy outcomes.

Another commonality between these cities is found in the mayor: all mayors in these cities are white. Regardless of the demographics of the city, or of the council, all 
four of these cities elected a white mayor. The race of the mayor is an important variable, as suggested by Bobo and Gilliam (1990). Cities with descriptively representative mayors are more likely to have more representation in policy. Thus, choosing cities with white mayors I eliminate the variation in the cases due to the race of the mayor.

In addition to the typical variables (i.e. the things that the cases have in common), I used one major difference: racial demographics of the city. Portland is the whitest major city in the country (Semuels, 2016) whereas Albuquerque has a very large Latino population (approximately $42 \%$ ). Minneapolis has one of the largest refugee population from Somalia in the US (Shah, 2017) and New Orleans is a touchstone for African American culture. A city's demographic information is closely linked with its descriptive representation on the council. In fact, it is so closely linked that when I tested a previous iteration of the quantitative model, including both demographic and descriptive representation variables, it violated the assumption of no multicollinearity. I held relevant variables constant, while choosing cases with sufficient variation in the independent variable.

Using the methods identified in the field, I developed a case selection strategy that was appropriate to the research question. I used the typical and diverse methods of selection, and found four cases that were ideal for examination. The cities had important elements in common: they are all mid-sized, liberal cities led by a white mayor. The cities also differed in one important way: racial demographics. The similarities between these cities coupled with the stark difference means that the case study portion of my dissertation is compelling. 


\section{Methods}

In this section, I discuss how I explored each case and used it to better understand the key relationships in question, as well as the results presented in the previous chapter. This section also serves as a makeshift chapter outline; as I describe the methods that I used to better understand each case, I am simultaneously describing a section in each case study.

I first gathered background information on each case. This included relevant details about the councilors, like who they were and their racial identification. I identified the mayor and their race. I gathered information on structural and institutional variables, such as electoral system and form of council. I then gathered information about the demographics of the city. I considered the political landscape of each case, gathering information about the on-the-ground political context of the city in 2015. This information helped inform my understanding of the bills.

I then gathered information on the legislative output for the city in the study year. I found the number of bills that each city passed, and the number of bills that would be considered representation in policy. Finally, I learned more about the decision-making context, relying heavily on newspaper particles to add richness to my understanding of the cases.

After gathering background information, I dove into a deeper understanding of the legislative material. I identified the text and the name of the bills that had been categorized as representation in policy. I summarized the bills to better understand them, putting the text into my own words to gauge their effect. After identifying and marinating 
in the language of the bills, I reviewed the vote count for each. I was looking for additional insight; was a representative bill passed unanimously? Was it contentious, and thus passed by a narrow margin? I answered these questions, all the while checking in to see how what I was learning was measuring up to my theoretical hypotheses.

Then, after exploring these important elements, I did a final reckoning. I asked how well the case fit with my theory. I asked what additional can be learned from the case, what wrinkle it provides in terms of the theory. I asked what nuance could be gleaned, and then applied to my understanding of the quantitative results. The thesis that emerges from these case studies is that they tend to fit with the hypotheses. They provide compelling and interesting support for the findings presented in the previous chapter.

Finally, after considering each case separately, I brought them together.

Considered in concert, even as anecdotal evidence, they are compelling. When the data points are considered as a whole, they show a marked curvilinear relationship that aligns with the theoretical predictions of Chapter 2 .

\section{Case study - Diversity Policy in Portland, OR}

"There is a growing awareness that we have many different communities of new Portlanders, including refugee and immigrant communities" -- Amanda Fritz, a white Portland City Commissioner, as she advocates for a new City Commission for Immigrants and Refugees, actively positioning herself as representative of racial minority groups (Mulligan, 2016).

In Portland, I find an example of the effect of no general descriptive representation on diversity policy. It is a primarily white, liberal city that has a history of both rallying for civil rights, and latent white supremacy (Semuels, 2016). With its all 
white council, my theory suggests that I would find higher-than-average diversity policy outcomes. Theoretically, councilors should act in a representative way, posturing and performing as conduits of racial minority policy preferences so as to preclude the need for a descriptively representative councilor. In this case study I find support for my hypothesis. I find that, numerically, the city has a fairly high level of representation in policy. I also find anecdotal evidence that Portland commissioners actively posture as representatives of minority interests, effectively negating a constituent need for descriptive representation.

\section{Background}

Portland in 2015 was preoccupied with the Democratic primary candidacy of Bernie Sanders (Mapes, 2015). Oregon's primaries are late in the primary cycle, coming well after New Hampshire and Iowa set the political tone for the country. In 2015, by the time the Democratic primaries had reached Portland, it was clear that Hillary Clinton was going to win the nomination. Despite this - or perhaps because of it - Sanders' support in Portland was undiminished.

Also at play in 2015 was the litigation between the Department of Justice and Portland Police Bureau. In 2015, the DOJ was investigating the PPB's use of force against people with mental disabilities ${ }^{16}$ (e.g. “America's Cities Mirror Baltimore's Woes," 2015; Harris-Perry \& Seltz-Wald, 2015). The DOJ investigation paid particular attention to police brutality against people of color. This lawsuit was widely discussed in

\footnotetext{
${ }^{16}$ In addition the DOJ investigation, in 2015 the PPB launched a research project with consultants to develop a Strategic Equity Plan and a Strategic Equity Evaluation Plan. Portland State's Center for Public Service was hired to develop the latter plan, and I was one of the lead researchers on this project.
} 
Portland and received significant attention from the community (Bernstein, 2015). "This agreement, now affirmed, solidifies Portland's commitment to serving our diverse community. ... We're serious about having a police force that appreciates the issues around mental illness and that utilizes de-escalation tactics", said Portland Mayor (and Councilmember) Charlie Hales (Green, 2014).

In terms of the institutional variables in my model, Portland had the following elements in 2015. There were five city council members (called "commissioners"; Portland has one of the last remaining commission forms of government in a major US city $\left.^{17}\right)$. They were: Nick Fish, Amanda Fritz, Dan Saltzman and Steve Novick. The fifth commissioner was Mayor Charlie Hales. In Portland, there is a weak mayor.

Approximately $76.1 \%$ of Portland in 2010 was white - making it one of the whitest major cities in the US (Semuels, 2016). 6.3\% of the city was Black and 7.1\% of the city identified as Asian. 9.4\% of the population was Latino (including those who identified as white as well).

\section{The bills}

The Portland City Council passed 157 policies in 2015. Of those, two were about diversity and equity programs (i.e. $1.27 \%$ ). The average amount of diversity and equity policy passed across all cities in 2015 was $.564 \%$. In other words, Portland passed approximately twice as much diversity and equity policy that the sample average in the study year - with no general descriptive representation on the council.

\footnotetext{
${ }^{17}$ https://www.portlandoregon.gov/Auditor/article/9178
} 
The first policy passed was Council Ordinance $187030^{18}$. This policy is about increasing the amount of equity in contracting in the city. It explicitly aims to increase the amount of women and minority owned businesses that are contractual partners. Clearly this bill fits in the diversity and equity policy category. It increases diversity in the city's contractual partners and explicitly states this as a goal. This is part of a long tradition beginning in the 1960's to encourage diversity within the companies who partner with government. The ultimate goal is to support women and minority owned businesses (E. J. Barrett, 1995; Porter, 1995).

The second policy that the Council passed was Council Ordinance $186950^{19}$. This policy amends a previous contract, and is focused on cultural services in the city. Though the text of the previous contract is not included in this bill - and is therefore not part of this case study - its subject is considered diversity and equity. That is, the bill is providing cultural services to city residents.

Both diversity and equity bills passed with unanimous support. These policies constitute a relatively large percent of the entire slate of policies that was passed by the Portland commission. The average across cases is $.564 \%$, and it is more than double in Portland (1.27\%). Previous literature would point to the dearth of descriptive representation and hypothesize that this would result in a dearth in policy output as well (e.g. Dahlerup, 1988; Kanter, 1977; Mansbridge, 1999). I argue, however, that in order to

\footnotetext{
${ }^{18}$ The title of which is: CITY AUDITOR - CITY RECORDER - COUNCIL ORDINANCE - 187030 ESTABLISH THE COMMISSION ON EQUITABLE CONTRACTING AND PURCHASING TO INCREASE UTILIZATION OF MINORITIES AND WOMEN-OWNED BUSINESSES ORDINANCE

${ }^{19}$ The title of which is: "CITY AUDITOR - CITY RECORDER - COUNCIL ORDINANCE - 186950 REGIONAL ARTS AND CULTURE COUNCIL PUBLIC ART MATTERS AMEND CONTRACT 30001790 ORDINANCE"
} 
prevent a descriptively representative challenger, councilors support s minimum level of representation in policy. By positioning themselves as allies, white councilors hope to preempt the need for a descriptively representative challenger.

\section{How this fits with my theory}

The quote from Commissioner Fritz at the top of this case study suggests that there is political posturing by the commissioners. It shows an understanding of her vulnerability as a member of an all-white council. She acknowledges that there is a need for representation of racial minority groups. Commissioner Fritz could discuss a need for descriptive representation, or use her position to augment the work of community leaders. Instead she is putting herself in the middle of the conversation, claiming to represent the needs of racial minority groups in the city.

The posturing of Commissioner Fritz included, Portland is a strong example of my theory. It has an all-white council and mid-level diversity and equity policy in 2015. This signals that though other scholars have credited representation in policy to the effect of descriptive representation, there is something else afoot. The lack of general descriptive representation was not a barrier for passing $1.27 \%$ of representative policy more than double the average across cases. See figures below.

\section{Figure 4.1 Illustration of Portland's General Descriptive Representation}

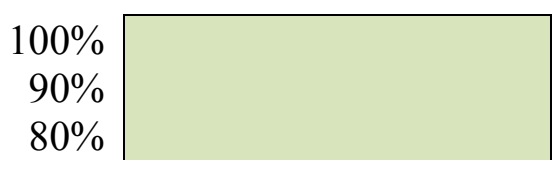




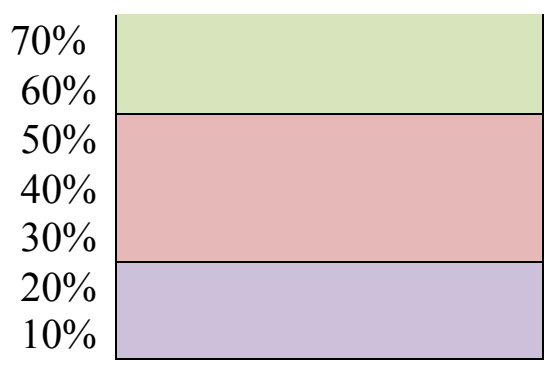

Majority descriptive representation

Critical mass

Tokenism

Portland

Figure 4.2 General Descriptive Representation in Policy, Portland as Compared to the National Average

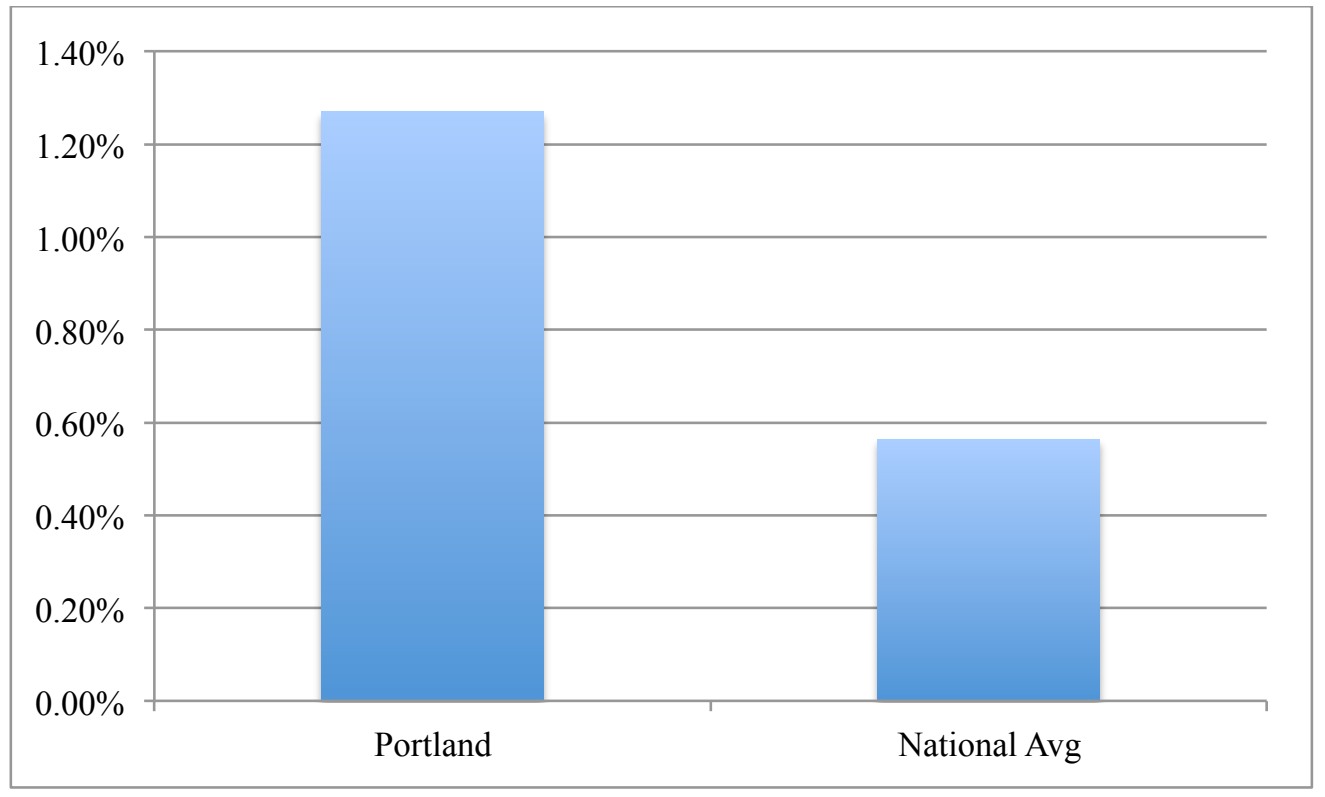

The unanimous support for these bills, too, implies that the all-white council was not a significant barrier. Though this finding contradicts previous scholarship, it aligns with my theory. I argue that councilors in an all-white council will work to stave off a racially representative councilor and thus will act so as to appear representative. The amount of policy here, considered with the unanimous support and the decision-making context, signals that mid-level policy outcomes are to be expected. 


\section{Case study - Asian Racial Policy in Minneapolis, MN}

" 'Certain people, they feel like they want to call people names," Yang said. " 'You're not progressive enough,' 'You're not liberal enough'... 'You don't care about this ... group of people.' My job is to do everything I can to help my constituents in Ward Five. My other job is to figure out what's best for the city of Minneapolis. I take those two things very seriously." - Councilor Blong Yang, the first Hmong American councilor of Minneapolis. In this interview, he is addressing the criticism that he was not doing enough to represent Asian groups in Minneapolis (Golden, 2016). In this quote, Councilor Yang illustrates balancing the needs of the represented group with the fears of white backlash and maintaining the status quo.

In Minneapolis in 2015, there was one Asian member of the Council. Councilor Blong Yang was a strong representative of his descriptive group; he brought $20 \mathrm{Hmong}$ children to tour city buildings (Clark, 2014), he frequently discussed his ties to the racial community, and advocated for Asian immigrants that did not speak English (Clark, 2013) That is, he was a great descriptive representative. He was not, however, a strong representative in policy. Councilor Yang and the rest of the Council passed exactly zero Asian racial policies in 2015. In Minneapolis, I find an excellent example of tokenism at work.

\section{Background}

In 2015, Minneapolis had one of the most important BLM movements in the country (Dalton, 2015). Its ties to the national organization were mirrored at home; the Minneapolis police department was accused of disproportionate use of force against people of color (Miller, 2015). The city was also in the middle of a political and racial 
moment, looking closely at how identity politics and political movements overlapped (Hausman, 2015; Karnowski, 2015; “LGBTQ Organizations Stand in Solidarity with Black Lives Matter," 2015; McClatchy, 2015). In addition to the momentum of BLM, general conversations about rising inequality in the city were prevalent both in general terms (Dehn, 2015; Rosen, Green, Zhou, Semuels, \& Pinsker, 2015), and specifically about jobs growth (Salisbury, 2015) and minimum wage (Hedges, 2015).

Politicians in Minneapolis had to walk a fine line, catering to the political moment while maintaining their electoral base. For one councilor in particular, this was difficult. In 2015, Councilor Yang was midway through his term as the elected councilor from Ward 5. As illustrated by the quote at the top of this case study, his role had an inherently difficult duality. As I argue all Token representatives experience, Yang had to balance the needs of the racial minority group with the needs of the rest of his constituency. And, he had to do this in a way that protected his electoral power.

Minneapolis is a liberal, northern city with a population of approximately 410,000 people. In 2015, its mayor was a white woman, Betsy Hodges of the Democratic Farmer Labor (DFL) Party, a socially liberal party in the region. Minneapolis has a strong mayor system, and uses a district electoral system. In addition, Minneapolis happens to be an excellent example of tokenism when considering Asian descriptive representation and related racial policy. The Minneapolis city council has 13 members. Yang was the only Asian councilor to serve that year, making up approximately $8 \%$ of the council - making a clear case of tokenism. Of the remaining twelve councilors, ten were white, one was Black and one was Latino. 


\section{Bills}

In 2015, a total of 519 policies were passed by the Minneapolis city council. None of these policies were Asian specific. One might then ask, was there any racial policy for any group? Perhaps the Minneapolis council does not deal with this type of policy; maybe this isn't in the city's ethos? I looked at the other categories of policy to check. In 2015, there was one Black specific policy, one Latino specific policy and two diversity and equity policies - indicating that the council is open to racial and diversity policies and, simultaneously, passed no specific Asian policy. Across cases, cities passed an average of $.209 \%$ Asian policy.

\section{How this fits with my theory}

The lack of Asian representation in policy, despite the presence of Councilor Yang, aligns well with my theory. I argue that there is considerable white backlash in the tokenism period. I argue that token councilors are unable to pass a racial policy agenda on their own, and that they will not have the support of their white counterparts. Thus, despite the presence of a representative, the represented group can expect very little policy. Kanthak and Krause (2012) predict similar outcomes. There is no chance of a race-based coalition for the represented minority, making it impossible to pass representative policy without the support of white councilors. The likelihood of white backlash in the tokenism period is high, however, and thus it is equally unlikely that the white counterparts on the council will rally with the Token representative to pass a slate of representative policies. 
Figure 4.3 Illustration of Minneapolis' Asian Descriptive Representation

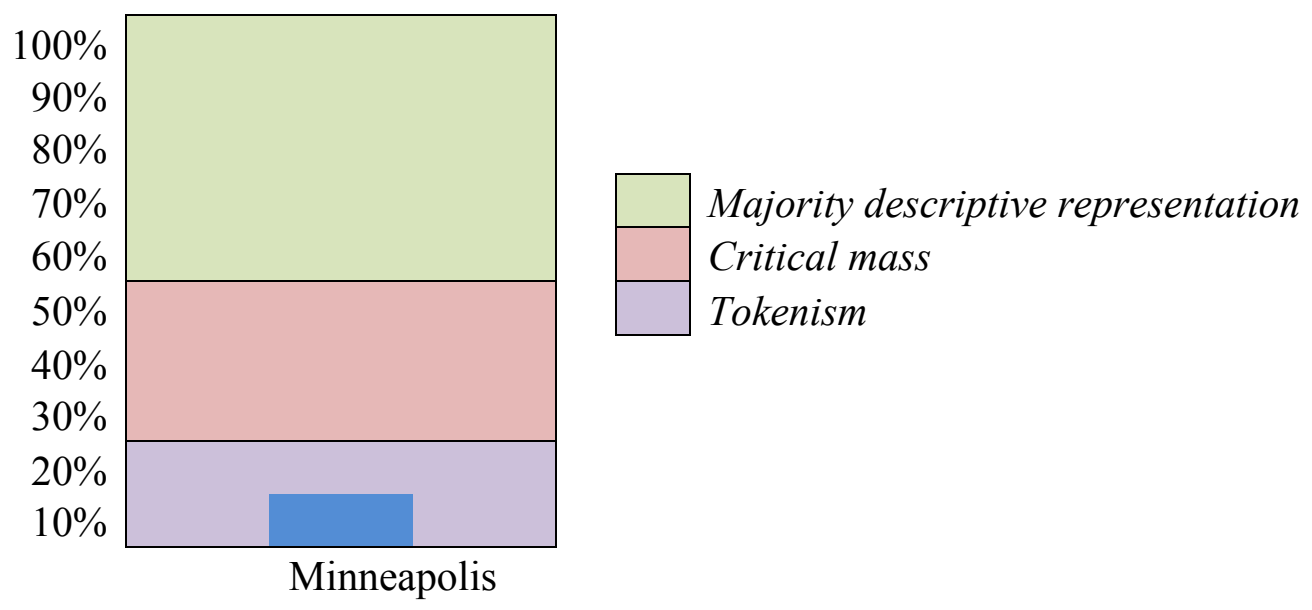

Figure 4.4 Asian Representation in Policy, Minneapolis as Compared to National Average

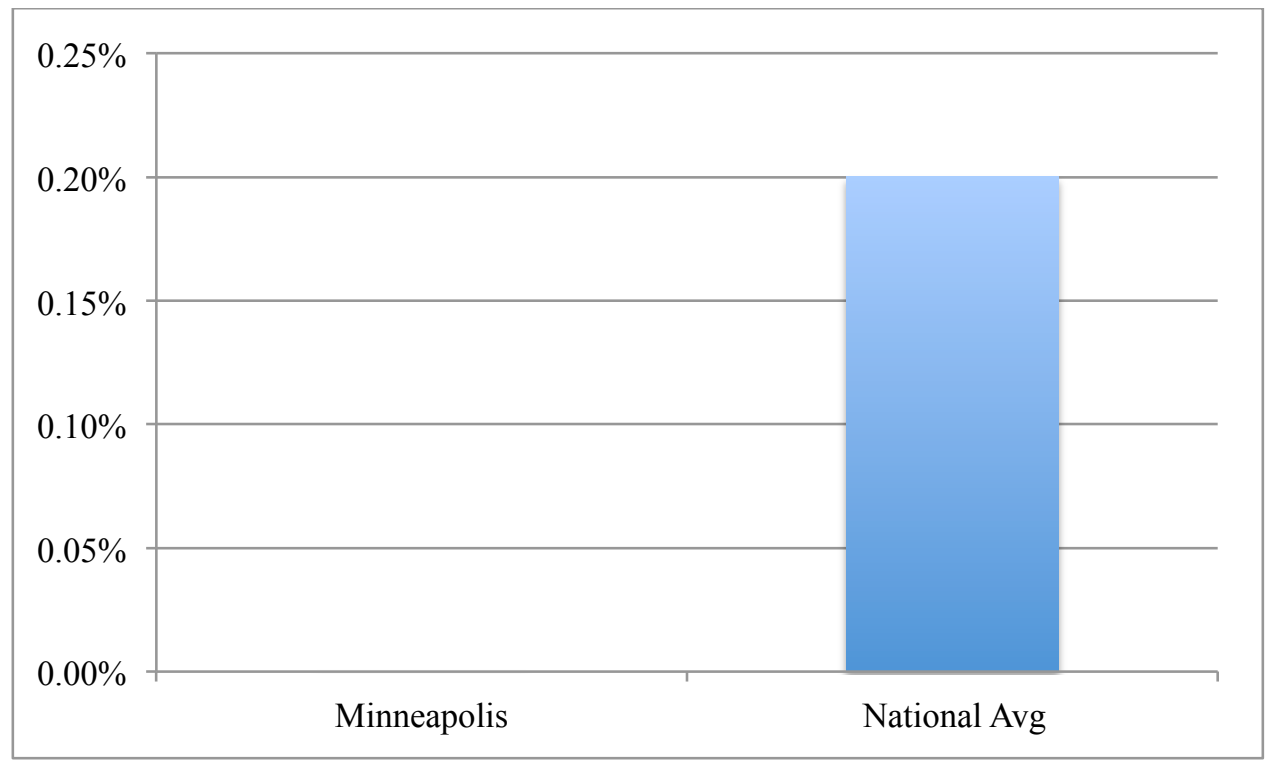




\section{Case Study - Diversity Policy in Albuquerque}

"City Council President Rey Garduño - with guidance and input from The Red Nation and community organizations - wrote, sponsored, and proposed the initiative. Six councilors endorsed and three abstained. Those who endorsed included Garduño, Ken Sanchez, Klarissa Peña, Isaac Benton, Brad Winter, and Diane Gibson. Those against included Dan Lewis, Trudy Jones, and Don Harris." - An article published in The Red Nation, a Native American publication in Albuquerque. This quote illustrates an allegiance between the minority members of the council, acting to enhance diversity and equity initiatives in the city, despite the opposition of white councilors.

Albuquerque illustrates the effect of critical mass on diversity policy. I

hypothesize that during a critical mass type, a group will experience very high levels of representation in policy, because they have the legislative power and stability to pursue a policy agenda without fear of white backlash (on the part of the voters, or the other council members), and without needing to have internal differentiation (as with majority descriptive representation). Based on the number of policies passed and the number of representatives on the council, I would argue that Albuquerque represents the effect of critical mass well. The above quote illustrates how minority councilors were able to act together to pursue a strong, diversity-based policy agenda.

\section{Background}

Susana Martinez was the first Latina governor in the country and was elected as governor of New Mexico in 2011. She framed herself as a staunch "compassionate conservative" Republican in a Democratic state (Nordlinger, 2014, p. 2). Her policies were markedly conservative; she was against amnesty for undocumented immigrants, in favor of increased border restrictions, and tried to convince the New Mexico legislature 
to repeal a bill allowing undocumented immigrants access to driver's licenses. Despite her conservative immigration stance, however, she was favored by the Latino community and attracted the support of many staunch Democrats. Her political opponent (a white male Democrat) argued that she did not possess a "Latino heart" (Nordlinger, 2014, p. 2). Exit polls and subsequent support indicated that the Latino community disagreed. New Mexico had its first Latina governor and a new era of descriptive representation at the executive level emerged.

In early August of 2014, Ferguson, MO captured national attention with the police shooting of the unarmed Black man, Michael Brown. The subsequent focus on racial bias and racially based violence on the part of police spanned cities across the country. In $2014^{20}$, Albuquerque was embroiled in a related controversy. There were allegations of systematic racial biases in the police department, and cases of extreme use of force by the bureau. These police actions were subject to national scrutiny (Davies et al., 2014; Golden \& Jany, 2015; Melber et al., 2014; Sharpe, 2014). As Sharpe writes, Hispanic residents of Albuquerque were the ones who were targeted by the overzealous police force. Following the allegations of racially based police violence, Eric Holder promised to investigate (Jones, 2014).

In 2014 there were nine city council members. They were (listed in order of the Districts that the represent): Ken Sanchez, Isaac Benton, Klarissa Peña, Brad Winter, Dan Lewis, Rey Garduño, Diane Gibson, Trudy Jones, and Don Harris. In Albuquerque, there is a strong mayor system; Mayor Richard Berry had both executive power and veto power.

\footnotetext{
${ }^{20}$ The study year, as a large portion of the council changed in 2015 .
} 
There were three minority members of the council in 2014 (Ken Sanchez, Klarissa Peña, and Rey Garduño), making up approximately one-third of the council and signaling critical mass. In Albuquerque in 2010, the city demographics were as follows. Approximately $42.1 \%$ of the population was white. $3.3 \%$ of the city was Black and $2.6 \%$ of the city identified as Asian. $46.7 \%$ of the population was Latino. Together, that means that more than half of the city identifies as a racial minority $(52.6 \%)$.

\section{The bills}

The Albuquerque city council passed 160 policies in 2014. Of those, six were about diversity and equity programs (i.e. 3.75\%). The average amount of diversity and equity policy passed across all cities was $.564 \%$. In other words, Albuquerque passed nearly six times more diversity and equity policy that the sample average in the study year. This very high amount of diversity and equity policy was passed with the critical mass level of descriptive representation.

Of the six bills that the council passed that pertained to diversity and equity, two were proposed by minority councilors. Councilor Peña introduced a bill that appropriated funds to the Hispanic Cultural Center Foundation ${ }^{21}$,. This bill promotes diversity and multiculturalism in its title and thus was double categorized as both a diversity and equity policy and a Latino racial policy. Councilor Sanchez also introduced a bill about equity and diversity ${ }^{22}$. This legislation appropriates funds to the Cultural Services Department; it

\footnotetext{
${ }^{21}$ The title of which is: "APPROPRIATING LODGERS' TAX FUNDS TO THE NATIONAL HISPANIC CULTURAL CENTER FOUNDATION FOR THE ADVERTISING, PUBLICIZING AND PROMOTION OF THE NATIONAL HISPANIC CULTURAL CENTER (PEÑA)"

${ }^{22}$ The title of which is "APPROVING AND AUTHORIZING THE ACCEPTANCE OF GRANT FUNDS FROM THE NEW MEXICO STATE LIBRARY FOR THE BASIC STATE GRANTS IN AID AND
} 
is considered a diversity and equity policy as it serves to enhance the cultural offerings of Albuquerque.

Councilor Harris introduced the third diversity bill ${ }^{23}$. This bill is ceremonial, recognizing the significance of a local community center's contributions to the city's culture. The fourth bill was proposed by Councilor Jones, and is another bill about receiving funds from the national government for the Cultural Services Department ${ }^{24}$. Though this does not name equity and diversity explicitly, the bill furthers diversity in cultural recognition. The fifth bill has the same title as the fourth bill, but was proposed by Councilor Benton ${ }^{25}$. The method that the Albuquerque City Council uses to track its legislation means that it is difficult to tell if this is a unique bill, or a reframing of the previous. Nevertheless, it passed as a piece of singular legislation and thus was counted. In all three of these bills, Albuquerque is clearly investing in building its cultural repertoire, and has received numerous grants from federal agencies to do so. It is also recognizing those in the field who are augmenting these goals. These kinds of bill reflect the city's commitment to the promotion of diverse culture.

PROVIDING FOR AN APPROPRIATION TO THE CULTURAL SERVICES DEPARTMENT IN FISCAL YEAR 2014 (SANCHEZ)".

${ }^{23}$ The title of which is, "“'RECOGNIZING THE SIGNIFICANCE OF THE HISTORIC SITE ADJACENT TO THE SINGING ARROW COMMUNITY CENTER, KNOWN AS RANCHO DE CARNUÉ, IN ORDER TO RECOGNIZE AND PRESERVE THE ARCHAEOLOGICAL AND CULTURAL SIGNIFICANCE OF THE SITE, AND DESIGNATE IT WORTHY OF ADDITIONAL ARCHAEOLOGICAL INVESTIGATIONS, PRESERVATION, AND INTERPRETATION; MAKING AN APPROPRIATION TO THE OPEN SPACE DIVISION OF THE PARKS AND RECREATION DEPARTMENT (HARRIS)".

24 “APPROVING AND AUTHORIZING ACCEPTANCE OF A LETTER OF AWARD FROM THE NATIONAL ENDOWMENT FOR THE ARTS (NEA) AND MAKING AN APPROPRIATION TO THE CULTURAL SERVICES DEPARTMENT IN FISCAL YEAR 2015 (JONES, BY REQUEST)"

25 "APPROVING AND AUTHORIZING ACCEPTANCE OF A LETTER OF AWARD FROM THE NATIONAL ENDOWMENT FOR THE ARTS (NEA) AND MAKING AN APPROPRIATION TO THE CULTURAL SERVICES DEPARTMENT IN FISCAL YEAR 2014 (BENTON, BY REQUEST)" 
Finally, the sixth bill, proposed by Councilor Benton, sought explicitly to increase equitable access to a government service for city residents - in terms of transportation ${ }^{26}$. It allocates funding for bike infrastructure, with the named goal of increasing equity in access to city services. The bill was all about enhancing access to city amenities for underserved groups. It is clearly an equity bill.

\section{How this fits with my theory}

In Albuquerque, there is a critical mass level of general descriptive representation - between 30 and 50\%. And the related policy outcomes are very high - almost 6.7 times the average across cases. This data, when considered through the lens of the literature and my theory, implies that the minority members of the committee are able to pass beneficial policy in large amounts, without the fear of white backlash from other members of the council. Further, the council had not yet reached the majority descriptive representation period (i.e. over 50\%) - and thus there was no need for inter-group differentiation. Minority councilors could pursue a slate of diversity policies and enjoy political and electoral success.

\footnotetext{
26 “AUTHORIZING THE MAYOR TO EXECUTE A GRANT AGREEMENT WITH THE NEW MEXICO STATE HIGHWAY AND TRANSPORTATION DEPARTMENT FOR SAFE, ACCOUNTABLE, FLEXIBLE, EFFICIENT, TRANSPORTATION EQUITY ACT: A LEGACY FOR USERS (SAFETEA-LU) FUNDING TO OPERATE A BICYCLE SAFETY EDUCATION PROGRAM IN OUTDOOR RECREATION AND PROVIDING AN APPROPRIATION TO THE PARKS AND RECREATION DEPARTMENT (BENTON)"
} 
Figure 4.5 Illustration of Albuquerque's General Descriptive Representation

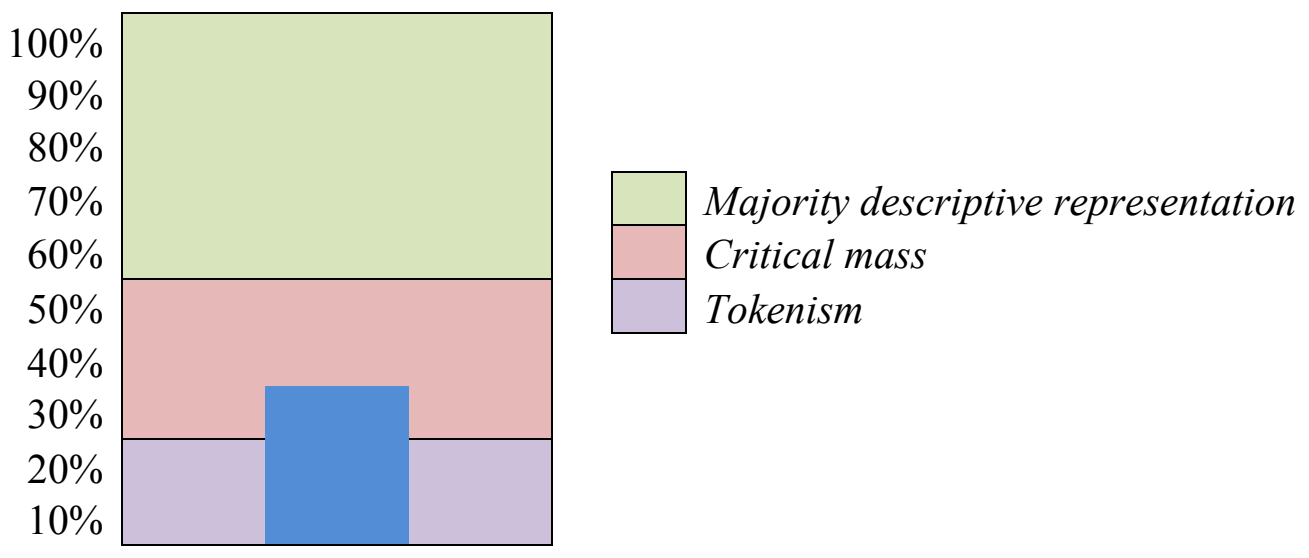

Figure 4.6 General Representation in Policy, Albuquerque as Compared to National Average

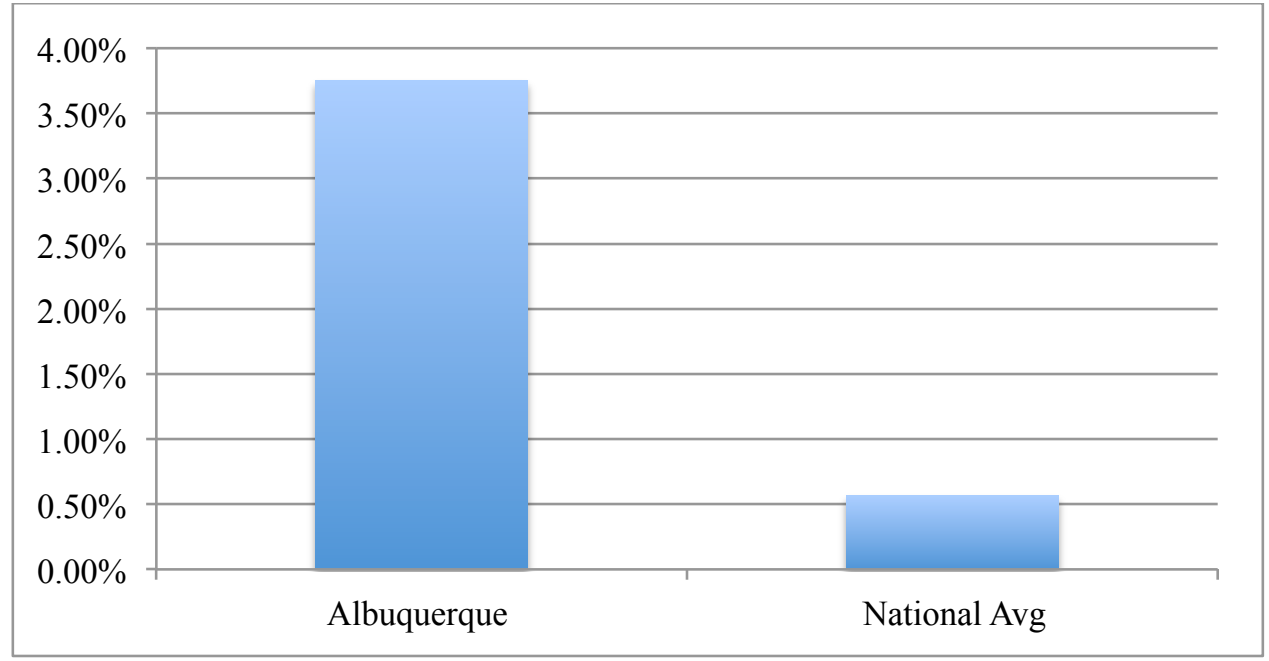

Case study - Black Racial Policy in New Orleans, LA

"It can be a win-win. I think it's about communication, and creating partnerships between the communities and the businesses" African 
American Councilor LaToya Cantrell, promoting business interests while talking about a proposed policy change (M. P. Welch, 2015).

"As Chair of the Committee on Public Works, Sanitation, and Environment, I welcome this settlement as a commitment to rebuild the damage that has negatively impacted the City's economy." - African American Councilor Nadine Ramsey, actively committing to the economic progress of the city ("CITY UNVIELS RESILIENCE STRATEGY," 2015).

In terms of Black racial, New Orleans is a prime example of majority descriptive representation. In Chapter 2, I argued that because of the need for internal differentiation, when there is Majority descriptive representation, there would be relatively low policy outputs. Councilors would need to distinguish and differentiate themselves from other descriptively representative councilors, and thus would pursue a policy agenda that is aligned with another interest group. That is, councilors will cultivate an issue-oriented identity so as to attract voters. This will lead to high levels of descriptive representation predicting low levels of representation in policy. Illustratively, New Orleans has very, very high levels of Black descriptive representation and lower-than-average Black representation in policy.

\section{Background}

Hurricane Katrina made landfall in 2005 - its ramifications were still being felt in 2015. The disproportionate impacts of Katrina, and the subsequent government response, on racial minorities in the city (e.g. August et al., 2015; Kimmett, 2015; Workneh, 2015). Scholarship has argued that Hurricane Katrina served as an exposer of truth in the city, 
that the hurricane called attention to the preexisting structural discrimination and racism that was largely being ignored (Thompson, 2009). Katrina brought it to light, exposing a city with vast racial tensions and dramatic racial political landscapes.

Because of physical damage, and then because of population shifts, the school system was left decimated by Katrina. Local government undertook a bold experiment: a public system that was made up completely of charter schools (e.g. Kimmett, 2015; Wong, Green, \& Zhou, 2015). In 2015, considerable attention was paid to how well the public school system was faring ten years on. The results were mixed and many called for additional funding and evaluation of the programs.

The city was intro- and retrospective in 2015 , focusing on the lasting implications of Katrina, including on specific policy matters. They focused on how Black residents were continuing to experience setbacks. Further, the national fervor about BLM and the 2016 presidential campaign were influencing New Orleans in a real way, affecting the local political conversation. Finally, the city was experiencing a local race-based scandal with the city's white mayor as the focus. All of these elements together would suggest that a savvy council might pursue a more sensitive policy agenda - lobbying for more racial Black policy to offset some of the apparent tensions. Instead, as my research finds, there is a noticeable paucity of racial Black policy. This is counterintuitive, and serves to support of my theory.

New Orleans, LA is a liberal, mid-sized city, with a white mayor, in the South. In 2015, there were seven city council members: Stacy Head, Jason Rogers Williams, Susan G. Guidry, LaToya Cantrell, Nadine M. Ramsey, Jared C. Brossett, and James Austin 
Gray II. There is a strong mayor system; Mayor Mitchell Joseph Landrieu was elected in 2010 and was serving in 2015. New Orleans uses a mixed electoral system, with two representatives serving at-large (Councilors Head and Williams), and the remaining five representing geographically defined districts in the city.

In 2015 , four of the seven (i.e. approximately $57 \%$ ) councilors were Black: Councilors Williams, Cantrell, Ramsey, and Gray. The remaining three councilors (i.e. 43\%) were white: Councilors Head, Guidry, and Brossett. A council with more than 50\% descriptive representation is considered in the majority descriptive representation type. In New Orleans in 2010 , the city demographics were as follows: $59.8 \%$ of the city was Black, $30.5 \%$ was white, $4.9 \%$ was Latino, and $3 \%$ was Asian.

\section{The bills}

There were 2,320 policies passed in New Orleans in 2015 . Of these policies, only two were categorized as Black policy (approximately .09\%). The average amount of Black policy across cases was $.29 \%$. In other words, far fewer policies were passed in New Orleans than the average across cities in this study. This is despite the high levels of Black descriptive representation on the council. Brief descriptions of these policies are reproduced below, as well as a summarization of why they are considered Black representation in policy.

The first policy's description is Ordinance $26490^{27}$. This ordinance waives fees so as to aid an event called the Black Men of Labor. This ordinance clearly relates to Black

\footnotetext{
${ }^{27}$ The title of which is, AN ORDINANCE TO TEMPORARILY WAIVE CERTAIN FEES, PERMIT FEES, AND REQUIREMENTS WITHIN AND AROUND THE TREME RECREATION COMMUNITY CENTER LOCATED IN THE 900 BLOCK OF NORTH VILLERE STREET, NEW ORLEANS,
} 
representation. Further research on the Black Men of Labor produced the organization's mission statement is: "To educate, preserve, and perpetuate our rich African \& AfricanAmerican Culture by creating sustainable economic opportunities that break the cycle of generational poverty in New Orleans" (“Our Mission: The Black Men of Labor,” n.d.). The policy aims to support the actions of the organization, and thus this is clearly a representative policy. Ordinance 26490 was proposed by Councilor Ramsey (the Black representative from District C) and was approved on July 15, 2015. Six members of the council were present for the vote - all present voted in favor of the bill. One councilor (Councilor Gray) was absent and thus did not vote.

The second representative policy is Ordinance $26408^{28}$. This bill pertains to the annual jazz festival. It waives certain fees for event participant, as a way for the city to support the event. The event is described in the bill's title as a tribute to the city's connection to South Africa. The specified link to South African culture is a clear indicator of racial policy. Ordinance 26408 was approved on May 8, 2015. The policy was proposed by Councilor Ramsey from District C. Five councilors were present for the vote on this policy; all voted to support its passage. Two councilors were absent for the vote (Councilors Cantrell and Gray) and thus did not vote.

LOUISIANA, IN CONJUNCTION WITH THE BLACK MEN OF LABOR EVENT ON SATURDAY, JUNE 13, 2015, AND SATURDAY, JULY 11, 2015 FROM 8:30 A.M. TO 1:00 P.M., TO SPECIFY THE DURATION AND BOUNDARIES OF SAID WAIVER, AND TO PROVIDE OTHERWISE WITH RESPECT THERETO.”

${ }^{28}$ The title of which is, "AN ORDINANCE TO TEMPORARILY WAIVE CERTAIN FEES, PERMIT FEES, AND REQUIREMENTS WITHIN AND AROUND LABELLE GALLERY LOCATED IN THE 300 BLOCK OF CHARTRES STREET, NEW ORLEANS, LOUISIANA, IN CONJUNCTION WITH THE NEW ORLEANS SOUTH AFRICAN CONNECTION'S “JAZZ FEST” EVENT ON THURSDAY, APRIL 23, 2015 FROM 3:00 P.M. TO 8:00 P.M., TO SPECIFY THE DURATION AND BOUNDARIES OF SAID WAIVER, AND TO PROVIDE OTHERWISE WITH RESPECT THERETO.” 


\section{How this fits with my theory}

There is majority descriptive representation in New Orleans. The large percent of African American councilors does not translate to an abundance of representative policy. The apparent disconnect runs contrary to previous literature, but it substantiates my hypotheses. Those who have not studied the majority descriptive representation period, but have extrapolated theories out without data (e.g. the critical mass theories that do not address an upper bound and thus imply that the relationship continues ad infinitum) are directly challenged by the lack of Black racial policy in New Orleans. Further, the context in which these decisions were made gives no clue as to why there is so little policy. It is not as if New Orleans did not care about Black representation in policy in 2015. On the contrary, there is a robust conversation about the lasting racial legacy of Katrina, the impact of policy choices and how to move forward, and a racially based political scandal. I argue that the lack of representation in policy can be explained by just one thing: Black Councilors are pursuing other policy agendas, striving for differentiation in an oversaturated field and thus Black racial policy has fallen by the wayside.

\section{Figure 4.7 Illustration of New Orleans' Black Descriptive Representation}

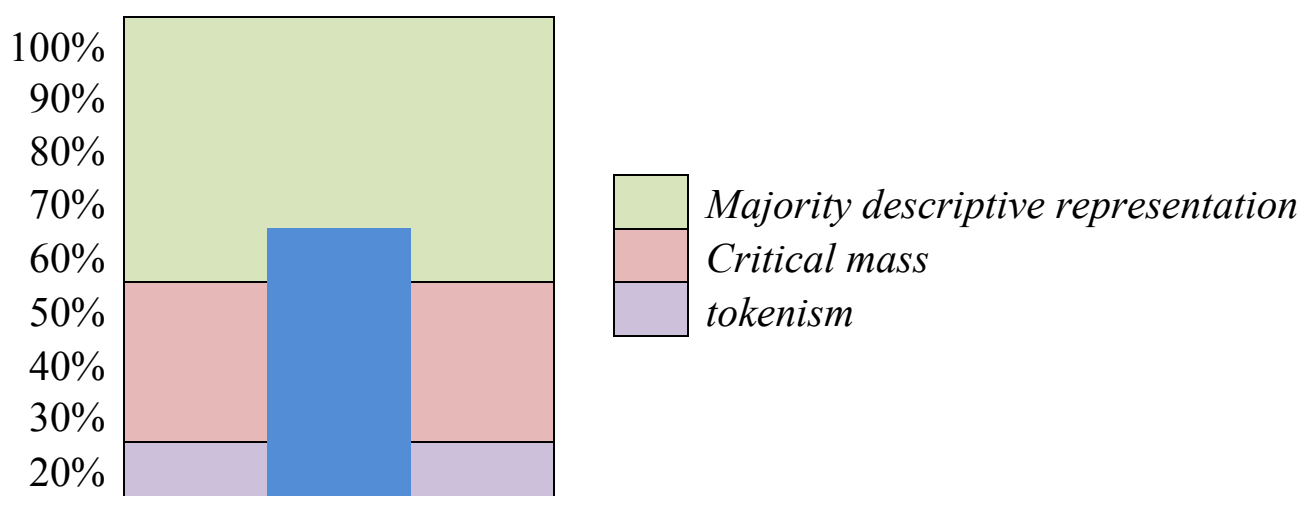




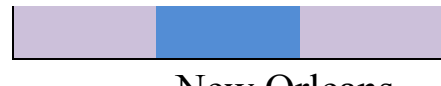

New Orleans

Figure 4.8 Black Representation in Policy, New Orleans as Compared to National Average

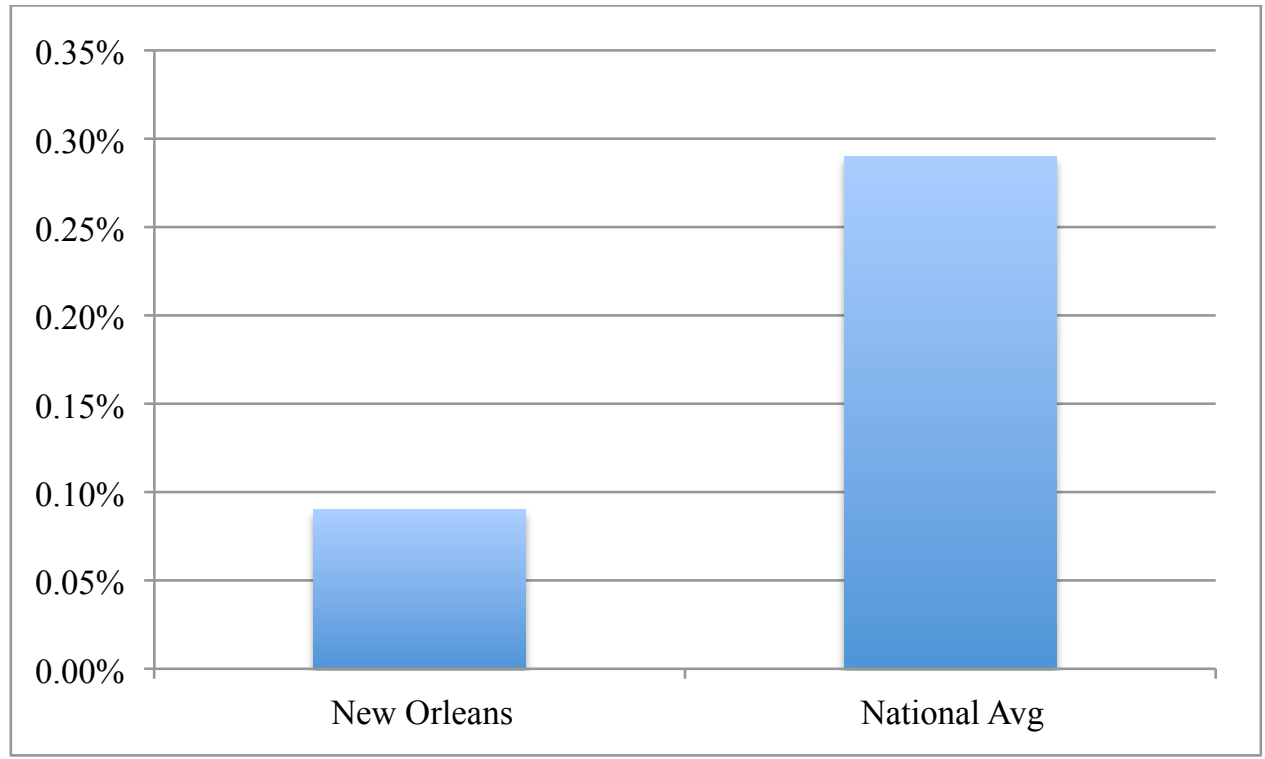

\section{Conclusion}

My theoretical and data work were explained in detail in previous chapters. In this chapter, I considered how well my overarching theory mapped on to individuals cases. I chose four cities with crucial elements in common (ideology, size, electoral institutions) and tested if my theory held at the ground level. Were these cases illustrative of my theoretical work and of the larger trend - or were they anomalies? The thesis that emerged from these case studies is that the cases added to the theoretical understanding of the project - and did not detract from the findings. In fact, when considered in concert, the case studies paint a very interesting picture. 
This chapter considered each case study alone. I chronicled the background of each case, the descriptive representation and policy outcomes present in the study year, and then discussed how well that met with theoretical expectations. I now present these results to be considered together. See Figure 4.9 below. In summary, Portland, which had no descriptive representation exhibited relatively high levels of diversity policy. Minneapolis had one Asian councilor (i.e. tokenism) and passed no Asian racial policies. Albuquerque had 33\% general descriptive representation (i.e. critical mass) and passed a very large percentage of diversity and equity policy. And New Orleans, with a majority Black council (i.e. majority descriptive representation) passed very little Black racial policy.

\section{Figure 4.9 Plot of Case Studies}




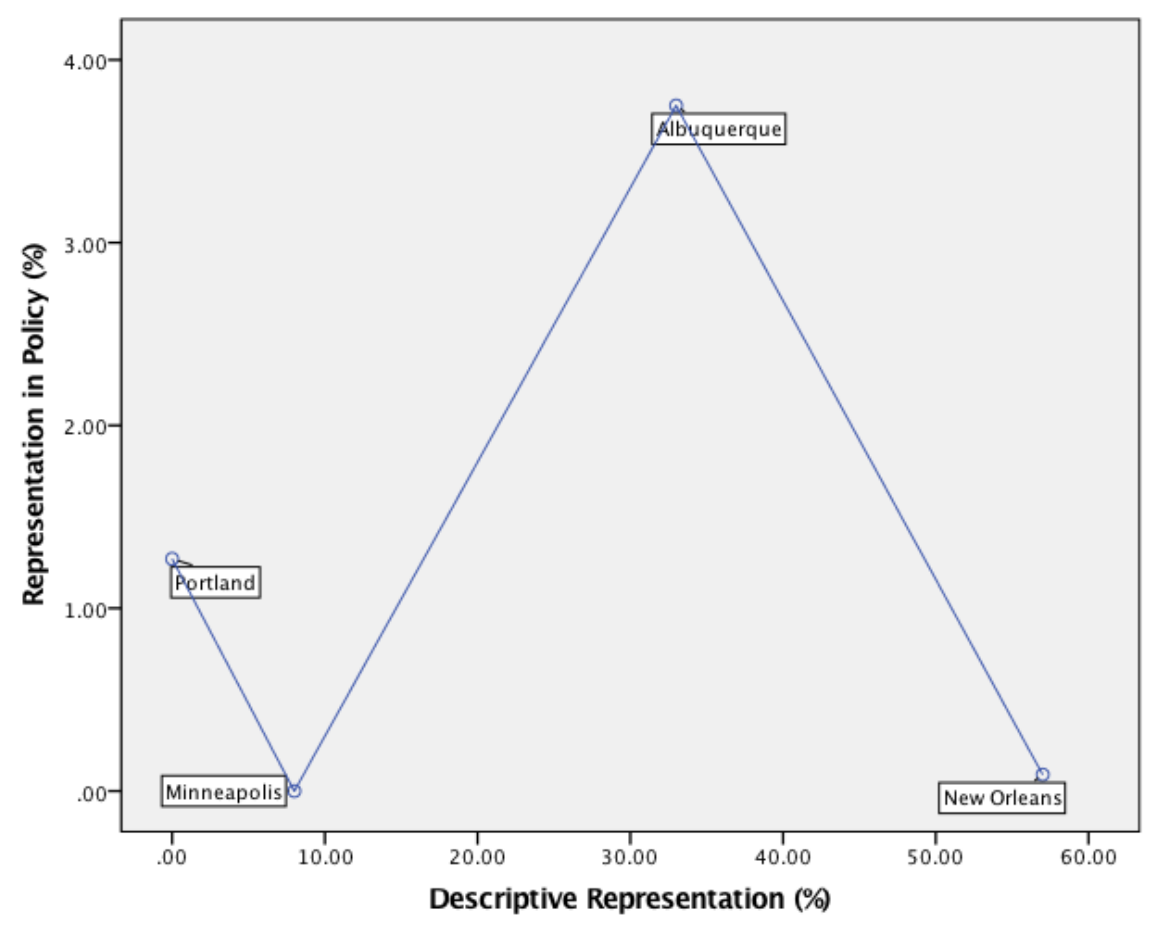

Considered individually, the case studies add important nuance to the findings in Chapter 3. I find evidence of political posturing that indicates political strategies of Councilors. I consider how the political and racial context of the city impacts the motivations of the individual. And I consider the individual relationship between descriptive representation and representation in policy. Considered together, however, the case studies paint a fascinating picture. Anecdotally, the results substantiate my claims about the expected outcomes at each level of descriptive representation. 


\section{CHAPTER 5. DISCUSSION, IMPLICATIONS AND FUTURE RESEARCH}

In this dissertation, I have shown how the varying levels of descriptive representation affect representation in policy for racial minority groups. In Chapter 2, I presented an overview of my theory - pulling heavily from the literature to build an argument in favor of a curvilinear relationship. In Chapter 3, I outlined the quantitative methods that I used to test my theory and subsequent results. In Chapter 4, I presented four case studies that illustrated the manifestation of my theoretical mechanisms, allowing for an exploration of the decision-making context that surrounded the politicians as they introduce and support representation in policy. Finally, in this chapter, I bring the study to a close. I start with a discussion of the results (both qualitative and quantitative), and assess which align with hypotheses and which do not. I then consider the implications of this research both for the scholarly field and for political activists seeking to increase representation for racial minority groups. Finally, I discuss what further research should be conducted to continue this project.

\section{Discussion of the Results}

My overarching argument is that there are four distinct types in descriptive representation, and each of these types has a predictable effect on representation in policy. Through the quantitative testing and qualitative exploration, I find varying levels of support for my argument. In this section, I discuss the results of my study. In short, there are some elements that aligned with my expectations. There are also elements that 
differ from my expectations in significant and important ways. Overall, there is a ripe opportunity for more research.

This section is organized as follows. I first discuss how well the quantitative results aligned with the hypotheses stated in Chapter 3 . The thesis that emerges is that specific descriptive representation's effect on racial policy outcomes was as expected. The effect of general descriptive representation on diversity policy, however, was a surprise. I then discuss the results by type of descriptive representation. This allows me to pair the qualitative narrative information with the ANOVA results and paint a compelling picture.

In terms of specific descriptive representation, I find support for the Hypotheses 1 and 2. First, I find that there is considerable evidence that the relationship between specific descriptive representation and racial policy outcomes is not linear (supporting Hypothesis 1). Second, I find support that the relationship is curvilinear and that the best fit model occurs when descriptive representation is cubed (supporting Hypothesis 2). Overall, specific descriptive representation's effect on racial policy is as expected. In terms of general descriptive representation, I find mixed support for my argument. First, I find evidence that the relationship is not linear (Hypothesis 3 ) - in accordance with my expectations. However, there is not evidence that the relationship is curvilinear, either. General descriptive representation is not a significant predictor of diversity policy in the linear model (as expected), but it is not a significant predictor of diversity policy in any of the other models either. In other words, I do not find evidence for Hypothesis 4. 
There are many reasons that a researcher may not find support for a hypothesis. One possible explanation is that the data is not robust enough. The diversity policy data was set up so that there were 108 cases in the dataset. For the racial policy model, the data was set up differently, and the number of cases was 324 . One interpretation of this difference is that there was not enough statistical power in the diversity model to present significant findings. However, when I couple the results of the regression model with those of the ANOVA testing (explained below), I am led to believe that this is not simply a matter of a relatively small-N. That is, the ANOVA testing does not perform as expected either; if this was simply a matter of needing more data for the regression, the ANOVA should align more with expectations.

Thus, I am left with two alternative explanations. The unexpected results can be explained by either a) a misspecification in the research design, or b) an incorrect theory. Allowing for the possibility of the latter, I argue that these results probably stem from the former. That is, I believe there may be a misspecification in the research design that has led to spurious results for the general descriptive representation models. To identify diversity and equity policy, I used a series of keywords informed by the literature. The process was exactly parallel to the one I undertook to identify racial policy. However, diversity and equity policy may simply be a more nuanced concept than racial policy. The parallel process may be inappropriate for identifying diversity policy. A different approach for to identifying diversity policy should be tested; more research is called for. 


\section{Descriptive Representation Types}

Theoretically, there are four types of descriptive representation. I find qualitative evidence of each of these types. From the ANOVA testing I find evidence of three of the types; tokenism is not substantiated by the qualitative results. In this section, I consider each type and its related evidence. I pay particular attention to the causal mechanism at work for each type.

The mechanism at work in the no descriptive representation type is one of rational protectionism. Councilors in an all white council know that there is a distinct possibility of a challenge to their power. They are vulnerable to a descriptively representative candidate, who could rally the voting bloc and pull support from the white incumbent. To prevent this challenge to their power, the white councilors pass representation in policy for minority groups. If minority groups are being represented in terms of policy outcomes, perhaps they will not demand a descriptively representative councilor.

This underlying logic is evident in Portland, OR. Portland a liberal city with an all-white council and, as the case study highlighted, the council passed a remarkably high level of diversity and equity policy. Councilors were quoted posturing as representatives of minority constituents' interests. The quotes highlight the rationality to the politicians' actions. They know that appearing to represent the interests of minority groups is the only way to retain their power. 
The results from the specific descriptive representation ANOVA test supported my theoretical claim about no descriptive representation period $^{29}$. I found that for African Americans and Latinos, the amount of representation in policy was mid-level. For both groups, it was lower than average across all cases, but not extremely so (Black representation in policy average is $.29 \%$, for no descriptive representation it was $.136 \%$; Latino representation in policy averages . $197 \%$, for no descriptive representation, it averaged .113\%).

In Minneapolis, I found an excellent case of the effect of tokenism on policy outcomes. The city had one Asian councilor, and though he acted in a representative way to his Asian constituents, posturing through Asian-specific events (like taking 20 Asian children on a tour of city hall), there was no representation in policy for Asians during 2015. Councilor Yang also spoke to tokenism fairly directly, saying that his constituency was complaining that he was not pushing their policy agenda, but that he had to balance the needs of his constituency with those of the city as a whole. This internal pressure being the only representative of a group, having to balance the weight of that representation with the status quo - is inherent to tokenism.

However, in the specific descriptive representation ANOVAs, I do not find much support for the theoretical effect of tokenism. Representation in policy for both African Americans and Latinos is higher in the tokenism period, as compared to the no descriptive representation period. Both groups experience approximately their average level of representation in policy. For African Americans the tokenism representation in

\footnotetext{
${ }^{29}$ Note that because the general descriptive representation ANOVA results were not significant, interpreting those results would be inappropriate.
} 
policy is about $.257 \%$, as compared to $.29 \%$. For Latino the tokenism representation in policy is higher than average, at about $.231 \%$, as compared to .197\%. Though I found support of tokenism in the case study, the ANOVA results did not align with expectations.

In Albuquerque, I found an excellent example of critical mass in terms of general descriptive representation. About one-third of the council identified as a racial minority, making it a clear case of critical mass. And in 2015, there was a considerable amount of diversity policy passed. Further, there were examples of the minority councilors working together to pass diversity policy - even with opposition from white councilmembers. This appears to clearly reflect the ethos of critical mass: there is a large, politically strong group of representatives that can advocate for a policy agenda without fear of backlash.

In the specific descriptive representation ANOVAs, I find evidence of the effect of critical mass. Both groups that were tested experienced very high levels of representation in policy in the critical mass type. Black representation in policy during critical mass had an average of $.586 \%$ - nearly twice its average across all cases. Latino representation in policy was $.312 \%$ in critical mass, significantly higher than its average across cases $(.197 \%)$.

In New Orleans, I found a strong example of the effect of majority descriptive representation in terms of Black representation. The New Orleans city council was $57 \%$ African American in 2015. This is clearly in the majority descriptive representation period. And the policy outcomes were as hypothesized. Despite very high descriptive representation, there was relatively low representation in policy. Further, there was 
evidence of Black city councilors highlighting allegiances with business, economic development, and environmental interests.

In terms of Black specific descriptive representation, I find evidence of the hypothesized effect of majority descriptive representation in the ANOVA testing. There is a distinct drop in policy outcomes between the critical mass period and the majority descriptive representation period. Further, the amount of representation in policy is almost exactly the level that was achieved with no descriptive representation. This finding is very exciting - Black representation in policy was essentially the same when there were no Black councilors as when there were a majority of Black councilors. This is a true affirmation of my theory.

However, when considering Latino specific descriptive representation, there is no support for my theory on majority descriptive representation. Instead of dropping off in the majority descriptive representation period, representation in policy for Latinos continues to grow. In the majority descriptive representation period, representation in policy for Latinos is, on average, .638\% -- more than three times the average across all cases. There is literature that substantiates a real difference between the political behavior of African American and Latino representatives (e.g. Trounstine \& Valdini, 2008), and thus this finding is not a complete surprise. It does, however, call for further research.

The divergence from my hypotheses could also be explained by my use of panethnic categories. The Latino category encompasses different ethnic groups, which are distributed throughout the country. The results may differ from hypotheses because I am not teasing out the inter-ethnic differences. That is, it may be that Mexican Americans 
have a different relationship with representation politics than Puerto Ricans in New York or Cuban Americans in Miami. Further research, which focuses on ethnic groups as opposed to larger racial categories, would further the field's understanding.

\section{Implications}

For those who care about the normative benefits of political representation for racial minority groups, the implications of my work are serious. The logical conclusion of my findings is that racial minorities must choose between achieving the highest possible descriptive representation or achieving major policy outcomes. It appears, holding everything else constant, that they cannot effectively pursue both. My data show that pursuing more presence will eventually lead a group out of critical mass and into majority descriptive representation, and that the group's ability to pursue an agenda geared towards representation in policy is then limited. The idea that a minority group will achieve high descriptive representation and then pursue a reflective policy agenda simply is not substantiated by my study.

But perhaps, the normative implications can be read a different way. Instead of seeing a foregone conclusion - that high descriptive representation must lead to low representation in policy - we can see an opportunity for a change. If minority groups want presence and to pursue a representative political agenda, then there needs to change in strategy to overcome the existing political conditions. Armed with this data, groups can pursue a more effective political and electoral strategy, one that allows for gains in presence without sacrificing the political importance of the voting bloc and thus negating 
the need for representation in policy. Perhaps, with this study in hand, groups can achieve both ends simultaneously.

White councilors can actively help or actively hinder the policy agenda of minority groups. Of those who are actively and explicitly working to further white supremacy through policy, maintaining a racist status quo. And there are those who are furthering a racist agenda simply to maintain their power; they are selfish and opportunistic, exploiting the racism within their community to maintain control of the political agenda. Throughout this study, I have focused on the actions of the minority group in their pursuit of representation. This perspective mirrors that of the field, both in terms of racial and gender representation. However, this perspective ignores the actions of the hegemon. That is, I focus on the ability of minority councilors to achieve representative policy - not on the impact of the white councilors on minority representative policy. Cutting edge research is beginning to incorporate the role of the hegemon (see Valdini's forthcoming work on the role of men in women's representation); however, most continue to ignore the group's importance. I discuss this dynamic explicitly when considering the no descriptive representation and tokenism types of representation. Further consideration would have been outside the scope of my project; I have not given the role of the hegemon a thorough theoretical treatment. The field needs more research that explicitly investigates and discusses where and why white politicians promote or subvert a minority group's political agenda.

In terms of scholarly implications, my results challenge decades of conclusions. Using the most comprehensive dataset (as far as I can tell), pulling from political science 
and public administration literatures, I have developed a new theory - and substantiated the bulk of my assertions with measurable, quantitative evidence. The qualitative case studies support my claims and provide insight into the decision-making context in which counselors are placed. This is to say, I believe that I have brought a formidable challenge to the field. In this section, I address exactly which points in the literature that I believe I have refuted.

Politicians have known for a long time what I have shown in this book.

Politicians know that only so many candidates can run under the same banner and get elected. They know that differentiation between candidates is key to win. They know that you can only split a voting bloc so many times before it looses its electoral strength. And they know that once a voting bloc is split into too small of pieces, there is no reason to advocate for that bloc's policies preferences. Winning a portion of a split bloc is not enough to win office; strategic politicians will seek electoral support elsewhere. And when those strategic politicians are in office, they will be beholden to the policy interests of others.

If the above logic is right, we as a field of representation scholars have a lot of work to do. We have failed to understand the internal calculus of politicians and the way those calculations affect policy outcomes. This calls into question the very nature of representation politics. There is a real way in which the constituencies lose their power, lose their ability to advocate for policy change - even with an ostensibly representative candidate. I argue that this could explain so much of what is observed in current politics electoral fatigue, voter ambivalence and frustration, even the rising power of special 
interests. The application of this lens to new research, and to evaluating the field's seminal theories, will produce rich results.

A more practical implication of this research is the recognition of upper bounds to theory. Theories like critical mass implied that the positive relationship between presence and policy would continue ad infinitum. By not adding a bound to the theory, scholars have left gaping holes in the field. I call for a more careful approach. When creating new theory, let us all consider the upper and lower bounds and speak directly to them. Let us all consider the big picture, into which our theory fits.

I also challenge the assumption in political science that local politics are less important than state and regional level politics. This belief is illustrated by the vast number of representation studies that are at the national and state levels as opposed to the local level. The lack of scholarly attention paid to city level governance is a misstep. Local governance is where the bulk of policy is made, where constituencies are frequently in contact with their representatives, and where representatives are more responsive and accountable to their voters than any other level in US politics. It is the only place in the country where we can regularly see natural experiments in representative politics. I call for a renewed interest in local level politics, and that political scientists use this level of governance to build and test new theory.

The US is diversifying. Demographics are shifting; more people of color (and women) are holding more legislative positions - and scholars believe that this upward trend will continue (Colby \& Ortman, 2015). City governments in the US are the only governing bodies that are capturing this trend and thus they are the only bodies with 
ample diversity to fully study representation Therefore focusing on city councils is doubly important. It is important not only to better understand the true nature of representation and race, but also to forecast the trends in policy as the demographics of state and regional bodies have more descriptive representation.

\section{Future Research}

There are three distinct calls for research that emanate from my study. They are: reconfiguring diversity and equity policy and retesting my theoretical models; expanding the project to include policy that disproportionately affects racial minorities; and testing accepted theory at the local level. These undertakings are important to continue the progress in the field.

The conception of diversity and equity policy needs to be reconfigured. I stand by my method, in that it was an appropriate and parallel process to that of racial policy. However, because the results are so unexpected, the conceptualization of the key variable may be wrong. There is inherent nuance to identifying policy. The methods used here tried to capture that nuance, while creating a process that was expandable over the 108 cases. It may be that that method was simply insufficient. Further research, with a more involved policy identification process, must be conducted. I imagine that the results from that research can take two forms. First, with the more nuanced identifier of diversity policy, there is evidence of my theory. This would bolster my work and be very useful for future studies. Alternatively, with the nuanced policy identifier, I could find that there is no evidence of my theory. This would indicate that there are fundamental, crucial differences between racial and diversity policies. That is, there could be evidence that 
diversity policy is unique in terms of representation in policy. Overall, diversity policy is relatively understudied - a finding of this magnitude would open up a vast field of research and exploration.

To conduct this research project, I propose a mixed methods research project that begins with a qualitative review of key cities' legislation, looking for policies that have a diversity and equity lens but may not use those key words. The models presented here could then be run on that new dataset. Results would undoubtedly open a new field of inquiry.

The second area of research is an expansion of the policies considered. Racial and diversity policies were two clean, distinct categories. However, policies that disproportionately affect racial minority groups - without naming them directly - warrant attention. These are the policies that oftentimes have the largest impact of racial groups. These are the policies that change neighborhoods, schools, access to social services, and ability to work. They are frequent and potent - and have effects that span generations. Redlining, for example, was one of the most potent, racially motivated policies of the $20^{\text {th }}$ century. Its effects are still being felt within the Black communities, in terms of cyclical poverty and the lack of inter-generational wealth (Massey \& Denton, 1993; Wilson, 1998, 2009). Yet, very purposefully, the policy was created with non-racial terms. A research project that captures the policies that disproportionately affect racial minority groups, without using racial terms, across many cities would be a herculean feat. However, its importance cannot be overstated. 
To conduct this research, one would need a mixed-methods approach. The researcher would heavily on city-level experts who could parse legislation for the unstated racial ramifications in their cities. Then, using thematic analysis, the researcher would identify terms that most often accompany these policies. The policy-identifying program would then have to be retrained and many iterations would have to be conducted. I suspect that the results would be a continuation of the logic presented here and further shake the field's understanding of political representation.

Finally, I believe my project highlights the importance of testing accepted theory at different levels of governance. I call for more scholarship that explicitly tests the most prominent national-level theories at the local context. As shown in this dissertation, the results can oftentimes be unexpected, and call attention to theoretical holes. We must continue to challenge the status quo and further the state of understanding. 


\section{Works Cited}

Abrajano, M., \& Hajnal, Z. (2015). White Backlash: Immigration, Race, and Politics.

Princeton, New Jersey: Princeton University Press.

America's Cities Mirror Baltimore's Woes. (2015). State Capital Newsfeed: Fox Hounds.

Anderson, C. J. (2000). Economic voting and political context: A comparative

perspective. Electoral Studies, 19(2-3), 151-170.

Aragones, E., Palfrey, T., \& Postlewaite, A. (2007). Political Reputations and Campaign

Promises. Journal of the European Economic Association, 5(4), 846-884.

August, C., Obama, P., Orleans, N., Katrina, H., Sanchez, A. P., Orleans, N., ... Agency, M. (2015, August). POLITICS: Obama says Katrina strengthened the nation's response to catastrophes. ClimateWire, 77-79.

Bailey, K. (2008). Methods of Social Research. New York: Simon \& Schuster Inc.

Banducci, S. A., Donovan, T., \& Karp, J. A. (2004). Minority Representation, Empowerment, and Participation. The Journal of Politics, 66(2), 534-556.

Baqir, R. (2002). Districting and Government Overspending. Journal of Political Economy, 110(6), 1318-1354.

Barrett, A. W., \& Barrington, L. W. (2005). Is a Picture Worth a Thousand Words? Newspaper Photographs and Voter Evaluations of Political Candidates. Press/Politics, 10(4), 98-113.

Barrett, E. J. (1995). The Policy Priorities of African American Women in State Legislature. Legislative Studies Quarterly, 20(2), 223-247.

Bartels, L. M. (1996). Uninformed Votes: Information Effects in Presidential Elections. 
American Journal of Political Science, 40(1), 194-230.

Beckwith, K., \& Cowell-Meyers, K. (2007). Sheer Numbers: Critical Representation Thresholds and Women's Political Representation. Perspectives on Politics, 5(3), 553.

Bernstein, M. (2015, September 17). Federal justice officials cite significant concerns about Portland police practices. The Oregonian.

Bobo, L., \& Gilliam, F. D. (1990). Race, Sociopolitical Participation, and Black Empowerment. The American Political Science Review, 84(2), 377-393.

Branton, R. P. (2009). The Importance of Race and Ethnicity in Congressional Primary Elections, 459-473.

Braswell, S. (2010). Separate and Equal : Minority Representation and the Māori Electoral Roll in New Zealand. William and Mary Policy Review, 2(122), 122-170.

Bratton, K. A., \& Haynie, K. L. (1999). Agenda Setting and Legislative Success in State Legislatures: The Effects of Gender and Race. The Journal of Politics, 61(3), 65879.

Brown, M. (2006). Survey Article: Citizen Panels and the Concept of Representation. The Journal of Political Philosophy, 14(2), 203-225.

Browning, R. P., Marshall, D. R., \& Tabb, D. H. (1997). Mobilization, Incorporation, and Policy in Ten California Cities. In R. P. Browning, D. R. Marshall, \& D. H. Tabb (Eds.), Racial Politics in American Cities (2nd ed.). White Plains, NY.

Bueno, N. S., \& Dunning, T. (2017). Race, Resources, and Representation: Evidence from Brazilian Politicians. World Politics, 69(2), 327-65. 
Butler, D. M. (2009). The Effect of the Size of Voting Blocs on Incumbents' Roll-Call Voting and the Asymmetric Polarization of Congress. Legislative Studies Quarterly, 34(3), 297-318.

Cameron, C., Epstein, D., \& O’Halloran, S. (1996). Do Majority-Minority Districts Maximize Substantive Black Representation in Congress. The American Political Science Review, 90(4), 794-812.

Canon, D. (1999). Race, Redistricting, and Representation. Chicago: University of Chicago Press.

Canon, D. T., Schousen, M. M., \& Sellers, P. J. (1996). The Supply Side of Congressional Redistricting: Race and Strategic Politicians , 1972-1992. The Journal of Politics, 58(3), 846-862.

Carey, J. M. (2009). Competing Principals, Political Institutions, and Party Unity in Legislative Voting. American Journal of Political Science, 51(1), 92-107.

Carroll, S. J. (2001). The Impact of Women in Public Office. Bloomington, IN: Indiana Univ Press.

Chang, E. C. C., \& Golden, M. A. (2007). Electoral Systems, District Magnitude and Corruption. British Journal of Political Science, 37(1), 115.

Cheyne, C. (2004). Changing Local Political Leadership: The New Zealand Mayor in Contemporary Local Governance. Political Science, 56(2), 51-64.

Childs, S. (2001). In their own words : New Labour women and the substantive representation of women. Political Studies, 3(2), 173-190.

Childs, S., \& Krook, M. L. (2008). Critical Mass Theory and Women's Political 
Representation. Political Studies, 56(3), 725-736.

Childs, S., \& Krook, M. L. (2009). Analysing Women's Substantive Representation: From Critical Mass to Critical Actors. Government and Opposition, 44(2), 125-145. CITY UNVIELS RESILIENCE STRATEGY. (2015, August 25). US State News.

Clark, J. (2013, November 10). COMMUNITY VOICES | Hmong North Minneapolis Soccer Players Cheer Coach Blong Yang Victory. Twin Cities Daily Planet.

Clark, J. (2014, April 7). COMMUNITY VOICES - Councilmember Blong Yang gives City Hall tour to North Minneapolis Hmong students. Twin Cities Daily Planet. Colby, S. L., \& Ortman, J. M. (2015). Projections of the size and composition of the US population: 2014 to 2060. Current Population Reports.

Collet, C. (2005). Bloc Voting, Polarization, and the Panethnic Hypothesis: The Case of Little Saigon. The Journal of Politics, 67(3), 907-933.

Crowley, E. (2014). When Tokens Matter, 29(1), 109-136.

Dahlerup, D. (1988). From a Small to a Large Minority: Women in Scandinavian Politics. Scandinavian Political Studies, 11(4), 275-297.

Dahlerup, D. (2006). The Story of the Theory of Critical Mass. Politics \& Gender, 2(4), $513-522$.

Dahlerup, D., \& Freidenvall, L. (2005). Quotas as a "Fast Track" to Equal Representation for Women: Why Scandanavia is no longer the model. International Feminist Journal of Politics, 7(1), 26-48.

Dalton, D. (2015, December 31). Black Lives Matter's biggest moments of 2015. The Daily Dot, pp. 38-41. 
Davidson, C., \& Korbel, G. (1981). At-Large Elections and Minority-Group Representation: A Re-Examination of Historical and Contemporary Evidence. The Journal of Politics, 43(4), 982-1005.

Davies, B. A., Hilsum, L., Marcus, R., Gerson, M., Woodruff, J., \& Brown, J. (2014). PBS NewsHour for July 4, 2014. United States: PBS.

Dehn, R. (2015, December 30). Legislative Update: Making Our Economy Work For Every Minnesotan. State Capital Newsfeed, pp. 5-6.

Dovi, S. (2002). Preferable Descriptive Representatives: Will Just Any Woman, Black, or Latino Do? The American Political Science Review, 96(4), 729-743.

Downs, A. (1957). An Economic Theory of Democracy. Journal of Political Economy, 65(2), 135-150.

Druckman, J. N. (2004). Priming the Vote: Campaign Effects in a U.S. Senate Election. Political Psychology, 25(4), 577-594.

Egner, B., \& Heinelt, H. (2008). Explaining the Differences in the Role of Councils: An Analysis Based on a Survey of Mayors. Local Government Studies, 34(4), 529-544.

Engstrom, R. L., \& Mcdonald, M. D. (1981). The Election of Blacks to City Councils: Clarifying the Impact of Electoral Arrangements on the Seats/Population Relationship. The American Political Science Review, 75(2), 344-354.

Epstein, D., \& O’Halloran, S. (1998). Measuring the Electoral and Policy Impact of Majority-Minority Voting Districts: Candidates of Choice, Equal Opportunity, and Representation (No. September 3-6, 1998). Boston, MA.

Epstein, D., \& O’Halloran, S. (1999a). A Social Science Approach to Race, Redistricting, 
and Representation. The American Political Science Review, 93(1), 187-191.

Epstein, D., \& O'Halloran, S. (1999b). Delegating Powers: A Transaction Cost Politics Approach to Policy Making Under Separate Powers. New York: Cambridge University Press.

Ethridge, M. E. (2002). The Political Research Experience: Readings and Analysis (3rd ed.). New York: M. E. Sharpe, Inc.

Fassinger, R. E. (2008). Workplace diversity and public policy: challenges and opportunities for psychology. The American Psychologist, 63(4), 252-268.

Ferner, A., Almond, P., \& Colling, T. (2005). Institutional Theory and the Cross-National Transfer of Employment Policy: The Case of "Workford Diversity" in US Multinationals. Journal of International Business, 36(3), 304-321.

Gay, C. (2002). Spirals of Trust? The Effect of Descriptive Representation on the Relationship between Citizens and Their Government. American Journal of Political Science, 46(4), 717-732.

Gerber, E. R., Morton, R. B., \& Rietz, T. A. (1998). Minority Representation in Multimember Districts. The American Political Science Review, 92(1), 127-144.

Gerring, J. (2008). Case Selection for Case-Study Analysis: Qualitative and Quantitative Techniques. In The Oxford Handbook of Political Methodology (pp. 1-48).

Golden, E. (2016, March 14). In north Minneapolis, Council Member Blong Yang faces balancing act. Star Tribune.

Golden, E., \& Jany, L. (2015, December 1). Call to stand down, as charges filed. Star Tribune. 
Gormley, I. C., \& Murphy, T. B. (2008). Exploring Voting Blocs Within the Irish Electorate: A Mixture Modeling Approach. Journal of the American Statistical Association, 103(483), 1014-1027.

Green, A. (2014, August 29). "Groundbreaking” settlement on Portland police use of excessive force draws praise, disappointment. The Oregonian.

Grey, S., Tremblay, M., Dahlerup, D., Childs, S., \& Krook, M. L. (2006). Do Women Represent Women? Rethinking the "Critical Mass" Debate. Politics and Gender, 2(4), 491-530.

Hajnal, Z. L. (2001). White Residents, Black Incumbents, and a Declining Racial Divide. The American Political Science Review, 95(3), 603-617.

Hajnal, Z. L. (2009). Who Loses in American Democracy? A Count of Votes Demonstrates the Limited Representation of African Americans. American Political Science Review, 103(1), 37.

Hajnal, Z., \& Trounstine, J. (2005). Where Turnout Matters : The Consequences of Uneven Turnout in City Politics Where Turnout Matters : The Consequences of Uneven. The Journal of Politics, 67(2), 515-535.

Harris-Perry, M., \& Seltz-Wald, A. (2015). MSNBC Melissa Harris-Perry for May 30, 2015. United States: MSNBC.

Hausman, J. (2015, December 29). The faces of the Fourth Precinct protest. Twin Cities Daily Planet, pp. 3-5.

Hedges, K. (2015, December 15). With 82\% support for $\$ 15$ minimum wage in Minneapolis, is it time to bypass City Hall? Twin Cities Daily Planet. 
Hero, R. E., \& Tolbert, C. J. (1995). Latinos and Substantive Representation in the US House of Representatives: Nonexistent. American Journal of Political Science, $39(3), 640-652$.

Htun, M. (2004). Is Gender like Ethnicity? The Political Representation of Identity Groups. Perspectives on Politics, 2(3), 439-458.

Htun, M. N. (2003). Dimensions of Political Inclusion and Exclusion in Brazil : Gender and Race (Technical Papers). Washington, D.C.

Johnson III, O. A. (1998). Racial Representation and Brazilian Politics: Black Members of the National Congress, 1983-1999. Journal of International Studies and World Affairs, 40(4), 97-118.

Jones, A. (2014, December 4). Historic Echoes in Washington's Civil Rights Response. Cnn.com.

Juenke, E. G., \& Preuhs, R. R. (2012). Irreplaceable Legislators? Rethinking Minority Representatives in the New Century. American Journal of Political Science, 56(3), $705-715$.

Kanter, R. M. (1977). Some Effects of Proportions on Group Life. American Journal of Sociology, 82(5), 965-990.

Kanthak, K., \& Krause, G. A. (2012). The Diversity Paradox: Political Parties, Legislatures, and the Organizational Foundations of Representation in America. New York: Oxford University Press.

Karnig, A. K., \& Welch. (1980). Black Representation and Urban Policy. Chicago: University of Chicago Press. 
Karnowski, S. (2015, November 21). Minneapolis protest leader shakes up civil rights politics. Associated Press Online.

Kezdi, G. (2003). Robust Standard Error Estimation In Fixed-Effects Panel Models. Quarterly Journal of Economics, (January 2003).

Kimmett, C. (2015, October). The Myth of New Orleans 'Charter School "Miracle"; Ten years after Katrina, the much - hyped experiment is a bust. In These Times, 18.

King, G. (1986). How Not to Lie with Statistics: Avoiding Common Mistakes in Quantitative Political Science. American Journal of Political Science, 30(3), 666687.

King, G., Keohane, R. O., \& Verba, S. (1994). Designing Social Inquiry: Scientific Inference in Qualitative Research. Princeton, New Jersey: Princeton University Press.

Kjaer, U. (2015). Urban Political Leadership and Political Representation: The Multifaceted Representational Role of Danish Mayors. Urban Affairs Review, 51(4), 563-577.

Kotter, J. P., \& Lawrence, P. R. (1974). Mayors in Action: Five Approaches to Urban Governance. New York: Wiley.

Krebs, T. B. (1998). The Determinants of Candidates' Vote Share and the Advantages of Incumbency in City Council Elections. American Journal of Political Science, $42(3), 921-935$.

Kukutai, T. (2004). The problem of defining an ethnic group for public ${ }^{-}$policy: who is maori and why does it matter? Social Policy, (23), 86-108. 
Kumar, R. (2011). Research Methodology (3rd ed.). Los Angeles: SAGE Publications.

Lau, R. R., \& Redlawsk, D. P. (2001). Advantages and Disadvantages of Cognitive Heuristics in Political Decision Making. American Journal of Political Science, 45(4), 951.

Leal, D. L., Martinez-Ebers, V., \& Meier, K. J. (2004). The Politics of Latino Education: The Biases of At-Large Elections. The Journal of Politics, 66(4), 1224-1244.

LGBTQ Organizations Stand in Solidarity with Black Lives Matter. (2015, December 3). State News Service.

Linz, J. J. (1990). The Perils of Presidentialism. Journal of Democracy, 1(1), 51-69.

Lopez, D., \& Espiritu, Y. (1990). Panethnicity in the United States: a theoretical framework. Ethnic and Racial Studies, 13(2).

Lublin, D. (1997). The Paradox of Representation: Racial Gerrymandering and Minority Interests in Congress. Princeton, New Jersey: Princeton University Press.

Lublin, D. (1999). Racial Redistricting and African-American Representation: A Critique of "Do Majority-Minority Districts Maximize Substantive Black Representation in Congress?” The American Political Science Review, 93(1), 183-186.

Lupia, A. (1994). Shortcuts versus Encylopedias: Information and Voting Behavior in Calfiornia Insurance Reform Elections. The American Political Science Review, 88(1), 63-76.

Mainwaring, S., \& Shugart, M. S. (1997). Juan Linz, Presidentialism, and Democracy: A Critical Appraisal. Comparative Politics, 29(4), 449-471.

Manning, J. E. (2016). Membership of the 114 th Congress: A Profile. CRS Report. 
Washington, D.C.

Mansbridge, J. (1999). Should Blacks Represent Blacks and Women Represent Women? A Contingent "Yes." The Journal of Politics, 61(3), 628-657.

Mansbridge, J. (2003). Rethinking Representation. The American Political Science Review, 97(4), 515-528.

Mapes, J. (2015, August 10). Bernie Sanders speaks to packed crowd at Portland's Moda Center. The Oregonian.

Massey, D. S., \& Denton, N. A. (1993). The Construction of the Ghetto. In American Apartheid: Segregation and Making of the Underclass (pp. 17-59). Cambridge, MA: Harvard University Press.

Matsubayashi, T., \& Rocha, R. R. (2012). Racial Diversity and Public Policy in the States. Political Research Quarterly, 65(3), 600-614.

McClatchy, D. L. (2015, July 26). “All Lives Matter” Now A Loaded Phrase For Democrats; Racial Politics Are Frustrating Efforts To Build Coalitions In 2016 Race. Providence Journal.

Mcdermott, M. L. (1998). Race and Gender Cues in Low-Information Elections. Political Research Quarterly, 51(4), 895-918.

Mcdermott, M. L. (2005). Candidate Occupations and Voter Information Shortcuts. The Journal of Politics, 67(1), 201-219.

Meier, K. J., \& England, R. E. (1984). Black Representation and Educational Policy: Are They Related? The American Political Science Review, 78(2), 392-403.

Meier, K. J., Stewart, J., \& England, R. E. (1991). The Politics of Bureaucratic 
Discretion: Educational Access as an Urban Service. American Journal of Political Science, 35(1), 155-177.

Melber, B. A., Sakuma, A., Bacon, P., Robinson, E., Alter, J., Davis, D., ... Robinson, R. (2014). HARDBALL WITH CHRIS MATTHEWS for November 26, 2014. United States: MSNBC.

Miller, J. (2015, June 3). Minorities in Minneapolis: Underprivileged and Over-Policed. The American Prospect Blog.

Moe, T. M., \& Caldwell, M. (1994). The Institutional Foundations of Democratic Government: A Comparison of Presidential and Parliamentary Systems. Journal of Insitutional and Theoretical Economics (JITE), 150(1), 171-195.

Morgan, D. L. (1998). Practical Strategies for Combining Qualitative and Quantitative Methods: Applications to Health Research. Qualitative Health Research, 8(3), 362376.

Morgan, D. R., \& Watson, S. S. (1992). Policy Leadership in Council-Manager Cities : Comparing Mayor and Manager. Public Administration Review, 52(5), 438-446. Mouritzen, P. E., \& Svara, J. H. (2002). Leadership at the apex: politicians and administrators in Western local governments. Pittsburgh, PA: University of Pittsburgh Press.

Mulligan, J. (2016, May 26). Portland Commissioner Amanda Fritz Proposes City Commission for Immigrants and Refugees. Willamette Week.

Myers, J. L., Well, A. D., \& Jr., Lorch, R. F. (2010). Research Design and Statistical Analysis (3rd ed.). New York: Routledge. 
Nelson, J. S. (2007). White Challengers, Black Majorities: Reconciling Competition in Majority-Minority Districts with the Promise of the Voting Rights Act. Faculty Publications, 95, 1298-1312.

Nishishiba, M. (2003). Assessing the Impact of a Diversity Intitiative in Local Government.

Nordlinger, J. (2014, October 20). Viva Susana! - The governor of New Mexico runs for reelection. National Review.

Ornstein, N. J. (2014). Vital Statistics on Congress. Washington, D.C.

Our Mission: The Black Men of Labor. (n.d.).

Pantoja, A. D., \& Segura, G. M. (2003). Does Ethnicity Matter? Descriptive Representation in Legislatures and Political Alienation Among Latinos*. Social Science Quarterly, 84(2), 441-460.

Peterson, P. E. (1995). The Price of Federalism. Washington, D.C.: Brookings Institute Press.

Phillips, A. (1995). The Politics of Presence. New York: Oxford University Press.

Pitkin, H. F. (1967). The Concept of Representation. Berkeley: University of California Press.

Popkin, S. L. (1995). Information shortcuts and the reasoning voter. In Information, participation and choice: An economic theory of democracy in perspective (pp. 1735). Ann Arbor, Michigan: University of Michigan Press.

Porter, M. E. (1995). The Competitive Advantage of the Inner City. Harvard Business Review, May-June, 55-71. 
Preuhs, R. R. (2007). Descriptive Representation as a Mechanism to Mitigate Policy Backlash: Latino Incorporation and Welfare Policy in the American States. Political Research Quarterly, 60(2), 277-292.

Przeworski, A. (2004). The Last Instance: Are Institutions the Primary Cause of Economic Development? European Journal of Sociology, 45(2), 165-188.

Przeworski, A., Stokes, S. C., \& Manin, B. (1999). Democracy, Accountability, and Representation. Cambridge, MA: Cambridge University Press.

Reingold, B. (2000). Representing Women: Sex, Gender, and Legislative Behavior in Arizona and California. Chapel Hill, NC: University of North Carolina Press.

Reingold, B., \& Harrell, J. (2010). The Impact of Descriptive Representation on Women's Political Engagement: Does Party Matter? Political Research Quarterly, 63(2), 280-294.

Robinson, T. P., \& Dye, T. R. (1978). Reformism and Black Representation on City Councils. Social Science Quarterly, 59(1), 133-141.

Rocca, M. S., \& Sanchez, G. R. (2007). The Effect of Race and Ethnicity on Bill Sponsorship and Cosponsorship in Congress. American Politics Research, 36(1), $130-152$.

Rosen, R. J., Green, A., Zhou, L., Semuels, A., \& Pinsker, J. (2015, December). Will Inequality Ever Stop Growing? Atlantic Online, 8-10.

Salisbury, B. (2015, October 7). Dayton urges business leaders to address racial disparities in jobs, income. St Paul Pioneer Press.

Schrodt, P. A. (2014). Seven deadly sins of contemporary quantitative political analysis. 
Journal of Peace Research, 51(2), 287-300.

Semuels, A. (2016). The Racist History of Portland, the Whitest City in American. The Atlantic.

Shah, A. (2017, March 2). Go inside "Little Mogadishu," the Somali capital of America. Star Tribune.

Sharpe, P. L. (2014, December 10). Public Diplomacy Post Ferguson. WhirledView.

Shotts, K. W. (2003). Does Racial Redistricting Cause Conservative Policy Outcomes? Policy Preferences of Southern Representatives in the 1980s and 1990s. The Journal of Politics, 65(1), 216-226.

Shugart, M. S., Valdini, M. E., \& Suominen, K. (2005). Looking for Locals : Voter Information Demands and Personal Vote-Earning Attributes of Legislators under Proportional Representation. American Journal of Political Science, 49(2), 437-449.

Stone, C. S. (1993). Urban Regimes and the Capacity to Govern: A Political Economy Approach. Journal of Urban Affairs, 15(1), 1-28.

Strøm, K. (2000). Delegation and accountability in parliamentary democracies. European Journal of Political Research, 37, 261-289.

Swiss, L., Fallon, K. M., \& Burgos, G. (2012). Does Critical Mass Matter? Women's Political Representation and Child Health in Developing Countries. Social Forces, 91(2), 531-558.

Tate, K. (2001). The Political Representation of Blacks in Congress: Does Race Matter? Legislative Studies Quarterly, 26(4), 623-638.

Tausanovitch, C., \& Warshaw, C. (2014). Representation in Municipal Government. 
American Political Science Review, 108(3), 605-641.

Taylor-Robinson, M. M., \& Heath, R. M. (2003). Do Women Legislators Have Different Policy Priorities than Their Male Colleagues? Women \& Politics, 24(4), 77-101. Thomas, S. (1991). The Impact of Women on State Legislative Policies. The Journal of Politics, 53(4), 958-976.

Thompson, J. P. (2009). Race in New Orleans Since Katrina. In P. Marcuse, J. Connolly, J. Novy, I. Olivo, C. Potter, \& J. Steil (Eds.), Searching for the Just City: Debates in urban theory and practice. New York: Routledge.

Tolbert, C. J., \& Hero, R. E. (2001). Dealing with Diversity: Racial/Ethnic Context and Social Policy Change. Political Research Quarterly, 54(3), 571-604.

Trounstine, J., \& Valdini, M. E. (2008). The Context Matters: The Effects of SingleMember versus At-Large Districts on City Council Diversity. American Journal of Political Science, 52(3), 554-569.

Uslaner, E. M., \& Weber, R. E. (1983). Policy Congruence and American State Elites : Descriptive Representation versus Electoral Accountability. The Journal of Politics, 45(1), 183-196.

Valdini, M. E. (2006). Electoral Institutions and Information Shortcuts: The Effect of Decisive Intraparty Competition on the Behavior of Voters and Party Elites A dissertation submitted in partial satisf. University of California, San Diego, San Diego, CA.

Vega, A., \& Firestone, J. M. (1995). The Effects of Gender on Congressional Behavior and the Substantive Representation of Women. Legislative Studies Quarterly, 20(2), 
$213-222$.

Wängnerud, L. (2009). Women in Parliaments: Descriptive and Substantive Representation. Annual Review of Political Science, 12(1), 51-69.

Weir, M. (2007). Rights and Politics of Place in the U.S. In E. Strom \& J. H. Mollenkopf (Eds.), The Urban Politics Reader (pp. 19-27). New York: Routledge.

Welch, M. P. (2015, April 22). New Orleans goes smoke-free : a breath of fresh air or a blow to its character?; While some see a ban on indoor smoking as a threat to the freewheeling city's famed nightlife - and a source of noise nuisance - others sense an opportunity. The Guardian.

Welch, S. (1990). The Impact of At-Large Elections on the Representation of Blacks and Hispanics. The Journal of Politics, 52(4), 1050-1076.

Whitby, K. J., \& Krause, G. A. (2001). Race, Issue Heterogeneity and Public Policy: The Republican Revolution in the 104th US Congress and the Representation of AfricanAmerican Policy Interests. British Journal of Political Science, 31(3), 555-572.

Wilson, W. J. (1998). When Work Disappears : New Implications for Race and Urban Poverty in the Global Economy (No. 17). London.

Wilson, W. J. (2009). More than Just Race: Being Black and Poor in the Inner City. New York: W. W. Norton \& Company.

Wong, A., Green, A., \& Zhou, L. (2015). Can Schools Be Fixed? Atlantic Online.

Wooldridge, B. J. M. (2003). Cluster-Sample Methods in Applied Econometrics. The American Economic Review, 93(2), 133-138.

Workneh, L. (2015, August 28). Racial Disparities Still Rage On In New Orleans, But It 
Isn't All Bad News. The Huffington Post.

Wright, G., Schaffner, B. F., Streb, M., \& Wright, G. (2001). Tearns Without Uniforms : The Nonpartisan Ballot in State and Local Elections. Political Science Quarterly, 54(1), 7-30. 


\section{Appendix A - List of Cities}

Listed by population:

New York, New York

Los Angeles, California

Chicago, Illinois

Houston, Texas

Philadelphia, Pennsylvania

Phoenix, Arizona

San Antonio, Texas

San Diego, California

Dallas, Texas

San Jose, California

Austin, Texas

Jacksonville, Florida

San Francisco, California

Indianapolis, Indiana

Columbus, Ohio

Fort Worth, Texas

Charlotte, North Carolina

Seattle, Washington

Denver, Colorado

El Paso, Texas

Detroit, Michigan

Washington, District of Columbia

Boston, Massachusetts

Memphis, Tennessee

Nashville, Tennessee

Portland, Oregon

Oklahoma City, Oklahoma

Las Vegas, Nevada

Baltimore, Maryland

Louisville/Jefferson County, Kentucky

Milwaukee, Wisconsin

Albuquerque, New Mexico

Tucson, Arizona

Fresno, California

Sacramento, California

Kansas, Missouri

Long Beach, California

Mesa, Arizona

Atlanta, Georgia 
Colorado Springs, Colorado

Virginia Beach, Virginia

Raleigh, North Carolina

Omaha, Nebraska

Miami, Florida

Oakland, California

Minneapolis, Minnesota

Tulsa, Oklahoma

Wichita, Kansas

New Orleans, Louisiana

Arlington, Texas

Cleveland, Ohio

Bakersfield, California

Tampa, Florida

Aurora, Colorado

Urban Honolulu CDP, Hawaii

Anaheim, California

Santa Ana, California

Corpus Christi, Texas

Riverside, California

St. Louis, Missouri

Lexington-Fayette, Kentucky

Stockton, California

Pittsburgh, Pennsylvania

St. Paul, Minnesota

Anchorage, Alaska

Cincinnati, Ohio

Henderson, Nevada

Greensboro, North Carolina

Plano, Texas

Newark, New Jersey

Toledo, Ohio

Lincoln, Nebraska

Orlando, Florida

Chula Vista, California

Jersey City, New Jersey

Chandler, Arizona

Fort Wayne, Indiana

Buffalo, New York

Durham, North Carolina

St. Petersburg, Florida

Irvine, California

Laredo, Texas

Lubbock, Texas 
Madison, Wisconsin

Gilbert, Arizona

Norfolk, Virginia

Reno, Nevada

Winston-Salem, North Carolina

Glendale, Arizona

Hialeah, Florida

Garland, Texas

Scottsdale, Arizona

Irving, Texas

Chesapeake, Virginia

North Las Vegas, Nevada

Fremont, California

Baton Rouge, Louisiana

Richmond, Virginia

Boise, Idaho

San Bernardino, California

Spokane, Washington

Birmingham, Alabama

Modesto, California

Des Moines, Iowa

Rochester, New York

Tacoma, Washington

Fontana, California

Oxnard, California

Moreno Valley, California

Fayetteville, North Carolina

Huntington Beach, California

Yonkers, New York

Glendale, California

Aurora, Illinois

Montgomery, Alabama

Columbus, Georgia 


\section{Appendix B - Indicators of Racial and Diversity policies}

\section{Racial Policy}

Black racial policy -

"BLACK"

"AFRICA" - capturing African as well

"COLOR" "COLOUR" - to capture NAACP legislation

Latino racial policy -

"LATINO"

"LATINA" (separate from Latino because "LATIN" returned too many false positives, i.e. legislation containing "relating")

"HISPANIC"

"MEXIC"

"SPANISH" - to capture Spanish language programs

Asian racial policy -

"ASIA" - captures Asian as well.

"ORIENT"

"CHINA"

"CHINESE"

"JAPAN"

"KOREA"

"THAI"

"VIETNAM"

"INDONESIA"

"PHILLIPIN"

Diversity policy --

"DIVERS"

"INCLUSION"

"CULTUR"

"AFFIRMATIVE"

"EQUALITY"

"EQUIT" 


\section{Appendix C - SPSS Code}

Identifying Ordinances and Proclamations from Legislative Files

* Encoding: UTF-8.

SAVE OUTFILE='/Users/stephaniehawke/Dropbox/Dissertation/data/data collection/by city'+

'data/Fresno, California/fresno.sav' /COMPRESSED.

execute.

FREQUENCIES VARIABLES=type $/$ ORDER=ANALYSIS.

select if type $=$ "Resolution" or type $=$ "Ordinance" or type $=$ "Testimonial Resolution". execute.

SAVE OUTFILE='/Users/stephaniehawke/Dropbox/Dissertation/data/data collection/by city'+

'data/Detroit, Michigan/detroit_leg.sav'

/COMPRESSED.

execute.

FREQUENCIES VARIABLES=type

/ORDER=ANALYSIS.

NEW FILE.

DATASET NAME DataSet1 WINDOW=FRONT.

Identifying Ordinances and Proclamations from Agendas

compute title = concat(" ", title).

execute. 
select if (char.index(title, "Committee")) $=0$.

execute.

compute type $=$ "Ordinance".

execute.

frequencies variables $=$ type

/order $=$ analysis .

SAVE OUTFILE='/Users/stephaniehawke/Dropbox/Dissertation/data/data collection/by city'+

'data/Wichita, Kansas/wichita_leg.sav'

/COMPRESSED.

select if (type $=$ "RESOLUTION" OR type = "ORDINANCE").

execute.

select if (type = "Resolution" OR type = "Ordinance").

execute.

select if (type $=$ "Resolution" OR type $=$ "Ordinance" or type $=$ "Proclamation").

execute.

select if (type $=$ "City Resolution" or type = "Ordinance" or type = "Appointment - With Ordinance" or type = "City Code Amendments" or type = "Resolution" or type = "Staff Briefing - With Ordinance").

execute.

select if $($ type $=$ "ORDINANCES" or type = "ORDINANCES - NUMBERING" or type $=$ "ORDINANCES - TUESDAY" OR type $=$ "RESOLUTIONS" OR TYPE $=$ "RESOLUTIONS - NUMBERING").

execute.

select if (type $=$ "Motion / Motion Response" or type = "Ordinance" or type = "Policy" or type = "Resolution").

execute. 
frequencies variables $=$ res ord

/order = analysis.

SAVE OUTFILE='/Users/stephaniehawke/Dropbox/Dissertation/data/data collection/by city'+

'data/Wichita, Kansas/wichita.sav'

/COMPRESSED.

if (char.index(title, "resolution") $>0$ OR char.index(title, "Resolution") $>0$ or

char.index(title, "RESOLUTION") $>0$ or char.index(title, "RESOLVED") $>0$ ) res=1. execute.

if (char.index(type, "Resolution") $>0$ or char.index(type, "Resolutions") $>0$ ) res=1. execute.

if (char.index(type, "Ordinance") $>0$ ) ord=1.

execute.

select if title $\sim="$ ".

execute.

* Encoding: UTF-8.

compute title $=$ concat $("$ ", title $)$.

execute.

if (char.index(title, "resolution") $>0$ OR char.index(title, "Resolution") $>0$ or char.index(title, "RESOLUTION")>0) res=1.

exe.

if (char.index(title, "ordinance") $>0$ OR char.index(title, "Ordinance") $>0$ or char.index(title, "ORDINANCE") $>0$ ) ord $=1$.

if (char.index(title, "proclamation") $>0$ OR char.index(title, "Proclamation") $>0$ or char.index(title, "PROCLAMATION")>0) $\operatorname{proc}=1$.

execute. 
frequencies variables $=$ res ord proc auth

/order $=$ analysis.

execute.

SAVE OUTFILE='/Users/stephaniehawke/Dropbox/Dissertation/data/data collection/by city '+

'data/St. Paul, Minnesota/st paul.sav'

/COMPRESSED.

select if $($ ord $=1$ or res $=1$ or $\operatorname{proc}=1$ or auth $=1)$.

execute.

select if (ord $=1$ or res $=1)$.

execute.

SAVE OUTFILE='/Users/stephaniehawke/Dropbox/Dissertation/data/data collection/by city '+

'data/St. Paul, Minnesota/st paul_leg only.sav'

/COMPRESSED.

frequencies variables $=$ res ord

/order $=$ analysis.

execute.

select if type $=$ "Bill" or type $=$ "Resolution".

execute.

compute type = concat $("$ ", type $)$.

execute.

if char.index(type, "Ordinance") $>1$ ord $=1$.

if char.index(type, "Resolution") $>1$ res $=1$.

execute.

\section{Coding Racial and Diversity Policy}

* Encoding: UTF-8. 
*select if (type $=$ "Ordinance" or type = "Resolution").

*execute.

*select if (status $\sim=$ "Failed" or status $\sim=$ "Withdrawn").

*execute.

*select if(status = "Enacted" or status = "Enacted and Published" or status = "Sustained").

*execute.

*FREQUENCIES VARIABLES=status /ORDER=ANALYSIS.

compute title $=$ upper(title).

execute.

If char.index(title, "BLACK") $>0$ black $=1$.

if char.index(title, "AFRICA") $>0$ black $=1$.

if char.index(title, "COLOR") $>0$ black $=1$.

if char.index(title, "COLOUR") $>0$ black $=1$.

if char.index(title, "LATINO") $>0$ latino $=1$.

if char.index(title, "LATINA") $>0$ latino $=1$.

if char.index(title, "HISPANIC") $>0$ latino $=1$.

if char.index(title, "MEXIC") $>0$ latino $=1$.

if char.index(title, "SPANISH") $>0$ latino $=1$.

execute.

*if char.index(title, "NEW MEXIC") $>0$ new_mex $=1$.

*FREQUENCIES VARIABLES=new_mex

/ORDER=ANALYSIS.

$*_{\text {if }}($ latino $=1$ and new_mex $=1)$ latino $=0$.

*execute.

$*$ frequencies variables $=$ latino

/order $=$ analysis. ${ }^{*}$

if char.index(title, "ASIA") $>0$ asian $=1$.

if char.index(title, "ORIENT") $>0$ asian $=1$.

if char.index(title, "CHINA") $>0$ asian $=1$. 
if char.index(title, "CHINESE") $>0$ asian $=1$.

if char.index(title, "JAPAN") $>0$ asian $=1$.

if char.index(title, "KOREA") $>0$ asian $=1$.

if char.index(title, "THAI") $>0$ asian $=1$.

if char.index(title, "VIETNAM") $>0$ asian $=1$.

if char.index(title, "INDONESIA") $>0$ asian $=1$.

if char.index(title, "PHILLIPIN") $>0$ asian $=1$.

execute.

if black $\sim=1$ black $=0$.

if latino $\sim=1$ latino $=0$.

if asian $\sim=1$ asian $=0$.

execute.

recode black (MISSING $=0$ ).

recode latino (MISSING $=0$ ).

recode asian (MISSING $=0$ ).

execute.

FREQUENCIES VARIABLES=black latino asian $/$ ORDER=ANALYSIS.

$* *$ diversity policy**

compute $\operatorname{div}=0$.

execute.

compute divers= char.index(title, "DIVERS").

execute.

compute inclu $=$ char.index(title, "INCLUSION").

execute.

compute cultur $=$ char.index(title, "CULTUR").

execute.

compute affirmative = char.index(title, "AFFIRMATIVE").

execute.

compute equal $=$ char.index $($ title, "EQUALITY").

execute.

compute equit = char.index(title, "EQUIT").

execute. 
if divers $>0$ div $=1$.

if inclu $>0$ div $=1$.

if cultur $>0$ and (char.index(title, "AGRICULTUR")=0) div $=1$.

if affirmative $>0 \mathrm{div}=1$.

if equal $>0$ div $=1$.

if equit $>0 \operatorname{div}=1$.

execute.

recode $\operatorname{div}(\mathrm{MISSING}=0)$.

execute.

\section{FREQUENCIES VARIABLES=div}

/ORDER=ANALYSIS. 


\section{Appendix D - Explanation of creating the dataset}

The dataset included 108 cities. To create the Racial Policy Dataset, I used each relationship (i.e. racial group as compared to the amount of racial policy) as its own data point. I then ran tests of multicollinearity and independence, to ensure that this data set up did not violate any of the foundational assumptions of regression analysis. This set up did not violate those assumptions. The new dataset had 324 observations.

A parallel process could not be conducted to expand the Diversity Policy Dataset. This means that the Diversity Policy Dataset includes 108 observations. 


\section{Appendix E - Regression Results}

\section{Racial Policy Regressions}

\section{Regression}

\begin{tabular}{ll|l}
\multicolumn{4}{c}{$\begin{array}{c}\text { Variables Entered/Removed } \\
\text { Variables } \\
\text { Model }\end{array}$} & $\begin{array}{c}\text { Variables } \\
\text { Entered }\end{array}$ & \\
\hline 1 & $\begin{array}{l}\text { Removed } \\
\text { strong_mayor, } \\
\text { mayor_is, } \\
\text { elec_district, } \\
\text { city_dem, } \\
\text { council_multipl } \\
\text { els, perc_is }\end{array}$ & \\
\hline
\end{tabular}

a. Dependent Variable: percpol_is

b. All requested variables entered.

\begin{tabular}{ll|r|r|r} 
& & \multicolumn{2}{c}{ Model Summary } \\
Model & $\mathrm{R}$ & $\mathrm{R}$ Square & \multicolumn{1}{c}{$\begin{array}{c}\text { Adjusted R } \\
\text { Square }\end{array}$} & $\begin{array}{c}\text { Std. Error of } \\
\text { the Estimate }\end{array}$ \\
\hline 1 & $.248^{\mathrm{a}}$ & .061 & .043 & .59565110 \\
\hline
\end{tabular}

a. Predictors: (Constant), strong_mayor, mayor_is, elec_district, city_dem, council_multiplels, perc_is

\begin{tabular}{|c|c|c|c|c|c|}
\hline \multicolumn{6}{|c|}{ ANOVA $^{a}$} \\
\hline Model & $\begin{array}{l}\text { Sum of } \\
\text { Squares }\end{array}$ & $\mathrm{df}$ & Mean Square & $\mathrm{F}$ & Sig. \\
\hline
\end{tabular}




\begin{tabular}{l|l|r|r|r|r|r}
\hline 1 & 7.284 & 6 & 1.214 & 3.422 & $.003^{\mathrm{b}}$ \\
\hline Regression & 111.407 & 314 & .355 & & \\
\hline Residual & 118.691 & 320 & & & \\
\hline Total & & & \\
\hline
\end{tabular}

a. Dependent Variable: percpol_is

b. Predictors: (Constant), strong_mayor, mayor_is, elec_district, city_dem, council_multiplels, perc_is

\begin{tabular}{|c|c|c|c|c|c|c|}
\hline \multicolumn{7}{|c|}{ Coefficients $^{a}$} \\
\hline \multirow{2}{*}{\multicolumn{2}{|c|}{ Model }} & \multicolumn{2}{|c|}{$\begin{array}{c}\text { Unstandardized } \\
\text { Coefficients }\end{array}$} & \multirow{2}{*}{$\begin{array}{c}\text { Standardize } \\
\text { d } \\
\text { Coefficients } \\
\text { Beta }\end{array}$} & \multirow[b]{2}{*}{$\mathrm{t}$} & \multirow[b]{2}{*}{ Sig. } \\
\hline & & $\mathrm{B}$ & Std. Error & & & \\
\hline \multirow[t]{7}{*}{1} & (Constant) & .227 & .072 & & 3.149 & .002 \\
\hline & perc_is & .364 & .300 & .113 & 1.214 & .226 \\
\hline & mayor_is & .101 & .129 & .048 & .784 & .433 \\
\hline & $\begin{array}{l}\text { council_multiple } \\
\text { Is }\end{array}$ & .062 & .130 & .045 & .480 & .632 \\
\hline & elec_district & -.129 & .068 & -.105 & -1.903 & .058 \\
\hline & city_dem & -.141 & .073 & -.112 & -1.936 & .054 \\
\hline & strong_mayor & .165 & .069 & .136 & 2.402 & .017 \\
\hline
\end{tabular}

a. Dependent Variable: percpol_is

\section{Regression}

\begin{tabular}{lc|c|c} 
& \multicolumn{3}{c}{ Variables Entered/Removed $^{\mathrm{a}}$} \\
& Variables & Variables & \\
Model & Entered & Removed & Method \\
\hline
\end{tabular}




\begin{tabular}{ll|l}
\hline 1 & strong_mayor, & Enter \\
mayor_is, & & \\
elec_district, & \\
city_dem, & \\
PERC_IS2, & \\
council_multipl & \\
els, perc_is & & \\
\hline
\end{tabular}

a. Dependent Variable: percpol_is

b. All requested variables entered.

\begin{tabular}{ll|r|r|r} 
& & \multicolumn{2}{c}{ Model Summary } \\
Model & $\mathrm{R}$ & R Square & \multicolumn{1}{c}{$\begin{array}{c}\text { Adjusted R } \\
\text { Square }\end{array}$} & $\begin{array}{c}\text { Std. Error of } \\
\text { the Estimate }\end{array}$ \\
\hline 1 & $.248^{\mathrm{a}}$ & .062 & .041 & .59654881 \\
\hline
\end{tabular}

a. Predictors: (Constant), strong_mayor, mayor_is, elec_district, city_dem, PERC_IS2, council_multiplels, perc_is

\begin{tabular}{|c|c|c|c|c|c|c|}
\hline \multicolumn{7}{|c|}{ ANOVA $^{a}$} \\
\hline Model & & $\begin{array}{l}\text { Sum of } \\
\text { Squares }\end{array}$ & df & Mean Square & $\mathrm{F}$ & Sig. \\
\hline \multirow[t]{3}{*}{1} & Regression & 7.304 & 7 & 1.043 & 2.932 & $.005^{b}$ \\
\hline & Residual & 111.387 & 313 & .356 & & \\
\hline & Total & 118.691 & 320 & & & \\
\hline
\end{tabular}

a. Dependent Variable: percpol_is

b. Predictors: (Constant), strong_mayor, mayor_is, elec_district, city_dem, PERC_IS2, council_multiplels, perc_is

\begin{tabular}{|c|c|c|c|c|c|}
\hline \multicolumn{6}{|c|}{ Coefficients $^{a}$} \\
\hline \multirow[b]{2}{*}{ Model } & $\begin{array}{r}\text { Unstan } \\
\text { Coeff }\end{array}$ & $\begin{array}{l}\text { ardized } \\
\text { ients }\end{array}$ & $\begin{array}{c}\text { Standardize } \\
\text { d } \\
\text { Coefficients }\end{array}$ & & \\
\hline & $\mathrm{B}$ & Std. Error & Beta & $\mathrm{t}$ & Sig. \\
\hline $1 \quad$ (Constant) & .224 & .073 & & 3.057 & .002 \\
\hline
\end{tabular}




\begin{tabular}{l|r|r|r|r|r}
\hline perc_is & .497 & .637 & .154 & .779 & .437 \\
\hline PERC_IS2 & -.158 & .671 & -.035 & -.236 & .814 \\
\hline mayor_is & .101 & .129 & .048 & .785 & .433 \\
\hline $\begin{array}{l}\text { council_multipl } \\
\text { els }\end{array}$ & .045 & .150 & .032 & .300 & .764 \\
\hline elec_district & -.131 & .068 & -.107 & -1.914 & .056 \\
\hline city_dem & -.141 & .073 & -.113 & -1.938 & .054 \\
\hline strong_mayor & .166 & .069 & .136 & 2.407 & .017 \\
\hline
\end{tabular}

a. Dependent Variable: percpol_is

Regression

\begin{tabular}{|c|c|c|c|}
\hline \multicolumn{4}{|c|}{ Variables Entered/Removed ${ }^{a}$} \\
\hline & Variables & Variables & \\
\hline Model & & Removed & Method \\
\hline 1 & $\begin{array}{l}\text { strong_mayor, } \\
\text { mayor_is, } \\
\text { elec_district, } \\
\text { city_dem, } \\
\text { PERC_IS3, } \\
\text { council_multipl } \\
\text { els, perc_is, } \\
\text { PERC IS2 }\end{array}$ & & Enter \\
\hline
\end{tabular}

a. Dependent Variable: percpol_is

b. All requested variables entered.

\section{Model Summary}

\begin{tabular}{lr|r|r|r} 
Model & $\mathrm{R}$ & R Square & \multicolumn{1}{c|}{$\begin{array}{c}\text { Adjusted R } \\
\text { Square }\end{array}$} & $\begin{array}{c}\text { Std. Error of } \\
\text { the Estimate }\end{array}$ \\
\hline 1 & $.268^{\mathrm{a}}$ & .072 & .048 & .59425127 \\
\hline
\end{tabular}


a. Predictors: (Constant), strong_mayor, mayor_is, elec_district, city_dem, PERC_IS3, council_multiplels, perc_is, PERC_IS2

\begin{tabular}{|c|c|c|c|c|c|c|}
\hline \multicolumn{7}{|c|}{ ANOVA $^{a}$} \\
\hline Mode & & $\begin{array}{l}\text { Sum of } \\
\text { Squares }\end{array}$ & $\mathrm{df}$ & Mean Square & $\mathrm{F}$ & Sig. \\
\hline \multirow[t]{3}{*}{1} & Regression & 8.513 & 8 & 1.064 & 3.013 & $.003^{b}$ \\
\hline & Residual & 110.178 & 312 & .353 & & \\
\hline & Total & 118.691 & 320 & & & \\
\hline
\end{tabular}

a. Dependent Variable: percpol_is

b. Predictors: (Constant), strong_mayor, mayor_is, elec_district, city_dem, PERC_IS3, council_multiplels, perc_is, PERC_IS2

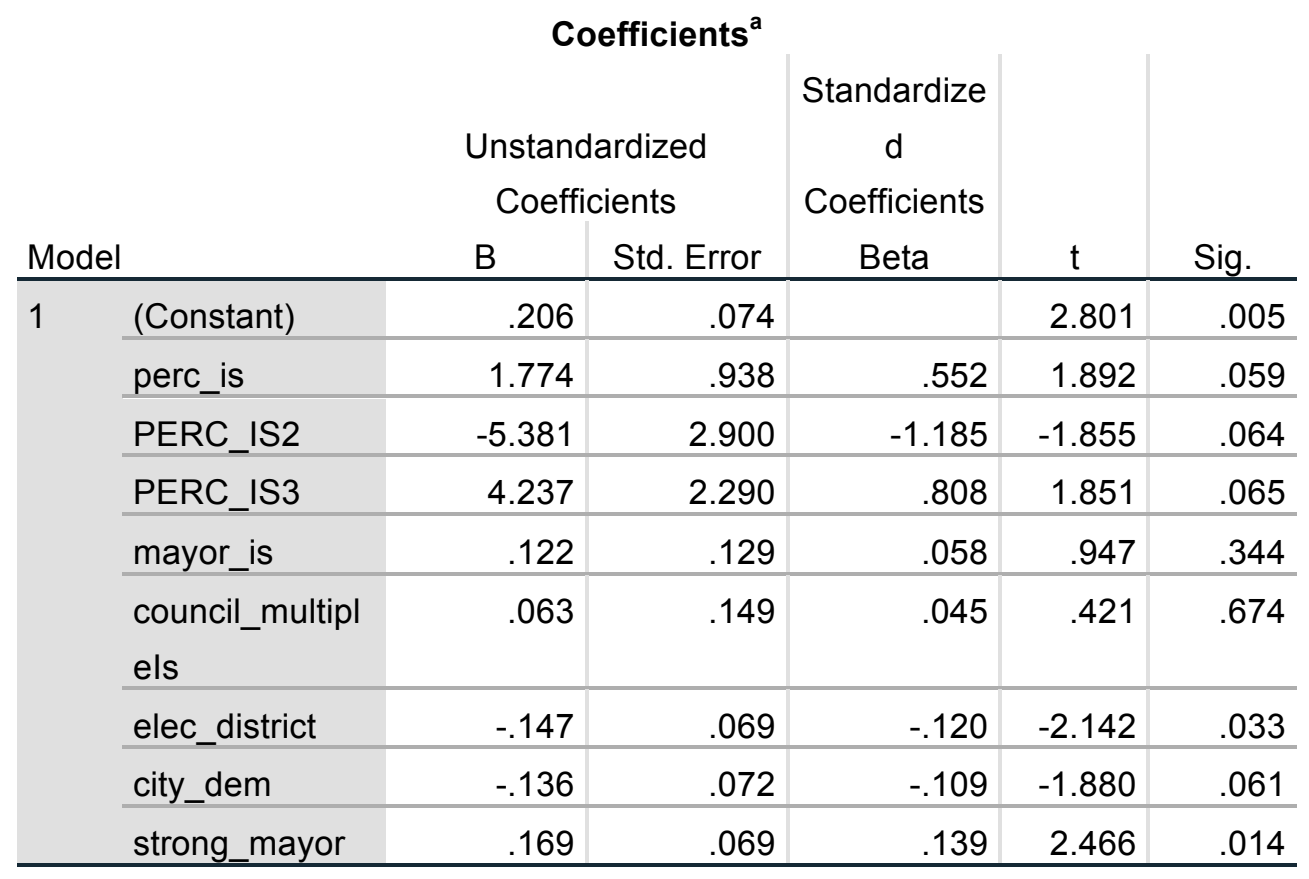

a. Dependent Variable: percpol_is

\section{Regression}




\begin{tabular}{|c|c|c|c|}
\hline \multicolumn{4}{|c|}{ Variables Entered/Removed ${ }^{a}$} \\
\hline \multirow[b]{2}{*}{ Model } & Variables & Variables & \\
\hline & Entered & Removed & Method \\
\hline \multirow[t]{9}{*}{1} & strong_mayor, & & Enter \\
\hline & PERC_IS4, & & \\
\hline & elec_district, & & \\
\hline & city_dem, & & \\
\hline & mayor_is, & & \\
\hline & council_multipl & & \\
\hline & els, perc_is, & & \\
\hline & PERC_IS2, & & \\
\hline & PERC_IS3 ${ }^{\mathrm{b}}$ & & \\
\hline
\end{tabular}

a. Dependent Variable: percpol_is

b. All requested variables entered.

\begin{tabular}{ll|l|r|r} 
& & \multicolumn{2}{c}{ Model Summary } \\
Model & $\mathrm{R}$ & R Square & $\begin{array}{c}\text { Adjusted R } \\
\text { Square }\end{array}$ & $\begin{array}{c}\text { Std. Error of } \\
\text { the Estimate }\end{array}$ \\
\hline 1 & $.281^{\mathrm{a}}$ & .079 & .052 & .59287646 \\
\hline
\end{tabular}

a. Predictors: (Constant), strong_mayor, PERC_IS4, elec_district, city_dem, mayor_is, council_multiplels, perc_is, PERC_IS2, PERC_IS3

\begin{tabular}{|c|c|c|c|c|c|c|}
\hline \multicolumn{7}{|c|}{ ANOVA $^{a}$} \\
\hline Model & & $\begin{array}{l}\text { Sum of } \\
\text { Squares }\end{array}$ & $\mathrm{df}$ & Mean Square & $\mathrm{F}$ & Sig. \\
\hline \multirow[t]{3}{*}{1} & Regression & 9.374 & 9 & 1.042 & 2.963 & $.002^{b}$ \\
\hline & Residual & 109.317 & 311 & .352 & & \\
\hline & Total & 118.691 & 320 & & & \\
\hline
\end{tabular}

a. Dependent Variable: percpol_is

b. Predictors: (Constant), strong_mayor, PERC_IS4, elec_district, city_dem, mayor_is, council_multiplels, perc_is, PERC_IS2, PERC_IS3 


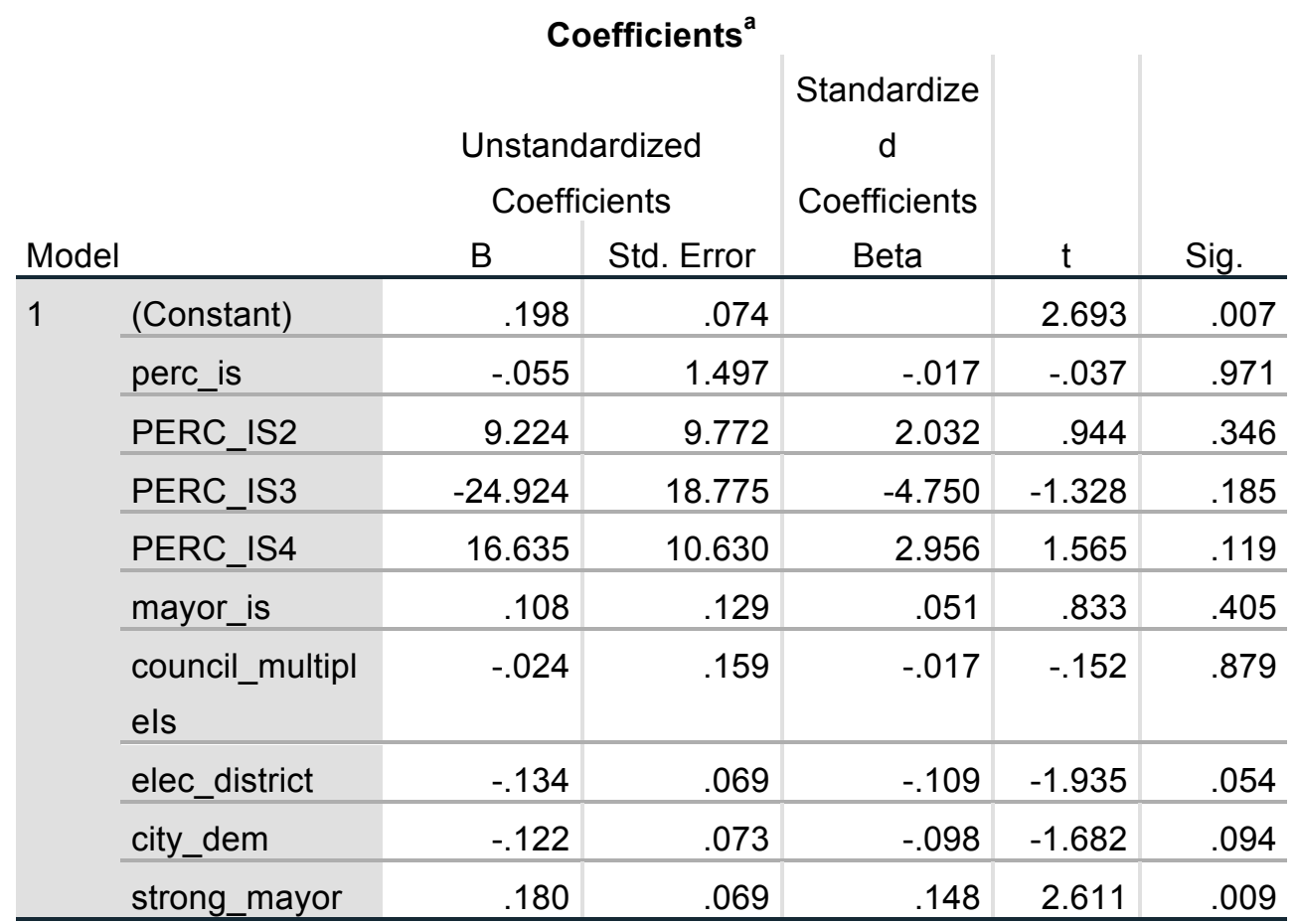

a. Dependent Variable: percpol_is

Diversity Regressions

Regression

\begin{tabular}{lc|c|c} 
& \multicolumn{3}{c}{ Variables Entered/Removed $^{\text {a }}$} \\
& Variables & Variables & \\
Model & Entered & Removed & Method \\
\hline
\end{tabular}




\begin{tabular}{|c|c|c|}
\hline 1 & $\begin{array}{l}\text { strong_mayor, } \\
\text { mayor_minorit } \\
\text { y, elec_district, } \\
\text { mayor_dem, } \\
\text { perc_minority, } \\
\text { council_multipl } \\
\text { eMinority }\end{array}$ & Enter \\
\hline
\end{tabular}

a. Dependent Variable: perc_divpol

b. All requested variables entered.

\begin{tabular}{ll|r|r|r} 
& & \multicolumn{2}{c}{ Model Summary } \\
Model & $\mathrm{R}$ & R Square & \multicolumn{1}{c}{$\begin{array}{c}\text { Adjusted R } \\
\text { Square }\end{array}$} & $\begin{array}{c}\text { Std. Error of } \\
\text { the Estimate }\end{array}$ \\
\hline 1 & $.246^{\mathrm{a}}$ & .060 & .003 & .00826246362 \\
& & & & 0000 \\
\hline
\end{tabular}

a. Predictors: (Constant), strong_mayor, mayor_minority, elec_district, mayor_dem, perc_minority, council_multipleMinority

\begin{tabular}{|c|c|c|c|c|c|c|}
\hline \multicolumn{7}{|c|}{ ANOVA $^{a}$} \\
\hline \multicolumn{2}{|c|}{ Model } & $\begin{array}{l}\text { Sum of } \\
\text { Squares }\end{array}$ & df & Mean Square & $\mathrm{F}$ & Sig. \\
\hline \multirow[t]{3}{*}{1} & Regression & .000 & 6 & .000 & 1.061 & $.391^{b}$ \\
\hline & Residual & .007 & 99 & .000 & & \\
\hline & Total & .007 & 105 & & & \\
\hline
\end{tabular}

a. Dependent Variable: perc_divpol

b. Predictors: (Constant), strong_mayor, mayor_minority, elec_district, mayor_dem, perc_minority, council_multipleMinority

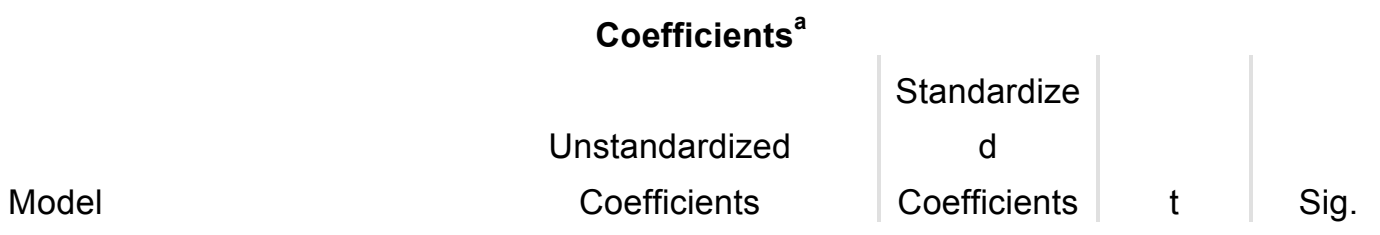




\begin{tabular}{ll|r|r|r|r} 
& B & Std. Error & Beta & & \\
\hline 1 & .005 & .002 & & 2.433 & .017 \\
\hline (Constant) & -.002 & .004 & -.056 & -.478 & .633 \\
\hline perc_minority & -.001 & .002 & -.053 & -.505 & .615 \\
\hline mayor_minority & -.003 & .002 & -.204 & -1.589 & .115 \\
\hline $\begin{array}{l}\text { council_multipleMino } \\
\text { rity }\end{array}$ & & & & & \\
\hline elec_district & .000 & .002 & .017 & .172 & .863 \\
\hline mayor_dem & .003 & .002 & .160 & 1.433 & .155 \\
\hline strong_mayor & .003 & .002 & .189 & 1.752 & .083 \\
\hline
\end{tabular}

a. Dependent Variable: perc_divpol

\section{Regression}

\begin{tabular}{|c|c|c|c|}
\hline \multicolumn{4}{|c|}{ Variables Entered/Removed ${ }^{a}$} \\
\hline Model & $\begin{array}{c}\text { Variables } \\
\text { Entered }\end{array}$ & $\begin{array}{l}\text { Variables } \\
\text { Removed }\end{array}$ & Method \\
\hline 1 & $\begin{array}{l}\text { strong_mayor, } \\
\text { mayor_minorit } \\
\text { y, elec_district, } \\
\text { mayor_dem, } \\
\text { perc_minority2 } \\
\text {, council_multipl } \\
\text { eMinority, } \\
\text { perc_minority }\end{array}$ & & Enter \\
\hline
\end{tabular}

a. Dependent Variable: perc_divpol

b. All requested variables entered. 


\begin{tabular}{ll|r|r|r} 
& & \multicolumn{2}{c}{ Model Summary } \\
Model & $\mathrm{R}$ & R Square & \multicolumn{1}{c}{$\begin{array}{c}\text { Adjusted R } \\
\text { Square }\end{array}$} & $\begin{array}{l}\text { Std. Error of } \\
\text { the Estimate }\end{array}$ \\
\hline 1 & $.270^{\mathrm{a}}$ & .073 & .007 & .00824817488 \\
& & & & 0000 \\
\hline
\end{tabular}

a. Predictors: (Constant), strong_mayor, mayor_minority, elec_district, mayor_dem, perc_minority2, council_multipleMinority, perc_minority

\begin{tabular}{|c|c|c|c|c|c|c|}
\hline \multicolumn{7}{|c|}{ ANOVA $^{a}$} \\
\hline \multicolumn{2}{|c|}{ Model } & $\begin{array}{l}\text { Sum of } \\
\text { Squares }\end{array}$ & $\mathrm{df}$ & Mean Square & $\mathrm{F}$ & Sig. \\
\hline \multirow[t]{3}{*}{1} & Regression & .001 & 7 & .000 & 1.105 & $.366^{b}$ \\
\hline & Residual & .007 & 98 & .000 & & \\
\hline & Total & .007 & 105 & & & \\
\hline
\end{tabular}

a. Dependent Variable: perc_divpol

b. Predictors: (Constant), strong_mayor, mayor_minority, elec_district, mayor_dem, perc_minority2, council_multipleMinority, perc_minority

\begin{tabular}{|c|c|c|c|c|c|c|}
\hline & & Coet & icients $^{a}$ & & & \\
\hline & & $\begin{array}{l}\text { Unstanc } \\
\text { Coefff }\end{array}$ & $\begin{array}{l}\text { ardized } \\
\text { ients }\end{array}$ & $\begin{array}{c}\text { Standardize } \\
\mathrm{d} \\
\text { Coefficients }\end{array}$ & & \\
\hline & & $\mathrm{B}$ & Std. Error & Beta & $\mathrm{t}$ & Sig. \\
\hline 1 & (Constant) & .006 & .002 & & 2.686 & .008 \\
\hline & perc_minority & -.016 & .013 & -.479 & -1.250 & .214 \\
\hline & perc_minority2 & .015 & .013 & .408 & 1.159 & .249 \\
\hline & mayor_minority & -.001 & .002 & -.069 & -.659 & .512 \\
\hline & $\begin{array}{l}\text { council_multipleMino } \\
\text { rity }\end{array}$ & -.002 & .002 & -.117 & -.787 & .433 \\
\hline & elec_district & .001 & .002 & .056 & .524 & .601 \\
\hline & mayor_dem & .003 & .002 & .168 & 1.499 & .137 \\
\hline & strong_mayor & .003 & .002 & .176 & 1.626 & .107 \\
\hline
\end{tabular}

a. Dependent Variable: perc_divpol 


\section{Regression}

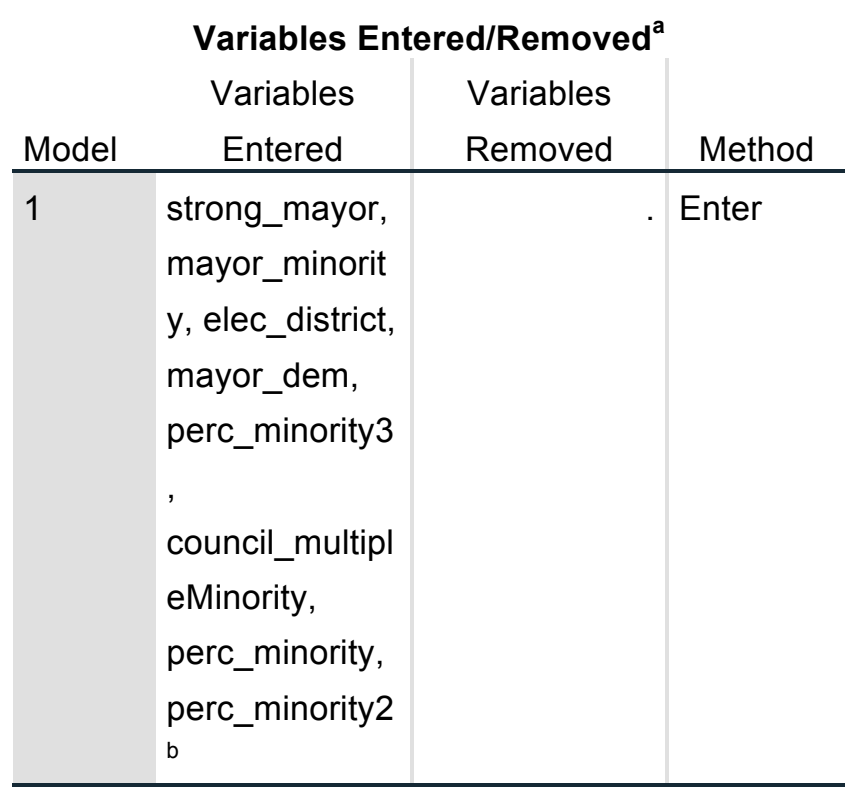

a. Dependent Variable: perc_divpol

b. All requested variables entered.

\begin{tabular}{ll|r|r|r} 
& & \multicolumn{2}{c}{ Model Summary } \\
Model & $\mathrm{R}$ & R Square & \multicolumn{1}{c}{$\begin{array}{c}\text { Adjusted R } \\
\text { Square }\end{array}$} & $\begin{array}{l}\text { Std. Error of } \\
\text { the Estimate }\end{array}$ \\
\hline 1 & $.274^{\mathrm{a}}$ & .075 & -.001 & .00828225076 \\
& & & & 0000 \\
\hline
\end{tabular}

a. Predictors: (Constant), strong_mayor, mayor_minority, elec_district, mayor_dem, perc_minority3,

council_multipleMinority, perc_minority, perc_minority2

\section{ANOVA $^{a}$}




\begin{tabular}{|c|c|c|c|c|c|c|}
\hline Model & & $\begin{array}{l}\text { Sum of } \\
\text { Squares }\end{array}$ & $\mathrm{df}$ & Mean Square & $\mathrm{F}$ & Sig. \\
\hline \multirow[t]{3}{*}{1} & Regression & .001 & 8 & .000 & .983 & $.454^{\mathrm{b}}$ \\
\hline & Residual & .007 & 97 & .000 & & \\
\hline & Total & .007 & 105 & & & \\
\hline
\end{tabular}

a. Dependent Variable: perc_divpol

b. Predictors: (Constant), strong_mayor, mayor_minority, elec_district, mayor_dem, perc_minority3, council_multipleMinority, perc_minority, perc_minority2

\begin{tabular}{|c|c|c|c|c|c|c|}
\hline \multicolumn{7}{|c|}{ Coefficients $^{a}$} \\
\hline \multirow[b]{2}{*}{ Mod } & & \multicolumn{2}{|c|}{$\begin{array}{l}\text { Unstandardized } \\
\text { Coefficients }\end{array}$} & \multirow{2}{*}{$\begin{array}{c}\text { Standardize } \\
\text { d } \\
\text { Coefficients } \\
\text { Beta } \\
\end{array}$} & \multirow[b]{2}{*}{$\mathrm{t}$} & \multirow[b]{2}{*}{ Sig. } \\
\hline & & $\mathrm{B}$ & Std. Error & & & \\
\hline \multirow[t]{9}{*}{1} & (Constant) & .007 & .003 & & 2.558 & .012 \\
\hline & perc_minority & -.024 & .022 & -.725 & -1.071 & .287 \\
\hline & perc_minority2 & .040 & .058 & 1.112 & .681 & .497 \\
\hline & perc_minority3 & -.018 & .042 & -.476 & -.442 & .660 \\
\hline & mayor_minority & -.001 & .002 & -.075 & -.705 & .482 \\
\hline & $\begin{array}{l}\text { council_multipleMino } \\
\text { rity }\end{array}$ & -.002 & .002 & -.128 & -.848 & .398 \\
\hline & elec_district & .001 & .002 & .056 & .527 & .599 \\
\hline & mayor_dem & .003 & .002 & .163 & 1.443 & .152 \\
\hline & strong_mayor & .003 & .002 & .175 & 1.607 & .111 \\
\hline
\end{tabular}

a. Dependent Variable: perc_divpol

\section{Regression}




\begin{tabular}{|c|c|c|c|}
\hline \multicolumn{4}{|c|}{ Variables Entered/Removed $^{a}$} \\
\hline Model & $\begin{array}{c}\text { Variables } \\
\text { Entered } \\
\end{array}$ & $\begin{array}{l}\text { Variables } \\
\text { Removed }\end{array}$ & Method \\
\hline 1 & $\begin{array}{l}\text { strong_mayor, } \\
\text { mayor_minorit } \\
\text { y, elec_district, } \\
\text { perc_minority4 } \\
\text {, mayor_dem, } \\
\text { council_multipl } \\
\text { eMinority, } \\
\text { perc_minority, } \\
\text { perc_minority2 } \\
\text {, } \\
\text { perc_minority3 } \\
\text { b }\end{array}$ & & Enter \\
\hline
\end{tabular}

a. Dependent Variable: perc_divpol

b. All requested variables entered.

\begin{tabular}{ll|r|r|r} 
& \multicolumn{2}{c}{ Model Summary } \\
Model & $\mathrm{R}$ & R Square & \multicolumn{1}{c}{$\begin{array}{c}\text { Adjusted R } \\
\text { Square }\end{array}$} & $\begin{array}{l}\text { Std. Error of } \\
\text { the Estimate }\end{array}$ \\
\hline 1 & $.274^{\mathrm{a}}$ & .075 & -.012 & .00832502735 \\
& & & 0000 \\
\hline
\end{tabular}

a. Predictors: (Constant), strong_mayor, mayor_minority, elec_district, perc_minority4, mayor_dem,

council_multipleMinority, perc_minority, perc_minority2, perc_minority3

\begin{tabular}{|c|c|c|c|c|c|c|}
\hline \multicolumn{7}{|c|}{ ANOVA $^{a}$} \\
\hline Model & & $\begin{array}{l}\text { Sum of } \\
\text { Squares }\end{array}$ & $\mathrm{df}$ & Mean Square & $\mathrm{F}$ & Sig. \\
\hline \multirow[t]{2}{*}{1} & Regression & .001 & 9 & .000 & .866 & $.559^{b}$ \\
\hline & Residual & .007 & 96 & .000 & & \\
\hline
\end{tabular}


a. Dependent Variable: perc_divpol

b. Predictors: (Constant), strong_mayor, mayor_minority, elec_district, perc_minority4, mayor_dem, council_multipleMinority, perc_minority, perc_minority2, perc_minority3

\begin{tabular}{|c|c|c|c|c|c|c|}
\hline & & Coef & icients ${ }^{a}$ & & & \\
\hline & & $\begin{array}{r}\text { Unstand } \\
\text { Coeffi }\end{array}$ & $\begin{array}{l}\text { ardized } \\
\text { sients }\end{array}$ & $\begin{array}{l}\text { Standardiz } \\
\text { ed } \\
\text { Coefficient } \\
\text { s }\end{array}$ & & \\
\hline & & $\mathrm{B}$ & Std. Error & Beta & $\mathrm{t}$ & Sig. \\
\hline 1 & (Constant) & .007 & .003 & & 2.504 & .014 \\
\hline & perc_minority & -.026 & .037 & -.794 & -.700 & .485 \\
\hline & perc_minority2 & .052 & .171 & 1.452 & .303 & .762 \\
\hline & perc_minority3 & -.040 & .284 & -1.025 & -.140 & .889 \\
\hline & perc_minority4 & .011 & .151 & .278 & .076 & .940 \\
\hline & mayor_minority & -.001 & .002 & -.075 & -.699 & .486 \\
\hline & $\begin{array}{l}\text { council_multipleMin } \\
\text { ority }\end{array}$ & -.002 & .003 & -.129 & -.846 & .400 \\
\hline & elec_district & .001 & .002 & .058 & .530 & .597 \\
\hline & mayor_dem & .003 & .002 & .164 & 1.430 & .156 \\
\hline & strong_mayor & .003 & .002 & .175 & 1.601 & .113 \\
\hline
\end{tabular}

a. Dependent Variable: perc_divpol 


\section{Appendix F - ANOVA results}

\section{African American ANOVAs}

\section{Oneway}

\section{Descriptives}

\begin{tabular}{|c|c|c|c|c|c|c|c|c|}
\hline & \multirow[b]{2}{*}{$\mathrm{N}$} & \multirow[b]{2}{*}{ Mean } & \multirow[b]{2}{*}{$\begin{array}{c}\text { Std. } \\
\text { Deviation }\end{array}$} & \multirow[b]{2}{*}{ Std. Error } & \multicolumn{2}{|c|}{$\begin{array}{l}95 \% \text { Confidence } \\
\text { Interval for Mean }\end{array}$} & \multirow[b]{2}{*}{ Minimum } & \multirow[b]{2}{*}{ Maximum } \\
\hline & & & & & $\begin{array}{l}\text { Lower } \\
\text { Bound }\end{array}$ & $\begin{array}{l}\text { Upper } \\
\text { Bound } \\
\end{array}$ & & \\
\hline $\begin{array}{l}\text { No } \\
\text { black } \\
\text { council } \\
\text { ors }\end{array}$ & $\begin{array}{l}3 \\
5\end{array}$ & $\begin{array}{l}.1359557 \\
66000000\end{array}$ & $\begin{array}{r}.52787596 \\
8000000\end{array}$ & $\begin{array}{r}.0892273 \\
24000000\end{array}$ & $\begin{array}{r}- \\
.0453759 \\
73700000\end{array}$ & $\begin{array}{r}.31728750 \\
5000000\end{array}$ & $\begin{array}{l}.0000000 \\
00000000\end{array}$ & $\begin{array}{r}2.9661016 \\
95000000\end{array}$ \\
\hline $\begin{array}{l}\text { Tokeni } \\
\text { sm (1 } \\
\text { black } \\
\text { council } \\
\text { or) }\end{array}$ & $\begin{array}{l}2 \\
4\end{array}$ & $\begin{array}{r}.2269215 \\
06000000\end{array}$ & $\begin{array}{r}.53240891 \\
7000000\end{array}$ & $\begin{array}{l}.1086775 \\
15000000\end{array}$ & $\begin{array}{r}.0021049 \\
36960000\end{array}$ & $\begin{array}{r}.45173807 \\
4000000\end{array}$ & $\begin{array}{l}.0000000 \\
00000000\end{array}$ & $\begin{array}{r}2.0000000 \\
00000000\end{array}$ \\
\hline $\begin{array}{l}\text { Tokeni } \\
\text { sm2 } \\
\text { ( } x<=.30 \\
\text { and } \\
\text { more } \\
\text { than } 1 \\
\text { blk } \\
\text { council } \\
\text { or) }\end{array}$ & $\begin{array}{l}1 \\
9\end{array}$ & $\begin{array}{r}.4771968 \\
57000000\end{array}$ & $\begin{array}{r}.97463736 \\
3000000\end{array}$ & $\begin{array}{r}.2235971 \\
46000000\end{array}$ & $\begin{array}{r}.0074366 \\
85120000\end{array}$ & $\begin{array}{r}.94695702 \\
9000000\end{array}$ & $\begin{array}{r}.0000000 \\
00000000\end{array}$ & $\begin{array}{r}4.1666666 \\
67000000\end{array}$ \\
\hline
\end{tabular}




\begin{tabular}{|c|c|c|c|c|c|c|c|c|}
\hline $\begin{array}{l}\text { Critical } \\
\text { Mass } \\
(.30<x< \\
=.50)\end{array}$ & $\begin{array}{l}2 \\
2\end{array}$ & $\begin{array}{r}.5188267 \\
45000000\end{array}$ & $\begin{array}{r}1.3432117 \\
07000000\end{array}$ & $\begin{array}{r}.2863736 \\
98000000\end{array}$ & $\begin{array}{r}- \\
.0767199 \\
62500000\end{array}$ & $\begin{array}{r}1.1143734 \\
52000000\end{array}$ & $\begin{array}{r}.0000000 \\
00000000\end{array}$ & $\begin{array}{r}6.2611806 \\
80000001\end{array}$ \\
\hline $\begin{array}{l}\text { Oversa } \\
\text { turation } \\
(.50<x)\end{array}$ & 8 & $\begin{array}{r}.1390594 \\
92000000\end{array}$ & $\begin{array}{r}.12495116 \\
5000000\end{array}$ & $\begin{array}{r}.0441769 \\
08000000\end{array}$ & $\begin{array}{r}.0345977 \\
04000000\end{array}$ & $\begin{array}{r}.24352128 \\
0000000\end{array}$ & $\begin{array}{r}.0000000 \\
00000000\end{array}$ & $\begin{array}{r}.38610038 \\
6000000\end{array}$ \\
\hline Total & $\begin{array}{l}1 \\
0 \\
8\end{array}$ & $\begin{array}{r}.2944256 \\
72000000\end{array}$ & $\begin{array}{r}.83169738 \\
6000000\end{array}$ & $\begin{array}{r}.0800301 \\
18200000\end{array}$ & $\begin{array}{r}.1357752 \\
96000000\end{array}$ & $\begin{array}{r}.45307604 \\
7000000\end{array}$ & $\begin{array}{r}.0000000 \\
00000000\end{array}$ & $\begin{array}{r}6.2611806 \\
80000001\end{array}$ \\
\hline
\end{tabular}

ANOVA

\begin{tabular}{lr|r|r|r|r} 
perc_blackpol & \multicolumn{1}{l}{ Sum of Squares } & df & Mean Square & F & \multicolumn{1}{c}{ Sig. } \\
\hline Between Groups & 2.924 & 4 & .731 & 1.059 & .381 \\
\hline Within Groups & 71.090 & 103 & .690 & & \\
\hline Total & 74.014 & 107 & & & \\
\hline
\end{tabular}

\section{Means Plots}




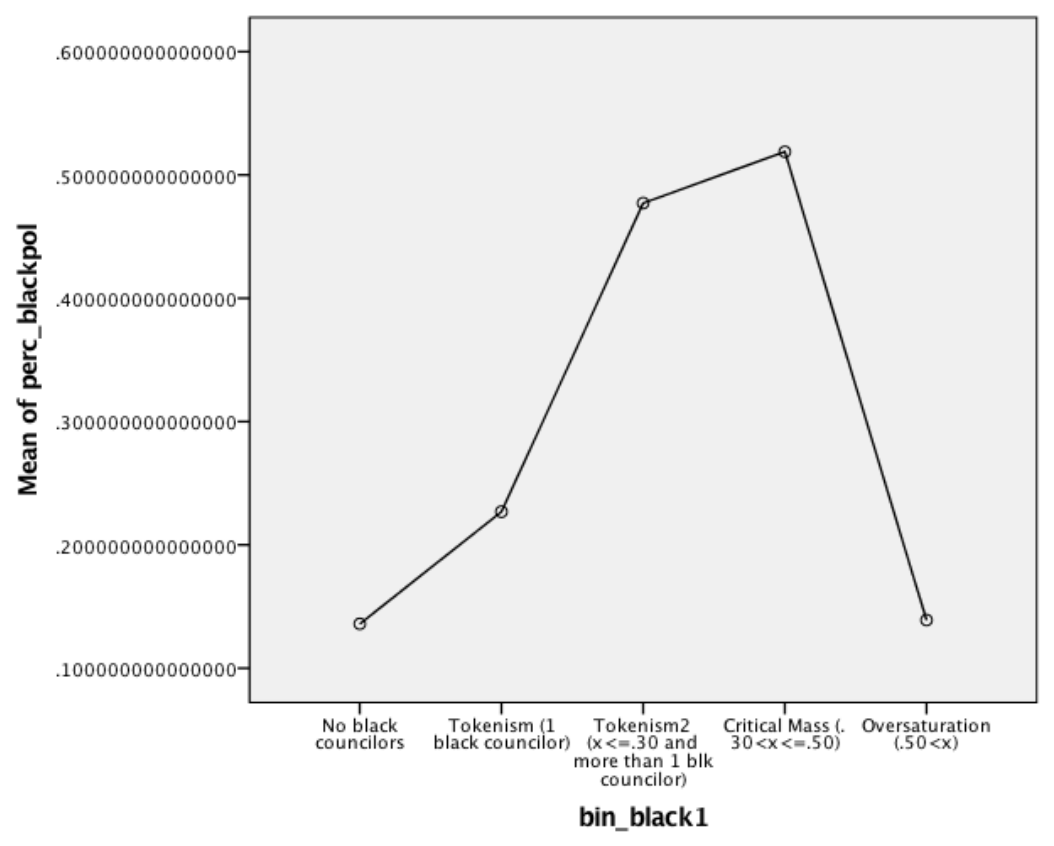

\section{Oneway}

\section{Descriptives}

\begin{tabular}{|c|c|c|c|c|c|c|c|c|}
\hline & \multirow[b]{2}{*}{$\mathrm{N}$} & \multirow[b]{2}{*}{ Mean } & \multirow[b]{2}{*}{$\begin{array}{c}\text { Std. } \\
\text { Deviation }\end{array}$} & \multirow[b]{2}{*}{ Std. Error } & \multicolumn{2}{|c|}{$\begin{array}{l}\text { 95\% Confidence } \\
\text { Interval for Mean }\end{array}$} & \multirow[b]{2}{*}{ Minimum } & \multirow[b]{2}{*}{ Maximum } \\
\hline & & & & & $\begin{array}{l}\text { Lower } \\
\text { Bound } \\
\end{array}$ & $\begin{array}{l}\text { Upper } \\
\text { Bound }\end{array}$ & & \\
\hline No & 3 & .1359557 & .52787596 & .0892273 & - & .3172875 & .0000000 & 2.9661016 \\
\hline $\begin{array}{l}\text { black } \\
\text { council } \\
\text { ors }\end{array}$ & 5 & 66000000 & 8000000 & 24000000 & $\begin{array}{r}.0453759 \\
73700000\end{array}$ & 05000000 & 00000000 & 95000000 \\
\hline
\end{tabular}




\begin{tabular}{|c|c|c|c|c|c|c|c|c|}
\hline $\begin{array}{l}\text { Tokeni } \\
\text { sm (1 } \\
\text { black } \\
\text { council } \\
\text { or) }\end{array}$ & $\begin{array}{l}2 \\
3\end{array}$ & $\begin{array}{r}.2367876 \\
58000000\end{array}$ & $\begin{array}{r}.54212673 \\
2000000\end{array}$ & $\begin{array}{r}.1130412 \\
38000000\end{array}$ & $\begin{array}{r}.0023544 \\
79420000\end{array}$ & $\begin{array}{r}.4712208 \\
37000000\end{array}$ & $\begin{array}{r}.0000000 \\
00000000\end{array}$ & $\begin{array}{r}2.0000000 \\
00000000\end{array}$ \\
\hline $\begin{array}{l}\text { Tokeni } \\
\text { sm2 } \\
(x<=.20 \\
)\end{array}$ & 4 & $\begin{array}{r}.1740441 \\
21000000\end{array}$ & $\begin{array}{r}.08547034 \\
6600000\end{array}$ & $\begin{array}{r}.0427351 \\
73300000\end{array}$ & $\begin{array}{r}.0380417 \\
26800000\end{array}$ & $\begin{array}{r}.3100465 \\
15000000\end{array}$ & $\begin{array}{r}.1030927 \\
84000000\end{array}$ & $\begin{array}{r}.28032619 \\
8000000\end{array}$ \\
\hline $\begin{array}{l}\text { Critical } \\
\text { Mass } \\
(.20<x< \\
=.50)\end{array}$ & $\begin{array}{l}3 \\
8\end{array}$ & $\begin{array}{r}.5206513 \\
73000000\end{array}$ & $\begin{array}{r}1.2169041 \\
59000000\end{array}$ & $\begin{array}{r}.1974079 \\
22000000\end{array}$ & $\begin{array}{r}.1206649 \\
30000000\end{array}$ & $\begin{array}{r}.9206378 \\
17000000\end{array}$ & $\begin{array}{r}.0000000 \\
00000000\end{array}$ & $\begin{array}{r}6.2611806 \\
80000001\end{array}$ \\
\hline $\begin{array}{l}\text { Oversa } \\
\text { turation } \\
(.50<x)\end{array}$ & 8 & $\begin{array}{r}.1390594 \\
92000000\end{array}$ & $\begin{array}{r}12495116 \\
5000000\end{array}$ & $\begin{array}{r}.0441769 \\
08000000\end{array}$ & $\begin{array}{r}.0345977 \\
04000000\end{array}$ & $\begin{array}{r}.2435212 \\
80000000\end{array}$ & $\begin{array}{r}.0000000 \\
00000000\end{array}$ & $\begin{array}{r}.38610038 \\
6000000\end{array}$ \\
\hline Total & $\begin{array}{l}1 \\
0 \\
8\end{array}$ & $\begin{array}{r}.2944256 \\
72000000\end{array}$ & $\begin{array}{r}.83169738 \\
6000000\end{array}$ & $\begin{array}{r}.0800301 \\
18200000\end{array}$ & $\begin{array}{r}.1357752 \\
96000000\end{array}$ & $\begin{array}{r}.4530760 \\
47000000\end{array}$ & $\begin{array}{r}.0000000 \\
00000000\end{array}$ & $\begin{array}{r}6.2611806 \\
80000001\end{array}$ \\
\hline
\end{tabular}

ANOVA

\begin{tabular}{lr|r|r|r|r} 
perc_blackpol & \multicolumn{1}{l}{ Sum of Squares } & df & Mean Square & F & Sig. \\
\hline Between Groups & 3.151 & 4 & .788 & 1.145 & .340 \\
\hline Within Groups & 70.863 & 103 & .688 & & \\
\hline Total & 74.014 & 107 & & & \\
\hline
\end{tabular}

\section{Means Plots}




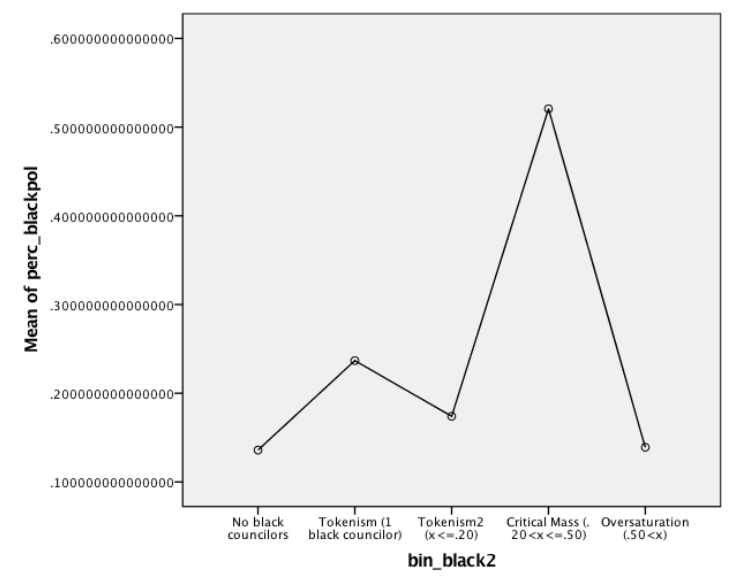

Oneway

\section{Descriptives}

\begin{tabular}{|c|c|c|c|c|c|c|c|c|}
\hline & \multirow[b]{2}{*}{$\mathrm{N}$} & \multirow[b]{2}{*}{ Mean } & \multirow[b]{2}{*}{$\begin{array}{c}\text { Std. } \\
\text { Deviation }\end{array}$} & \multirow[b]{2}{*}{ Std. Error } & \multicolumn{2}{|c|}{$\begin{array}{l}95 \% \text { Confidence } \\
\text { Interval for Mean }\end{array}$} & \multirow[b]{2}{*}{ Minimum } & \multirow[b]{2}{*}{ Maximum } \\
\hline & & & & & $\begin{array}{l}\text { Lower } \\
\text { Bound }\end{array}$ & $\begin{array}{l}\text { Upper } \\
\text { Bound }\end{array}$ & & \\
\hline No & 3 & .1359557 & .52787596 & .0892273 & - & .3172875 & .0000000 & 2.9661016 \\
\hline $\begin{array}{l}\text { black } \\
\text { council } \\
\text { ors }\end{array}$ & 5 & 66000000 & 8000000 & 24000000 & $\begin{array}{r}.0453759 \\
73700000\end{array}$ & 05000000 & 00000000 & 95000000 \\
\hline Tokeni & 2 & .2193675 & .49257692 & .0930882 & .0283662 & .4103689 & .0000000 & 2.0000000 \\
\hline $\begin{array}{l}\text { sm } \\
(x<=.20 \\
\text { OR } \\
\text { only } 1 \\
\text { black } \\
\text { council } \\
\text { or) }\end{array}$ & 8 & 94000000 & 6000000 & 89100000 & 01300000 & 86000000 & 00000000 & 00000000 \\
\hline
\end{tabular}




\begin{tabular}{|c|c|c|c|c|c|c|c|c|}
\hline Critical & 3 & .5347230 & 1.2305515 & .2023014 & .1244367 & .9450093 & .0000000 & 6.2611806 \\
\hline $\begin{array}{l}\text { Mass } \\
(.20<x< \\
=.50)\end{array}$ & 7 & 32000000 & 68000000 & 32000000 & 12000000 & 52000000 & 00000000 & 80000001 \\
\hline $\begin{array}{l}\text { Oversa } \\
\text { turation } \\
(.50<x)\end{array}$ & 8 & $\begin{array}{r}.1390594 \\
92000000\end{array}$ & $\begin{array}{r}.12495116 \\
5000000\end{array}$ & $\begin{array}{r}.0441769 \\
08000000\end{array}$ & $\begin{array}{r}.0345977 \\
04000000\end{array}$ & $\begin{array}{r}.2435212 \\
80000000\end{array}$ & $\begin{array}{r}.0000000 \\
00000000\end{array}$ & $\begin{array}{r}.38610038 \\
6000000\end{array}$ \\
\hline Total & $\begin{array}{l}1 \\
0 \\
8\end{array}$ & $\begin{array}{r}.2944256 \\
72000000\end{array}$ & $\begin{array}{r}.83169738 \\
6000000\end{array}$ & $\begin{array}{r}.0800301 \\
18200000\end{array}$ & $\begin{array}{r}.1357752 \\
96000000\end{array}$ & $\begin{array}{r}.4530760 \\
47000000\end{array}$ & $\begin{array}{r}.0000000 \\
00000000\end{array}$ & $\begin{array}{r}6.2611806 \\
80000001\end{array}$ \\
\hline
\end{tabular}

ANOVA

\begin{tabular}{lr|r|r|r|r} 
perc_blackpol & \multicolumn{1}{l}{ Sum of Squares } & df & Mean Square & F & \multicolumn{1}{c}{ Sig. } \\
\hline Between Groups & 3.366 & 3 & 1.122 & 1.652 & .182 \\
\hline Within Groups & 70.648 & 104 & .679 & & \\
\hline Total & 74.014 & 107 & & & \\
\hline
\end{tabular}

\section{Means Plots}

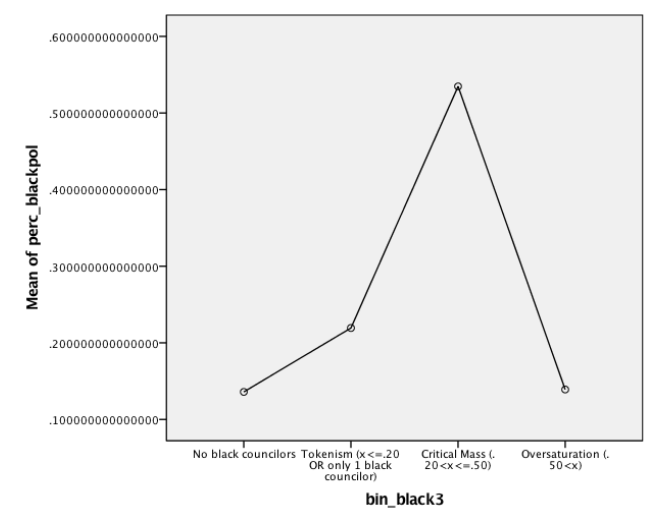




\section{Oneway}

\section{Descriptives}

perc_blackpol

\begin{tabular}{|c|c|c|c|c|c|c|c|c|}
\hline \\
\hline & \multirow[b]{2}{*}{$\mathrm{N}$} & \multirow[b]{2}{*}{ Mean } & \multirow[b]{2}{*}{$\begin{array}{c}\text { Std. } \\
\text { Deviation }\end{array}$} & \multirow[b]{2}{*}{ Std. Error } & \multicolumn{2}{|c|}{$\begin{array}{l}95 \% \text { Confidence } \\
\text { Interval for Mean }\end{array}$} & \multirow[b]{2}{*}{ Minimum } & \multirow[b]{2}{*}{ Maximum } \\
\hline & & & & & $\begin{array}{l}\text { Lower } \\
\text { Bound }\end{array}$ & $\begin{array}{l}\text { Upper } \\
\text { Bound }\end{array}$ & & \\
\hline No & 3 & .1359557 & .52787596 & .0892273 & - & .31728750 & .0000000 & 2.9661016 \\
\hline $\begin{array}{l}\text { black } \\
\text { council } \\
\text { ors }\end{array}$ & 5 & 66000000 & 8000000 & 24000000 & $\begin{array}{r}.0453759 \\
73700000\end{array}$ & 5000000 & 00000000 & 95000000 \\
\hline Tokeni & 3 & .2570830 & .50350960 & .0827764 & .0892045 & .42496149 & .0000000 & 2.0000000 \\
\hline $\begin{array}{l}\text { sm } \\
\text { ( } x<=.25 \\
\text { OR } \\
\text { only } 1 \\
\text { black } \\
\text { council } \\
\text { or) }\end{array}$ & 7 & 35000000 & 8000000 & 69600000 & 73700000 & 6000000 & 00000000 & 00000000 \\
\hline Critical & 2 & .5862490 & 1.3850479 & .2617494 & .0491834 & 1.1233145 & .0000000 & 6.2611806 \\
\hline $\begin{array}{l}\text { Mass } \\
(.25<x< \\
=.50)\end{array}$ & 8 & 18000000 & 60000000 & 61000000 & 86300000 & 50000000 & 00000000 & 80000001 \\
\hline Oversa & 8 & .1390594 & .12495116 & .0441769 & .0345977 & .24352128 & .0000000 & .38610038 \\
\hline $\begin{array}{l}\text { turation } \\
(.50<x)\end{array}$ & & 92000000 & 5000000 & 08000000 & 04000000 & 0000000 & 00000000 & 6000000 \\
\hline Total & 1 & .2944256 & .83169738 & .0800301 & .1357752 & .45307604 & .0000000 & 6.2611806 \\
\hline & 0 & 72000000 & 6000000 & 18200000 & 96000000 & 7000000 & 00000000 & 80000001 \\
\hline & 8 & & & & & & & \\
\hline
\end{tabular}




\section{ANOVA}

\begin{tabular}{lr|r|r|r|r} 
perc_blackpol & \multicolumn{1}{l}{ Sum of Squares } & df & Mean Square & F & \multicolumn{1}{c}{ Sig. } \\
\hline Between Groups & 3.508 & 3 & 1.169 & 1.725 & .166 \\
\hline Within Groups & 70.506 & 104 & .678 & & \\
\hline Total & 74.014 & 107 & & & \\
\hline
\end{tabular}

\section{Means Plots}

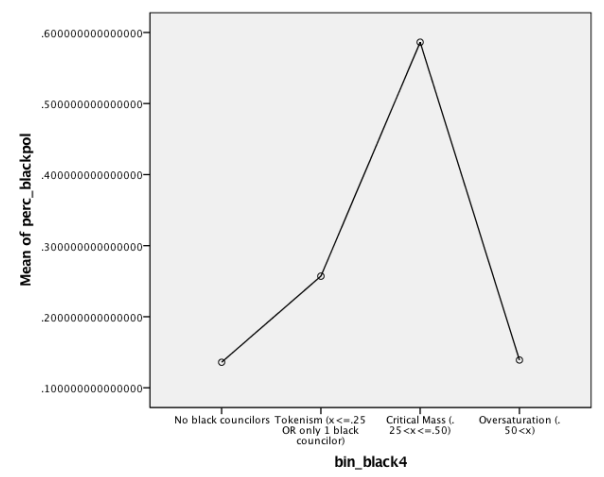

\section{Oneway}

\section{Descriptives}

perc_blackpol

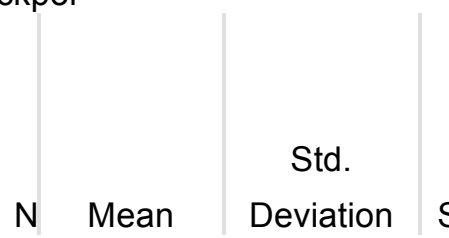

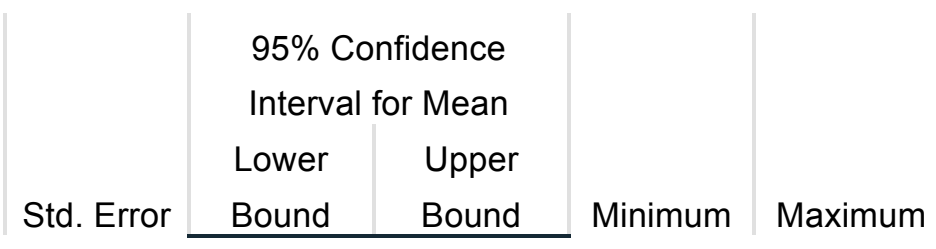




\begin{tabular}{|c|c|c|c|c|c|c|c|c|}
\hline $\begin{array}{l}\text { No } \\
\text { black } \\
\text { council } \\
\text { ors }\end{array}$ & $\begin{array}{l}3 \\
5\end{array}$ & $\begin{array}{r}.1359557 \\
66000000\end{array}$ & $\begin{array}{r}.52787596 \\
8000000\end{array}$ & $\begin{array}{r}.0892273 \\
24000000\end{array}$ & $\begin{array}{r}- \\
.0453759 \\
73700000\end{array}$ & $\begin{array}{r}.31728750 \\
5000000\end{array}$ & $\begin{array}{r}.0000000 \\
00000000\end{array}$ & $\begin{array}{r}2.9661016 \\
95000000\end{array}$ \\
\hline $\begin{array}{l}\text { Tokeni } \\
\text { sm } \\
\text { (x<=.25 } \\
\text { AND } \\
\text { more } \\
\text { than } \\
\text { one } \\
\text { black } \\
\text { council } \\
\text { or) }\end{array}$ & $\begin{array}{l}1 \\
3\end{array}$ & $\begin{array}{r}.3127658 \\
59000000\end{array}$ & $\begin{array}{r}.46053281 \\
7000000\end{array}$ & $\begin{array}{r}.1277288 \\
22000000\end{array}$ & $\begin{array}{r}.0344686 \\
62500000\end{array}$ & $\begin{array}{r}.59106305 \\
5000000\end{array}$ & $\begin{array}{r}.0000000 \\
00000000\end{array}$ & $\begin{array}{r}1.5723270 \\
44000000\end{array}$ \\
\hline $\begin{array}{l}\text { Critical } \\
\text { Mass } \\
(.25<x< \\
=.50)\end{array}$ & $\begin{array}{l}2 \\
8\end{array}$ & $\begin{array}{r}.5862490 \\
18000000\end{array}$ & $\begin{array}{r}1.3850479 \\
60000000\end{array}$ & $\begin{array}{r}.2617494 \\
61000000\end{array}$ & $\begin{array}{r}.0491834 \\
86300000\end{array}$ & $\begin{array}{r}1.1233145 \\
50000000\end{array}$ & $\begin{array}{r}.0000000 \\
00000000\end{array}$ & $\begin{array}{r}6.2611806 \\
80000001\end{array}$ \\
\hline $\begin{array}{l}\text { Oversa } \\
\text { turation } \\
(.50<x)\end{array}$ & 8 & $\begin{array}{r}.1390594 \\
92000000\end{array}$ & $\begin{array}{r}.12495116 \\
5000000\end{array}$ & $\begin{array}{r}.0441769 \\
08000000\end{array}$ & $\begin{array}{r}.0345977 \\
04000000\end{array}$ & $\begin{array}{r}.24352128 \\
0000000\end{array}$ & $\begin{array}{r}.0000000 \\
00000000\end{array}$ & $\begin{array}{r}.38610038 \\
6000000\end{array}$ \\
\hline Total & $\begin{array}{l}8 \\
4 \\
\end{array}$ & $\begin{array}{r}.3137125 \\
76000000 \\
\end{array}$ & $\begin{array}{r}.90082910 \\
2000000 \\
\end{array}$ & $\begin{array}{r}.0982885 \\
13000000 \\
\end{array}$ & $\begin{array}{r}.1182206 \\
77000000\end{array}$ & $\begin{array}{r}.50920447 \\
6000000 \\
\end{array}$ & $\begin{array}{r}.0000000 \\
00000000\end{array}$ & $\begin{array}{r}6.2611806 \\
80000001\end{array}$ \\
\hline
\end{tabular}

\section{ANOVA}

perc_blackpol

\begin{tabular}{lr|r|r|r|r} 
& Sum of Squares & \multicolumn{1}{c|}{ df } & Mean Square & F & \multicolumn{1}{c}{ Sig. } \\
\hline Between Groups & 3.430 & 3 & 1.143 & 1.431 & .240 \\
\hline Within Groups & 63.924 & 80 & .799 & & \\
\hline Total & 67.354 & 83 & & & \\
\hline
\end{tabular}

\section{Means Plots}




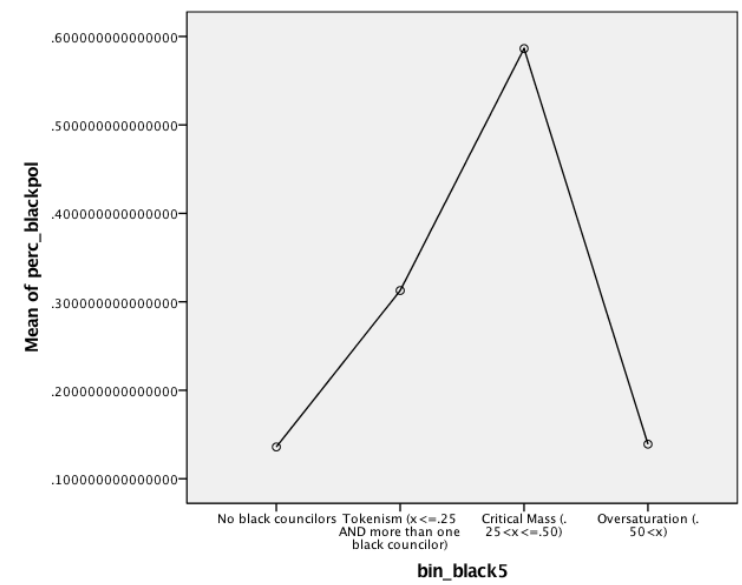

Oneway

Descriptives

\begin{tabular}{|c|c|c|c|c|c|c|c|c|}
\hline & \multirow[b]{2}{*}{$\mathrm{N}$} & \multirow[b]{2}{*}{ Mean } & \multirow[b]{2}{*}{$\begin{array}{c}\text { Std. } \\
\text { Deviation }\end{array}$} & \multirow[b]{2}{*}{ Std. Error } & \multicolumn{2}{|c|}{$\begin{array}{l}95 \% \text { Confidence } \\
\text { Interval for Mean }\end{array}$} & \multirow[b]{2}{*}{ Minimum } & \multirow[b]{2}{*}{ Maximum } \\
\hline & & & & & $\begin{array}{l}\text { Lower } \\
\text { Bound } \\
\end{array}$ & $\begin{array}{l}\text { Upper } \\
\text { Bound } \\
\end{array}$ & & \\
\hline No & 3 & .1359557 & .52787596 & .0892273 & - & .3172875 & .0000000 & 2.9661016 \\
\hline $\begin{array}{l}\text { black } \\
\text { council } \\
\text { ors }\end{array}$ & 5 & 66000000 & 8000000 & 24000000 & $\begin{array}{r}.0453759 \\
73700000\end{array}$ & 05000000 & 00000000 & 95000000 \\
\hline Tokeni & 3 & .2570830 & .50350960 & .0827764 & .0892045 & .4249614 & .0000000 & 2.0000000 \\
\hline $\begin{array}{l}\text { sm } \\
(x<=.25 \\
\text { or } 1 \\
\text { black } \\
\text { council } \\
\text { or) }\end{array}$ & 7 & 35000000 & 8000000 & 69600000 & 73700000 & 96000000 & 00000000 & 00000000 \\
\hline
\end{tabular}




\begin{tabular}{|c|c|c|c|c|c|c|c|c|}
\hline Critical & 3 & .5247739 & 1.2817539 & .2231247 & .0702837 & .9792641 & .0000000 & 6.2611806 \\
\hline $\begin{array}{l}\text { Mass } \\
(.25<x< \\
=.60)\end{array}$ & 3 & 39000000 & 91000000 & 30000000 & 36700000 & 42000000 & 00000000 & 80000001 \\
\hline Oversa & 3 & .0699694 & .06263840 & .0361642 & - & .2255719 & .0000000 & .12082158 \\
\hline turation & & 82200000 & 3200000 & 98900000 & .0856329 & 02000000 & 00000000 & 7000000 \\
\hline$(.60<x)$ & & & & & 37400000 & & & \\
\hline Total & 1 & .2944256 & .83169738 & .0800301 & .1357752 & .4530760 & .0000000 & 6.2611806 \\
\hline & 0 & 72000000 & 6000000 & 18200000 & 96000000 & 47000000 & 00000000 & 80000001 \\
\hline & 8 & & & & & & & \\
\hline
\end{tabular}

ANOVA

\begin{tabular}{lr|r|r|r|r} 
perc_blackpol & \multicolumn{1}{l}{ Sum of Squares } & df & Mean Square & F & \multicolumn{1}{c}{ Sig. } \\
\hline Between Groups & 2.833 & 3 & .944 & 1.380 & .253 \\
\hline Within Groups & 71.181 & 104 & .684 & & \\
\hline Total & 74.014 & 107 & & & \\
\hline
\end{tabular}

\section{Means Plots}

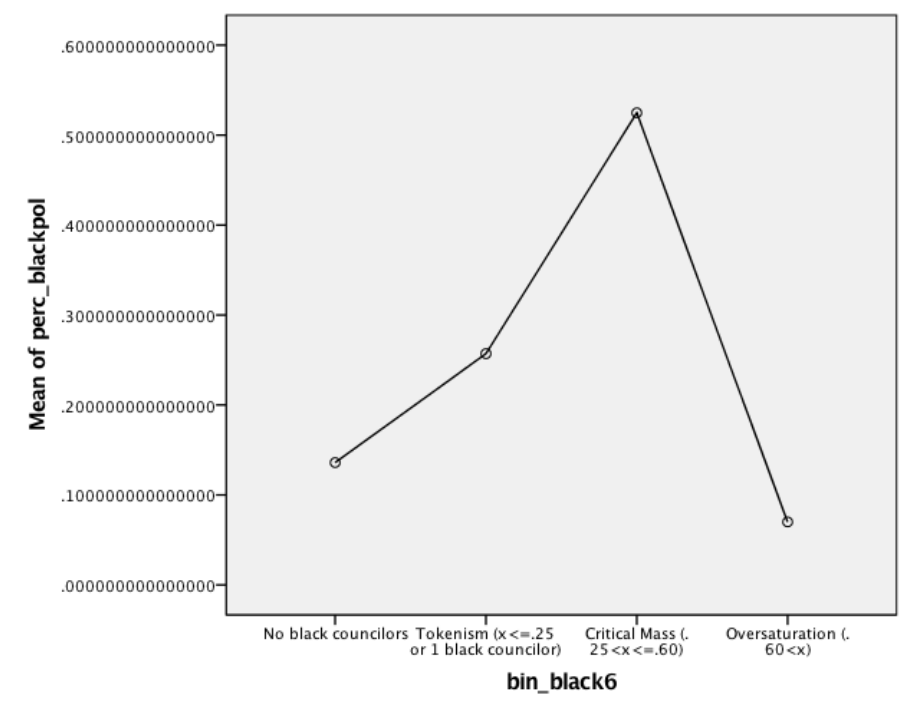




\section{Latino ANOVAs}

\section{Oneway}

\section{Descriptives}

\begin{tabular}{|c|c|c|c|c|c|c|c|c|}
\hline & \multirow[b]{2}{*}{$\mathrm{N}$} & \multirow[b]{2}{*}{ Mean } & \multirow[b]{2}{*}{$\begin{array}{c}\text { Std. } \\
\text { Deviation }\end{array}$} & \multirow[b]{2}{*}{ Std. Error } & \multicolumn{2}{|c|}{$\begin{array}{l}95 \% \text { Confidence } \\
\text { Interval for Mean }\end{array}$} & \multirow[b]{2}{*}{ Minimum } & \multirow[b]{2}{*}{ Maximum } \\
\hline & & & & & $\begin{array}{l}\text { Lower } \\
\text { Bound }\end{array}$ & $\begin{array}{l}\text { Upper } \\
\text { Bound }\end{array}$ & & \\
\hline No & 5 & .1133144 & .3083388 & .0415764 & .0299587 & .19667011 & .0000000 & 1.6304347 \\
\hline $\begin{array}{l}\text { Latino } \\
\text { council } \\
\text { ors }\end{array}$ & 5 & 37000000 & 93000000 & 07800000 & 58300000 & 6000000 & 00000000 & 83000000 \\
\hline $\begin{array}{l}\text { Tokeni } \\
\text { sm1 } \\
\text { (only } 1 \\
\text { Latino } \\
\text { council } \\
\text { or) }\end{array}$ & $\begin{array}{l}2 \\
7\end{array}$ & $\begin{array}{r}.2393243 \\
06000000\end{array}$ & $\begin{array}{r}.4924636 \\
67000000\end{array}$ & $\begin{array}{r}.0947746 \\
76900000\end{array}$ & $\begin{array}{r}.0445121 \\
67300000\end{array}$ & $\begin{array}{r}.43413644 \\
4000000\end{array}$ & $\begin{array}{r}.0000000 \\
00000000\end{array}$ & $\begin{array}{r}1.8867924 \\
53000000\end{array}$ \\
\hline $\begin{array}{l}\text { Tokeni } \\
\text { sm2 } \\
(x<=.30 \\
)\end{array}$ & $\begin{array}{l}1 \\
4\end{array}$ & $\begin{array}{r}.2319320 \\
13000000\end{array}$ & $\begin{array}{r}.2828122 \\
26000000\end{array}$ & $\begin{array}{r}.0755847 \\
46700000\end{array}$ & $\begin{array}{r}.0686410 \\
95600000\end{array}$ & $\begin{array}{r}.39522293 \\
1000000\end{array}$ & $\begin{array}{r}.0000000 \\
00000000\end{array}$ & $\begin{array}{r}1.0796221 \\
32000000\end{array}$ \\
\hline $\begin{array}{l}\text { Critical } \\
\text { Mass } \\
(.30<x< \\
=.50)\end{array}$ & 7 & $\begin{array}{r}.3121379 \\
25000000\end{array}$ & $\begin{array}{r}.3711055 \\
49000000\end{array}$ & $\begin{array}{r}.1402647 \\
13000000\end{array}$ & $\begin{array}{r}- \\
.0310774 \\
64200000\end{array}$ & $\begin{array}{r}.65535331 \\
5000000\end{array}$ & $\begin{array}{r}.0000000 \\
00000000\end{array}$ & $\begin{array}{r}.96153846 \\
2000000\end{array}$ \\
\hline
\end{tabular}




\begin{tabular}{|c|c|c|c|c|c|c|c|c|}
\hline $\begin{array}{l}\text { Oversa } \\
\text { turation } \\
(.50<x)\end{array}$ & 5 & $\begin{array}{r}.6383210 \\
88000000\end{array}$ & $\begin{array}{r}.9490297 \\
33000000\end{array}$ & $\begin{array}{r}.4244189 \\
99000000\end{array}$ & $\begin{array}{r}.5400549 \\
64000000\end{array}$ & $\begin{array}{r}1.8166971 \\
41000000\end{array}$ & $\begin{array}{r}.0000000 \\
00000000\end{array}$ & $\begin{array}{r}2.1186440 \\
68000000\end{array}$ \\
\hline \multirow[t]{3}{*}{ Total } & 1 & .1973858 & .4149701 & .0399305 & .1182282 & .27654342 & .0000000 & 2.1186440 \\
\hline & 0 & 28000000 & 17000000 & 18100000 & 33000000 & 3000000 & 00000000 & 68000000 \\
\hline & 8 & & & & & & & \\
\hline
\end{tabular}

\section{ANOVA}

\begin{tabular}{lr|r|r|r|r} 
perc_latinopol & \multicolumn{1}{l}{ Sum of Squares } & df & Mean Square & F & \multicolumn{1}{c}{ Sig. } \\
\hline Between Groups & 1.517 & 4 & .379 & 2.311 & .063 \\
\hline Within Groups & 16.908 & 103 & .164 & & \\
\hline Total & 18.425 & 107 & & & \\
\hline
\end{tabular}

\section{Means Plots}

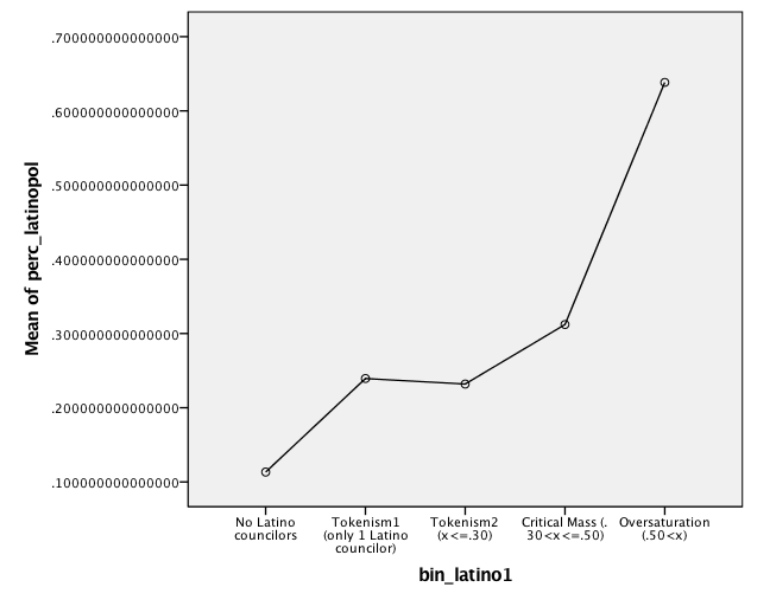

\section{Oneway}




\section{Descriptives}

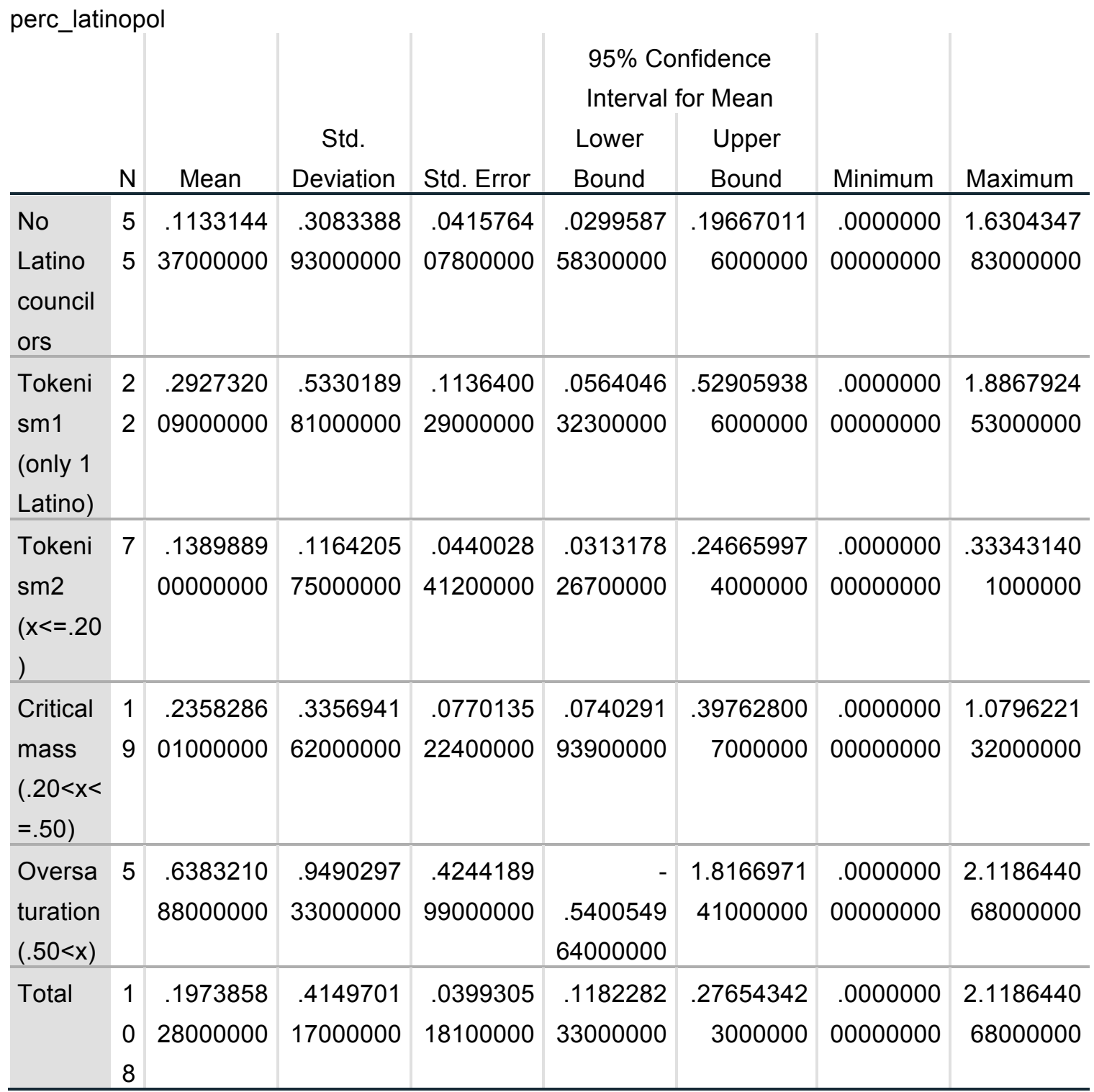

ANOVA

perc_latinopol

\begin{tabular}{lr|r|r|r|r} 
& Sum of Squares & df & Mean Square & F & \multicolumn{1}{c}{ Sig. } \\
\hline Between Groups & 1.613 & 4 & .403 & 2.470 & .049 \\
\hline Within Groups & 16.813 & 103 & .163 & & \\
\hline Total & 18.425 & 107 & & & \\
\hline
\end{tabular}




\section{Means Plots}

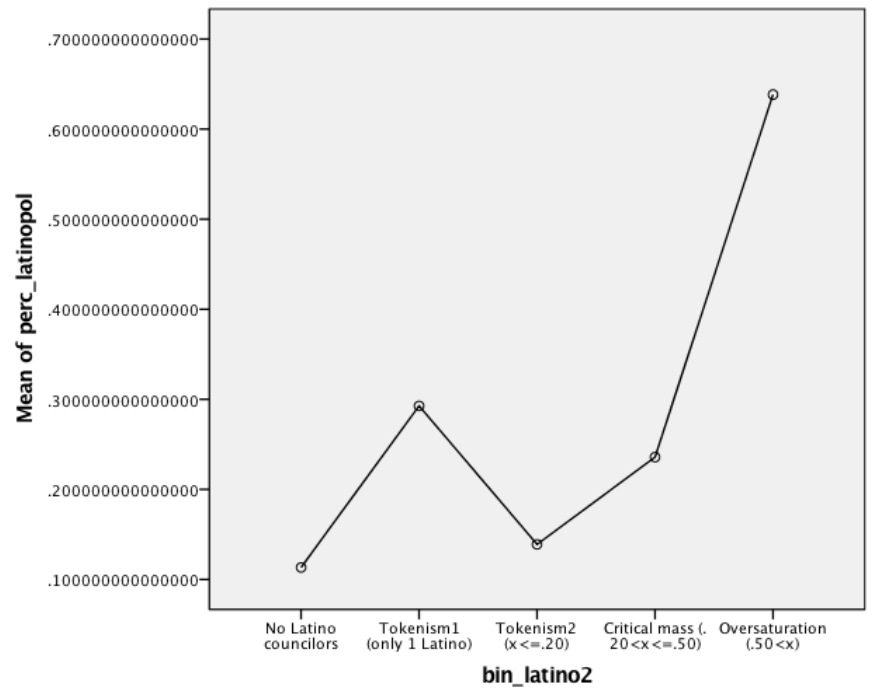

Oneway

\section{Descriptives}

perc_latinopol

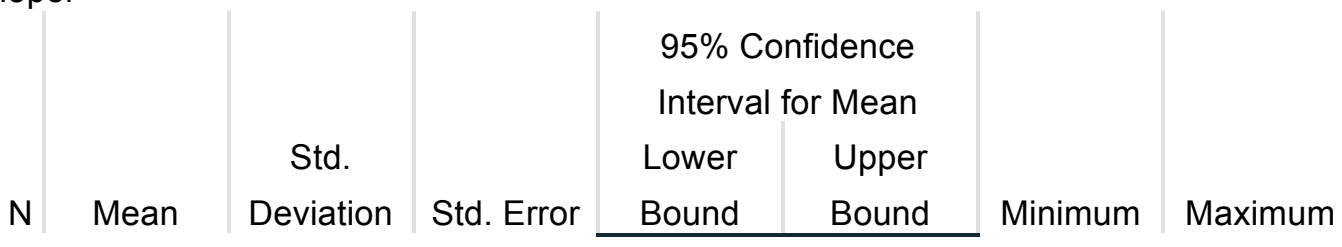




\begin{tabular}{|c|c|c|c|c|c|c|c|c|}
\hline $\begin{array}{l}\text { No } \\
\text { Latino } \\
\text { council } \\
\text { ors }\end{array}$ & $\begin{array}{l}5 \\
5\end{array}$ & $\begin{array}{r}.1133144 \\
37000000\end{array}$ & $\begin{array}{r}.3083388 \\
93000000\end{array}$ & $\begin{array}{r}.0415764 \\
07800000\end{array}$ & $\begin{array}{r}.0299587 \\
58300000\end{array}$ & $\begin{array}{r}19667011 \\
6000000\end{array}$ & $\begin{array}{r}.0000000 \\
00000000\end{array}$ & $\begin{array}{r}1.6304347 \\
83000000\end{array}$ \\
\hline $\begin{array}{l}\text { Tokeni } \\
\text { sm } \\
\text { ( } x<=.20 \\
\text { or only } \\
1 \\
\text { Latino } \\
\text { council } \\
\text { or) }\end{array}$ & $\begin{array}{l}3 \\
4\end{array}$ & $\begin{array}{r}.2186670 \\
16000000\end{array}$ & $\begin{array}{r}.4418561 \\
50000000\end{array}$ & $\begin{array}{r}.0757777 \\
04600000\end{array}$ & $\begin{array}{r}.0644961 \\
17100000\end{array}$ & $\begin{array}{r}.37283791 \\
6000000\end{array}$ & $\begin{array}{r}.0000000 \\
00000000\end{array}$ & $\begin{array}{r}1.8867924 \\
53000000\end{array}$ \\
\hline $\begin{array}{l}\text { Critical } \\
\text { Mass } \\
(.20<x< \\
=.50)\end{array}$ & $\begin{array}{l}1 \\
4\end{array}$ & $\begin{array}{r}.3185065 \\
26000000\end{array}$ & $\begin{array}{r}.3578137 \\
89000000\end{array}$ & $\begin{array}{r}.0956297 \\
57700000\end{array}$ & $\begin{array}{r}.1119109 \\
95000000\end{array}$ & $\begin{array}{r}.52510205 \\
7000000\end{array}$ & $\begin{array}{r}.0000000 \\
00000000\end{array}$ & $\begin{array}{r}1.0796221 \\
32000000\end{array}$ \\
\hline $\begin{array}{l}\text { Oversa } \\
\text { turation } \\
(.50<x)\end{array}$ & 5 & $\begin{array}{r}.6383210 \\
88000000\end{array}$ & $\begin{array}{r}.9490297 \\
33000000\end{array}$ & $\begin{array}{r}.4244189 \\
99000000\end{array}$ & $\begin{array}{r}- \\
.5400549 \\
64000000 \\
\end{array}$ & $\begin{array}{r}1.8166971 \\
41000000\end{array}$ & $\begin{array}{r}.0000000 \\
00000000\end{array}$ & $\begin{array}{r}2.1186440 \\
68000000\end{array}$ \\
\hline Total & $\begin{array}{l}1 \\
0 \\
8\end{array}$ & $\begin{array}{r}.1973858 \\
28000000\end{array}$ & $\begin{array}{r}.4149701 \\
17000000\end{array}$ & $\begin{array}{r}.0399305 \\
18100000\end{array}$ & $\begin{array}{r}.1182282 \\
33000000\end{array}$ & $\begin{array}{r}.27654342 \\
3000000\end{array}$ & $\begin{array}{r}.0000000 \\
00000000\end{array}$ & $\begin{array}{r}2.1186440 \\
68000000\end{array}$ \\
\hline
\end{tabular}

ANOVA

perc_latinopol

\begin{tabular}{lr|r|r|r|r} 
& Sum of Squares & \multicolumn{1}{c|}{ df } & Mean Square & F & \multicolumn{1}{c}{ Sig. } \\
\hline Between Groups & 1.582 & 3 & .527 & 3.255 & .025 \\
\hline Within Groups & 16.844 & 104 & .162 & & \\
\hline Total & 18.425 & 107 & & & \\
\hline
\end{tabular}

\section{Means Plots}




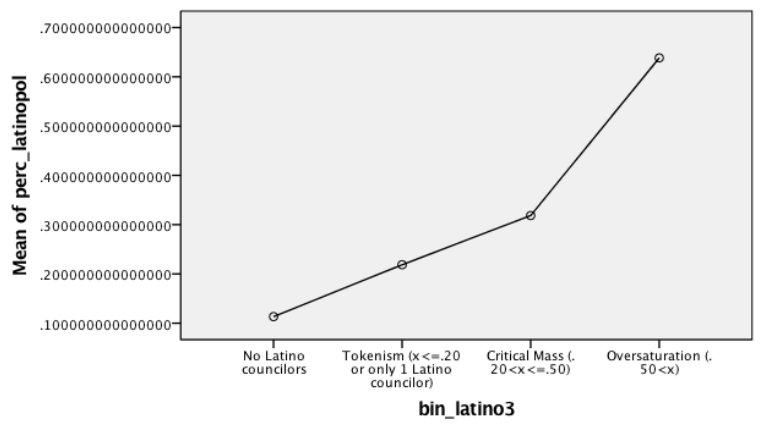

Oneway

perc_latinopol

\section{Descriptives}

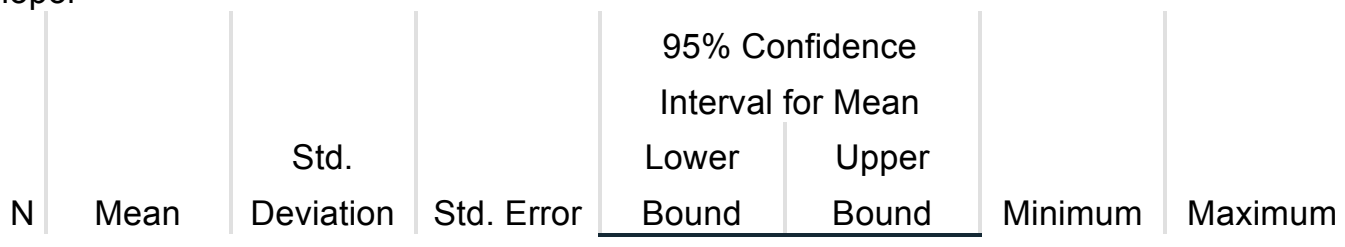




\begin{tabular}{|c|c|c|c|c|c|c|c|c|}
\hline $\begin{array}{l}\text { No } \\
\text { Latino } \\
\text { council } \\
\text { ors }\end{array}$ & $\begin{array}{l}5 \\
5\end{array}$ & $\begin{array}{r}.1133144 \\
37000000\end{array}$ & $\begin{array}{r}.3083388 \\
93000000\end{array}$ & $\begin{array}{r}.0415764 \\
07800000\end{array}$ & $\begin{array}{r}.0299587 \\
58300000\end{array}$ & $\begin{array}{r}19667011 \\
6000000\end{array}$ & $\begin{array}{r}.0000000 \\
00000000\end{array}$ & $\begin{array}{r}1.6304347 \\
83000000\end{array}$ \\
\hline $\begin{array}{l}\text { Tokeni } \\
\text { sm } \\
\text { ( } x<=.25 \\
\text { or only } \\
1 \\
\text { Latino } \\
\text { council } \\
\text { or) }\end{array}$ & $\begin{array}{l}3 \\
8\end{array}$ & $\begin{array}{r}.2310112 \\
96000000\end{array}$ & $\begin{array}{r}.4425744 \\
76000000\end{array}$ & $\begin{array}{r}.0717950 \\
60500000\end{array}$ & $\begin{array}{r}.0855406 \\
85200000\end{array}$ & $\begin{array}{r}.37648190 \\
6000000\end{array}$ & $\begin{array}{r}.0000000 \\
00000000\end{array}$ & $\begin{array}{r}1.8867924 \\
53000000\end{array}$ \\
\hline $\begin{array}{l}\text { Critical } \\
\text { Mass } \\
(.25<x< \\
=.50)\end{array}$ & $\begin{array}{l}1 \\
0\end{array}$ & $\begin{array}{r}.3115340 \\
68000000\end{array}$ & $\begin{array}{r}.3175361 \\
63000000\end{array}$ & $\begin{array}{r}.1004137 \\
51000000\end{array}$ & $\begin{array}{r}.0843823 \\
81100000\end{array}$ & $\begin{array}{r}.53868575 \\
5000000\end{array}$ & $\begin{array}{r}.0000000 \\
00000000\end{array}$ & $\begin{array}{r}.96153846 \\
2000000\end{array}$ \\
\hline $\begin{array}{l}\text { Oversa } \\
\text { turation } \\
(.50<x)\end{array}$ & 5 & $\begin{array}{r}.6383210 \\
88000000\end{array}$ & $\begin{array}{r}.9490297 \\
33000000\end{array}$ & $\begin{array}{r}.4244189 \\
99000000\end{array}$ & $\begin{array}{r}- \\
.5400549 \\
64000000 \\
\end{array}$ & $\begin{array}{r}1.8166971 \\
41000000\end{array}$ & $\begin{array}{r}.0000000 \\
00000000\end{array}$ & $\begin{array}{r}2.1186440 \\
68000000\end{array}$ \\
\hline Total & $\begin{array}{l}1 \\
0 \\
8\end{array}$ & $\begin{array}{r}.1973858 \\
28000000\end{array}$ & $\begin{array}{r}.4149701 \\
17000000\end{array}$ & $\begin{array}{r}.0399305 \\
18100000\end{array}$ & $\begin{array}{r}.1182282 \\
33000000\end{array}$ & $\begin{array}{r}.27654342 \\
3000000\end{array}$ & $\begin{array}{r}.0000000 \\
00000000\end{array}$ & $\begin{array}{r}2.1186440 \\
68000000\end{array}$ \\
\hline
\end{tabular}

ANOVA

perc_latinopol

\begin{tabular}{lr|r|r|r|r} 
& Sum of Squares & \multicolumn{1}{c|}{ df } & Mean Square & F & \multicolumn{1}{c}{ Sig. } \\
\hline Between Groups & 1.534 & 3 & .511 & 3.149 & .028 \\
\hline Within Groups & 16.891 & 104 & .162 & & \\
\hline Total & 18.425 & 107 & & & \\
\hline
\end{tabular}

\section{Means Plots}



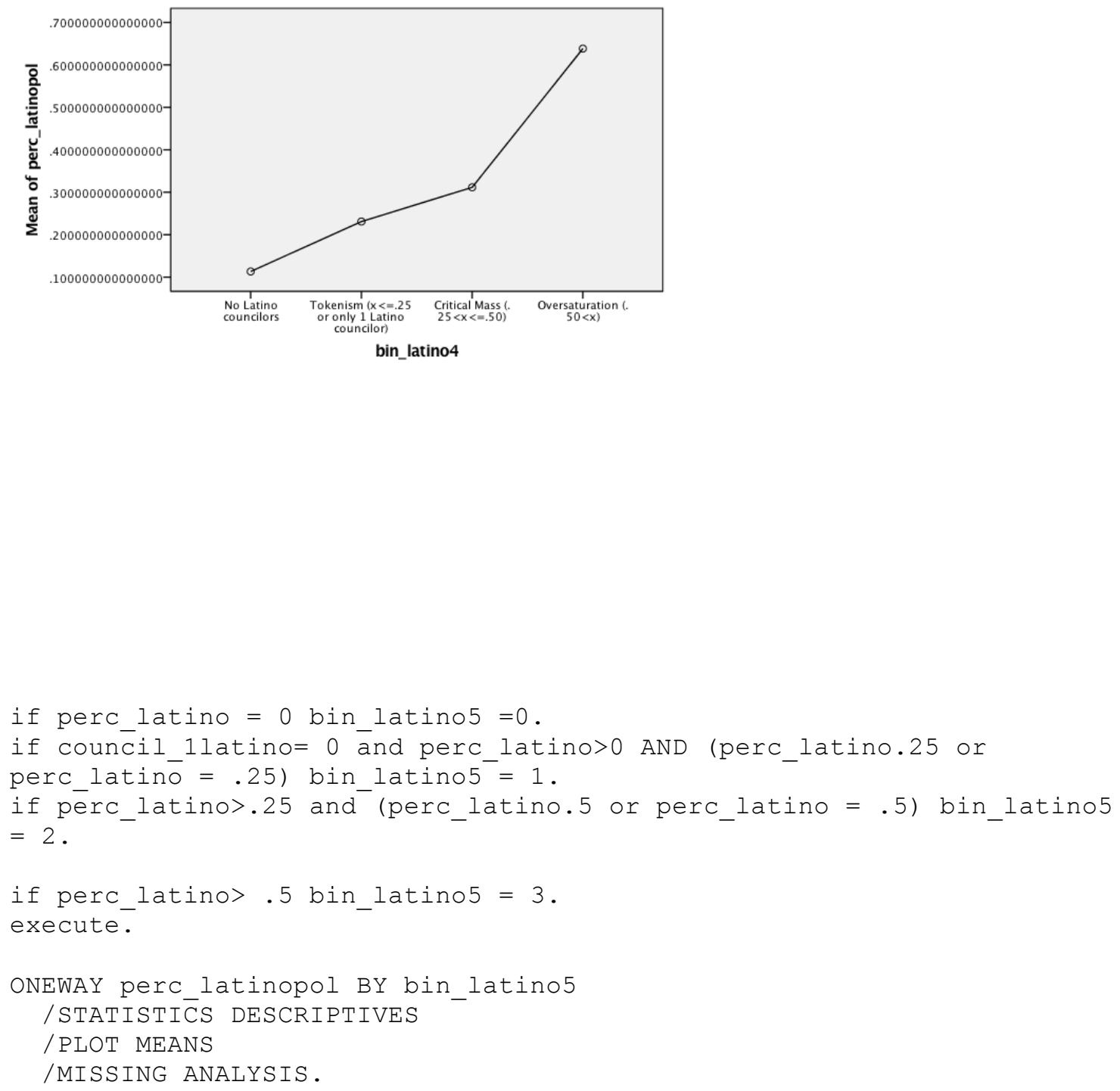

\section{Oneway}

\section{Descriptives}

perc_latinopol

\begin{tabular}{c|c|c|c|c|c} 
& Std. & & $95 \%$ Confidence & \\
$\mathrm{N} \quad$ Mean & Deviation & Std. Error & Interval for Mean & Minimum & Maximum
\end{tabular}




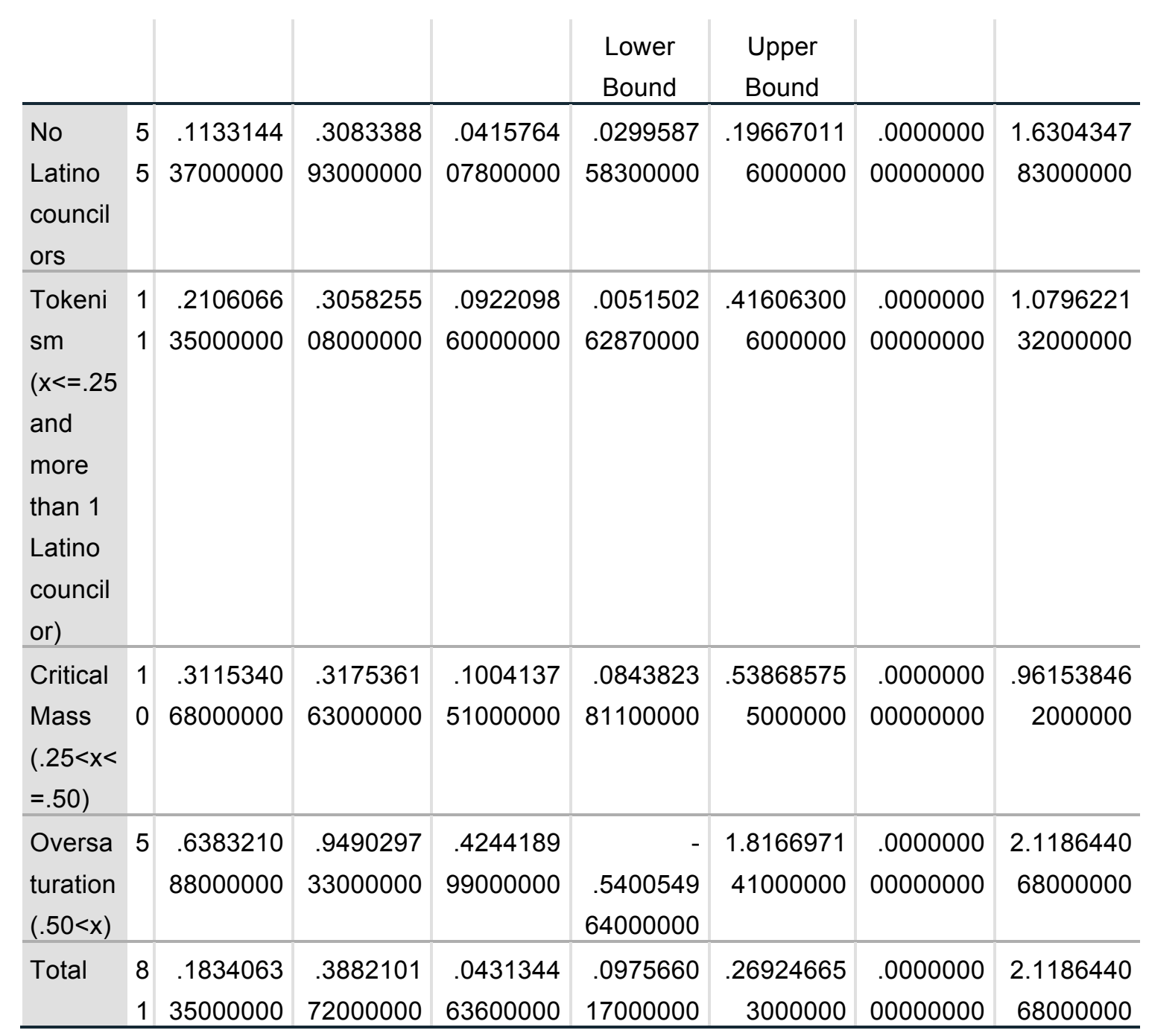

ANOVA

\begin{tabular}{lr|r|r|r|r} 
perc_latinopol & \multicolumn{2}{c}{} & & & \\
& Sum of Squares & df & Mean Square & F & \multicolumn{1}{c}{ Sig. } \\
\hline Between Groups & 1.477 & 3 & .492 & 3.584 & .018 \\
\hline Within Groups & 10.579 & 77 & .137 & & \\
\hline Total & 12.057 & 80 & & & \\
\hline
\end{tabular}

\section{Means Plots}




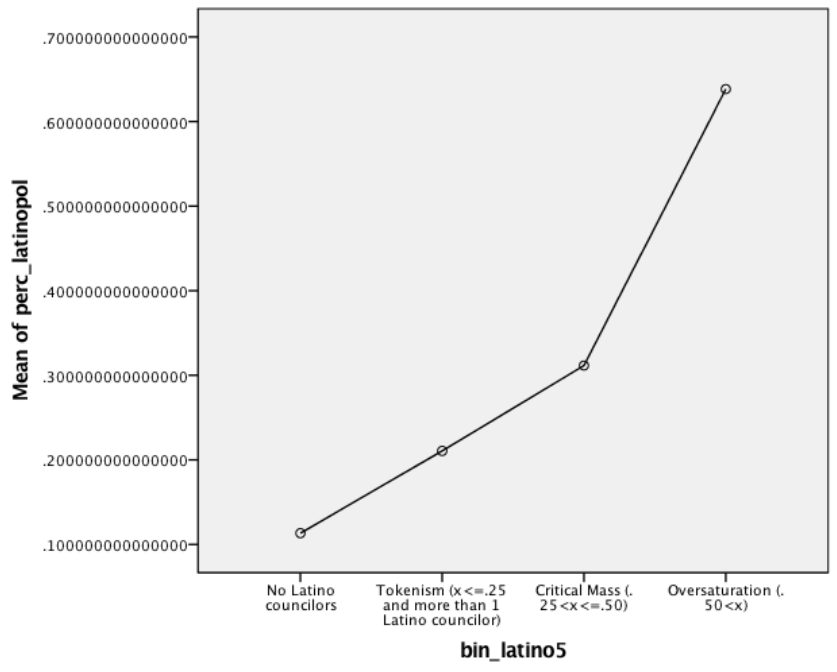

Oneway

Descriptives

\begin{tabular}{|c|c|c|c|c|c|c|c|c|}
\hline & \multirow[b]{2}{*}{$\mathrm{N}$} & \multirow[b]{2}{*}{ Mean } & \multirow[b]{2}{*}{$\begin{array}{c}\text { Std. } \\
\text { Deviation }\end{array}$} & \multirow[b]{2}{*}{ Std. Error } & \multicolumn{2}{|c|}{$\begin{array}{l}95 \% \text { Confidence } \\
\text { Interval for Mean }\end{array}$} & \multirow[b]{2}{*}{ Minimum } & \multirow[b]{2}{*}{ Maximum } \\
\hline & & & & & $\begin{array}{l}\text { Lower } \\
\text { Bound }\end{array}$ & $\begin{array}{l}\text { Upper } \\
\text { Bound } \\
\end{array}$ & & \\
\hline No & 5 & .1133144 & .3083388 & .0415764 & .0299587 & 19667011 & .0000000 & 1.6304347 \\
\hline $\begin{array}{l}\text { Latino } \\
\text { council } \\
\text { ors }\end{array}$ & 5 & 37000000 & 93000000 & 07800000 & 58300000 & 6000000 & 00000000 & 83000000 \\
\hline
\end{tabular}




\begin{tabular}{|c|c|c|c|c|c|c|c|c|}
\hline $\begin{array}{l}\text { Tokeni } \\
\text { sm } \\
\text { ( } x<=.25 \\
\text { and } \\
\text { more } \\
\text { than } 1 \\
\text { Latino } \\
\text { council } \\
\text { or) }\end{array}$ & $\begin{array}{l}3 \\
8\end{array}$ & $\begin{array}{r}.2310112 \\
96000000\end{array}$ & $\begin{array}{r}.4425744 \\
76000000\end{array}$ & $\begin{array}{r}.0717950 \\
60500000\end{array}$ & $\begin{array}{r}.0855406 \\
85200000\end{array}$ & $\begin{array}{r}.37648190 \\
6000000\end{array}$ & $\begin{array}{r}.0000000 \\
00000000\end{array}$ & $\begin{array}{r}1.8867924 \\
53000000\end{array}$ \\
\hline $\begin{array}{l}\text { Critical } \\
\text { Mass } \\
(.25<x< \\
=.60)\end{array}$ & $\begin{array}{l}1 \\
0\end{array}$ & $\begin{array}{r}.3115340 \\
68000000\end{array}$ & $\begin{array}{r}.3175361 \\
63000000\end{array}$ & $\begin{array}{r}.1004137 \\
51000000\end{array}$ & $\begin{array}{r}.0843823 \\
81100000\end{array}$ & $\begin{array}{r}.53868575 \\
5000000\end{array}$ & $\begin{array}{r}.0000000 \\
00000000\end{array}$ & $\begin{array}{r}.96153846 \\
2000000\end{array}$ \\
\hline $\begin{array}{l}\text { Oversa } \\
\text { turation } \\
(.60<x)\end{array}$ & 5 & $\begin{array}{r}.6383210 \\
88000000\end{array}$ & $\begin{array}{r}.9490297 \\
33000000\end{array}$ & $\begin{array}{r}.4244189 \\
99000000\end{array}$ & $\begin{array}{r}- \\
.5400549 \\
64000000\end{array}$ & $\begin{array}{r}1.8166971 \\
41000000\end{array}$ & $\begin{array}{r}.0000000 \\
00000000\end{array}$ & $\begin{array}{r}2.1186440 \\
68000000\end{array}$ \\
\hline Total & $\begin{array}{l}1 \\
0 \\
8\end{array}$ & $\begin{array}{r}1973858 \\
28000000\end{array}$ & $\begin{array}{r}.4149701 \\
17000000\end{array}$ & $\begin{array}{r}.0399305 \\
18100000\end{array}$ & $\begin{array}{r}.1182282 \\
33000000\end{array}$ & $\begin{array}{r}.27654342 \\
3000000\end{array}$ & $\begin{array}{r}.0000000 \\
00000000\end{array}$ & $\begin{array}{r}2.1186440 \\
68000000\end{array}$ \\
\hline
\end{tabular}

ANOVA

\begin{tabular}{lr|r|r|r|r} 
perc_latinopol & \multicolumn{1}{l}{ Sum of Squares } & df & Mean Square & F & \multicolumn{1}{c}{ Sig. } \\
\hline Between Groups & 1.534 & 3 & .511 & 3.149 & .028 \\
\hline Within Groups & 16.891 & 104 & .162 & & \\
\hline Total & 18.425 & 107 & & & \\
\hline
\end{tabular}

\section{Means Plots}




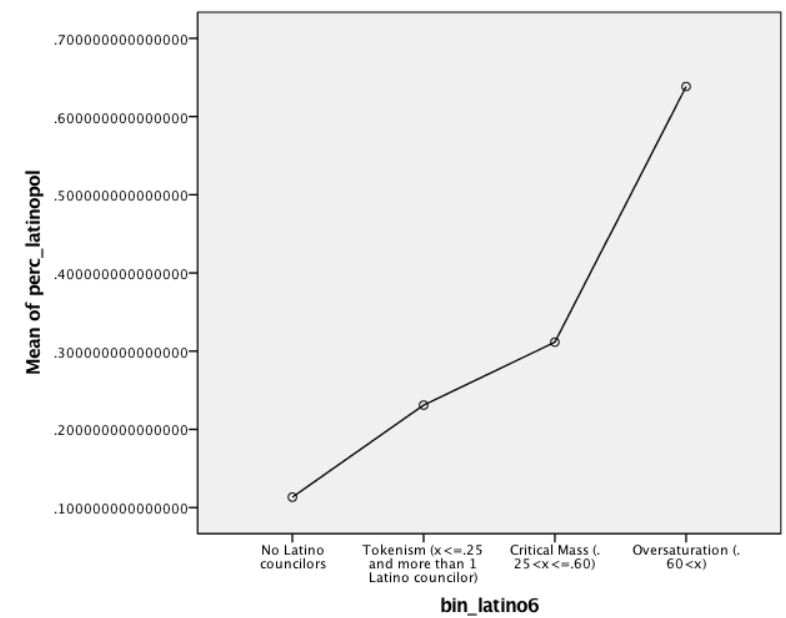

Diversity ANOVAs

\section{Oneway}

\section{Descriptives}

\begin{tabular}{|c|c|c|c|c|c|c|c|c|}
\hline & \multirow[b]{2}{*}{$\mathrm{N}$} & \multirow[b]{2}{*}{ Mean } & \multirow[b]{2}{*}{$\begin{array}{c}\text { Std. } \\
\text { Deviation }\end{array}$} & \multirow[b]{2}{*}{ Std. Error } & \multicolumn{2}{|c|}{$\begin{array}{l}95 \% \text { Confidence } \\
\text { Interval for Mean }\end{array}$} & \multirow[b]{2}{*}{ Minimum } & \multirow[b]{2}{*}{ Maximum } \\
\hline & & & & & $\begin{array}{l}\text { Lower } \\
\text { Bound }\end{array}$ & $\begin{array}{l}\text { Upper } \\
\text { Bound }\end{array}$ & & \\
\hline .0 & 1 & .00797234 & .01148193 & .00331454 & .00067707 & .01526761 & .00000000 & .03947368 \\
\hline 0 & 2 & 5640000 & 6200000 & 9460000 & 1456000 & 9800000 & 0000000 & 4200000 \\
\hline 1. & 1 & .00228358 & .00256713 & .00074106 & .00065250 & .00391466 & .00000000 & .00800000 \\
\hline 00 & 2 & 1840000 & 6720000 & 8539000 & 0984000 & 2700000 & 0000000 & 0000000 \\
\hline 2. & 2 & .00792663 & .01120406 & .00233620 & .00308163 & .01277163 & .00000000 & .0517 \\
\hline 00 & 3 & 3690000 & 2700000 & 8560000 & 3670000 & 3700000 & 0000000 & 7900000 \\
\hline 3. & 3 & .00417704 & .00655748 & .00107804 & .00199066 & .00636341 & .00000000 & .03750000 \\
\hline 00 & 7 & 1630000 & 0630000 & 3170000 & 8740000 & 4530000 & 0000000 & 0000000 \\
\hline 4. & 2 & .00624195 & .00649554 & .00132589 & .00349912 & .00898478 & .00000000 & .02564102 \\
\hline 00 & 4 & 6680000 & 4920000 & 7550000 & 8610000 & 4740000 & 0000000 & 5600000 \\
\hline
\end{tabular}




\begin{tabular}{l|l|r|r|r|r|r|r|r}
\hline $\mathrm{T}$ & 1 & .00564575 & .00820952 & .00078996 & .00407974 & .00721175 & .00000000 & .05172413 \\
\hline ot & 0 & 1900000 & 4200000 & 1834000 & 4700000 & 9100000 & 0000000 & 7900000 \\
\hline $\mathrm{al}$ & 8 & & & & & & & \\
\hline
\end{tabular}

ANOVA

\begin{tabular}{lr|r|r|r|r} 
perc_divpol & Sum of Squares & df & Mean Square & F & \multicolumn{1}{c}{ Sig. } \\
\hline Between Groups & .000 & 4 & .000 & 1.547 & .194 \\
\hline Within Groups & .007 & 103 & .000 & & \\
\hline Total & .007 & 107 & & & \\
\hline
\end{tabular}

\section{Means Plots}

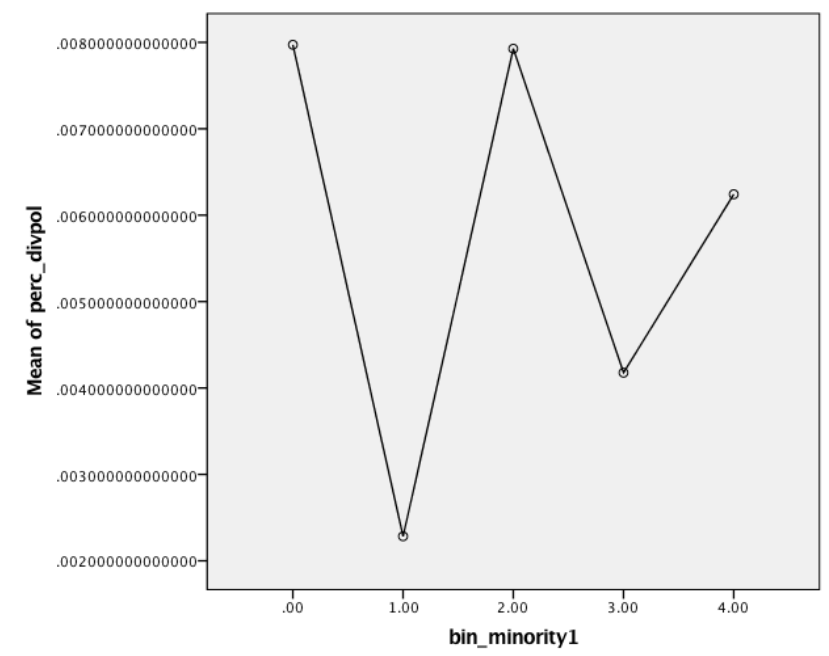

\section{Oneway}

\section{Descriptives}




\begin{tabular}{|c|c|c|c|c|c|c|c|c|}
\hline & \multirow[b]{2}{*}{$\mathrm{N}$} & \multirow[b]{2}{*}{ Mean } & \multirow[b]{2}{*}{$\begin{array}{c}\text { Std. } \\
\text { Deviation }\end{array}$} & \multirow[b]{2}{*}{ Std. Error } & \multicolumn{2}{|c|}{$\begin{array}{l}95 \% \text { Confidence } \\
\text { Interval for Mean }\end{array}$} & \multirow[b]{2}{*}{ Minimum } & \multirow[b]{2}{*}{ Maximum } \\
\hline & & & & & $\begin{array}{l}\text { Lower } \\
\text { Bound }\end{array}$ & $\begin{array}{l}\text { Upper } \\
\text { Bound }\end{array}$ & & \\
\hline .0 & 1 & .00797234 & .01148193 & .00331454 & .00067707 & .01526761 & .00000000 & .03947368 \\
\hline 0 & 2 & 5640000 & 6200000 & 9460000 & 1456000 & 9800000 & 0000000 & 4200000 \\
\hline 1. & \multirow[t]{2}{*}{7} & .00302649 & .00310566 & .00117383 & .00015423 & .00589876 & .00000000 & .00800000 \\
\hline 00 & & 8910000 & 7410000 & 1950000 & 5607000 & 2210000 & 0000000 & 0000000 \\
\hline 2. & 1 & .00783469 & .01397379 & .00387563 & - & .01627897 & .00000000 & .05172413 \\
\hline \multirow[t]{2}{*}{00} & \multirow[t]{2}{*}{3} & \multirow[t]{2}{*}{9740000} & \multirow[t]{2}{*}{3700000} & \multirow[t]{2}{*}{3050000} & .00060957 & \multirow[t]{2}{*}{8800000} & \multirow[t]{2}{*}{0000000} & \multirow[t]{2}{*}{7900000} \\
\hline & & & & & 9286000 & & & \\
\hline 3. & 5 & .00463902 & .00649769 & .00090106 & .00283005 & .00644800 & .00000000 & .03750000 \\
\hline 00 & 2 & 9010000 & 9680000 & 8822000 & 7860000 & 0150000 & 0000000 & 0000000 \\
\hline 4. & 2 & .00624195 & .00649554 & .00132589 & .00349912 & .00898478 & .00000000 & .02564102 \\
\hline 00 & 4 & 6680000 & 4920000 & 7550000 & 8610000 & 4740000 & 0000000 & 5600000 \\
\hline $\mathrm{T}$ & 1 & .00564575 & .00820952 & .00078996 & .00407974 & .00721175 & .00000000 & .05172413 \\
\hline ot & 0 & 1900000 & 4200000 & 1834000 & 4700000 & 9100000 & 0000000 & 7900000 \\
\hline al & 8 & & & & & & & \\
\hline
\end{tabular}

ANOVA

\begin{tabular}{lr|r|r|r|r} 
perc_divpol & Sum of Squares & df & Mean Square & F & \multicolumn{1}{c}{ Sig. } \\
\hline Between Groups & .000 & 4 & .000 & .873 & .483 \\
\hline Within Groups & .007 & 103 & .000 & & \\
\hline Total & .007 & 107 & & & \\
\hline
\end{tabular}

\section{Means Plots}




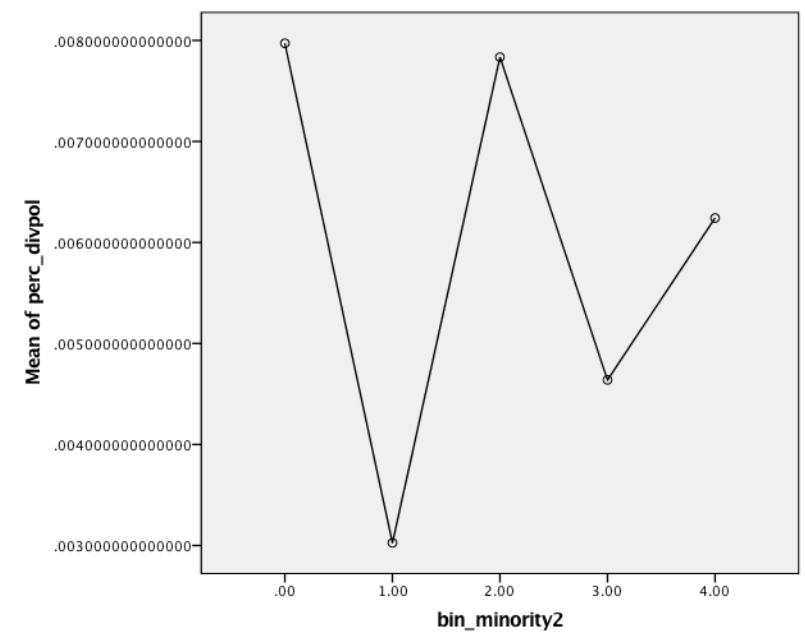

Oneway

Descriptives

\begin{tabular}{|c|c|c|c|c|c|c|c|c|}
\hline \multirow{2}{*}{\multicolumn{2}{|c|}{$\mathrm{N}$}} & \multirow[b]{2}{*}{ Mean } & \multirow[b]{2}{*}{$\begin{array}{c}\text { Std. } \\
\text { Deviation }\end{array}$} & \multirow[b]{2}{*}{ Std. Error } & \multicolumn{2}{|c|}{$\begin{array}{l}95 \% \text { Confidence } \\
\text { Interval for Mean }\end{array}$} & \multirow[b]{2}{*}{ Minimum } & \multirow[b]{2}{*}{ Maximum } \\
\hline & & & & & $\begin{array}{l}\text { Lower } \\
\text { Bound }\end{array}$ & $\begin{array}{l}\text { Upper } \\
\text { Bound }\end{array}$ & & \\
\hline .0 & 1 & .00797234 & .01148193 & .00331454 & .00067707 & .01526761 & .00000000 & .03947368 \\
\hline 0 & 2 & 5640000 & 6200000 & 9460000 & 1456000 & 9800000 & 0000000 & 4200000 \\
\hline 1. & 3 & .00463034 & .00904306 & .00155087 & .00147507 & .00778562 & .00000000 & .05172413 \\
\hline 00 & 4 & 8320000 & 0950000 & 2160000 & 5190000 & 1450000 & 0000000 & 7900000 \\
\hline 2. & 3 & .00544300 & .00731909 & .00118731 & .00303728 & .00784873 & .00000000 & .03750000 \\
\hline 00 & 8 & 6690000 & 1150000 & 3370000 & 1300000 & 2090000 & 0000000 & 0000000 \\
\hline 3. & 2 & .00624195 & .00649554 & .00132589 & .00349912 & .00898478 & .00000000 & .02564102 \\
\hline 00 & 4 & 6680000 & 4920000 & 7550000 & 8610000 & 4740000 & 0000000 & 5600000 \\
\hline $\mathrm{T}$ & 1 & .00564575 & .00820952 & .00078996 & .00407974 & .00721175 & .00000000 & .05172413 \\
\hline ot & 0 & 1900000 & 4200000 & 1834000 & 4700000 & 9100000 & 0000000 & 7900000 \\
\hline al & 8 & & & & & & & \\
\hline
\end{tabular}

\section{ANOVA}

perc_divpol 


\begin{tabular}{l|r|r|r|r|r}
\hline Between Groups & .000 & 3 & .000 & .538 & .658 \\
\hline Within Groups & .007 & 104 & .000 & & \\
\hline Total & .007 & 107 & & & \\
\hline
\end{tabular}

\section{Means Plots}

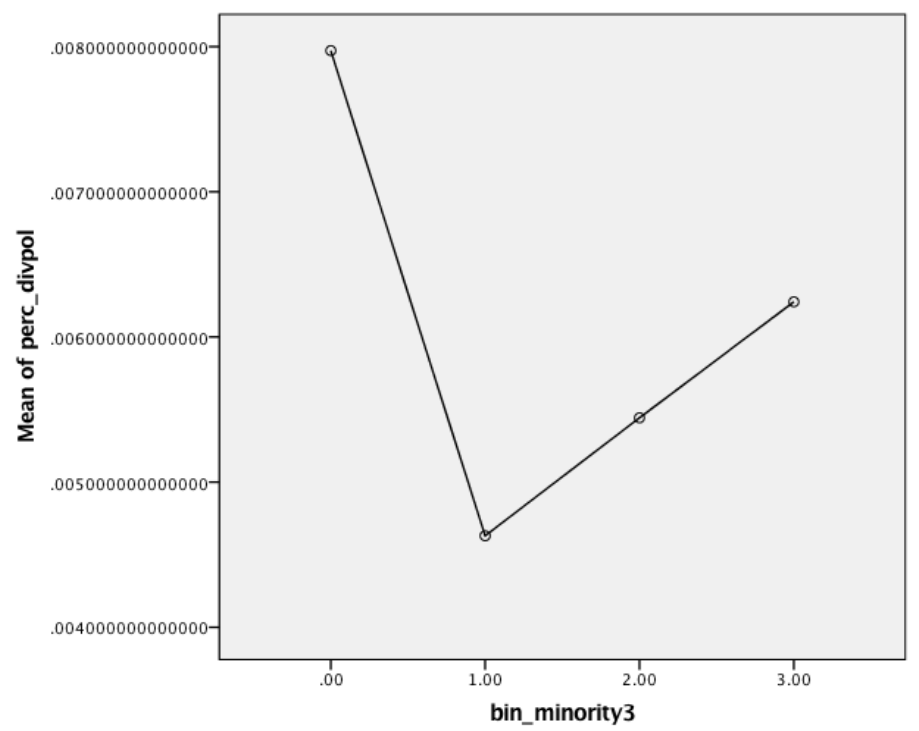

\section{Oneway}

\section{Descriptives}

perc_divpol

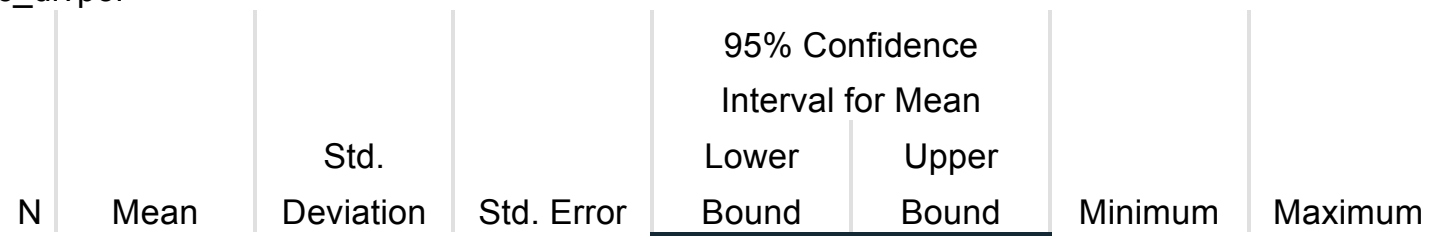




\begin{tabular}{|l|r|r|r|r|r|r|r|r|}
\hline .0 & 1 & .00797234 & .01148193 & .00331454 & .00067707 & .01526761 & .00000000 & .03947368 \\
\hline 0 & 2 & 5640000 & 6200000 & 9460000 & 1456000 & 9800000 & 0000000 & 4200000 \\
\hline 1. & 4 & .00503308 & .00860225 & .00132735 & .00235243 & .00771373 & .00000000 & .05172413 \\
\hline 00 & 2 & 2620000 & 1520000 & 6230000 & 2340000 & 2910000 & 0000000 & 7900000 \\
\hline 2. & 3 & .00509588 & .00756245 & .00138070 & .00227202 & .00791975 & .00000000 & .03750000 \\
\hline 00 & 0 & 7570000 & 1860000 & 8490000 & 1640000 & 3500000 & 0000000 & 0000000 \\
\hline 3. & 2 & .00624195 & .00649554 & .00132589 & .00349912 & .00898478 & .00000000 & .02564102 \\
\hline 00 & 4 & 6680000 & 4920000 & 7550000 & 8610000 & 4740000 & 0000000 & 5600000 \\
\hline $\mathrm{T}$ & 1 & .00564575 & .00820952 & .00078996 & .00407974 & .00721175 & .00000000 & .05172413 \\
\hline ot & 0 & 1900000 & 4200000 & 1834000 & 4700000 & 9100000 & 0000000 & 7900000 \\
\hline $\mathrm{al}$ & 8 & & & & & & & \\
\hline
\end{tabular}

ANOVA

\begin{tabular}{lr|r|r|r|r} 
perc_divpol & Sum of Squares & df & Mean Square & F & \multicolumn{1}{c}{ Sig. } \\
\hline Between Groups & .000 & 3 & .000 & .479 & .697 \\
\hline Within Groups & .007 & 104 & .000 & & \\
\hline Total & .007 & 107 & & & \\
\hline
\end{tabular}

\section{Means Plots}




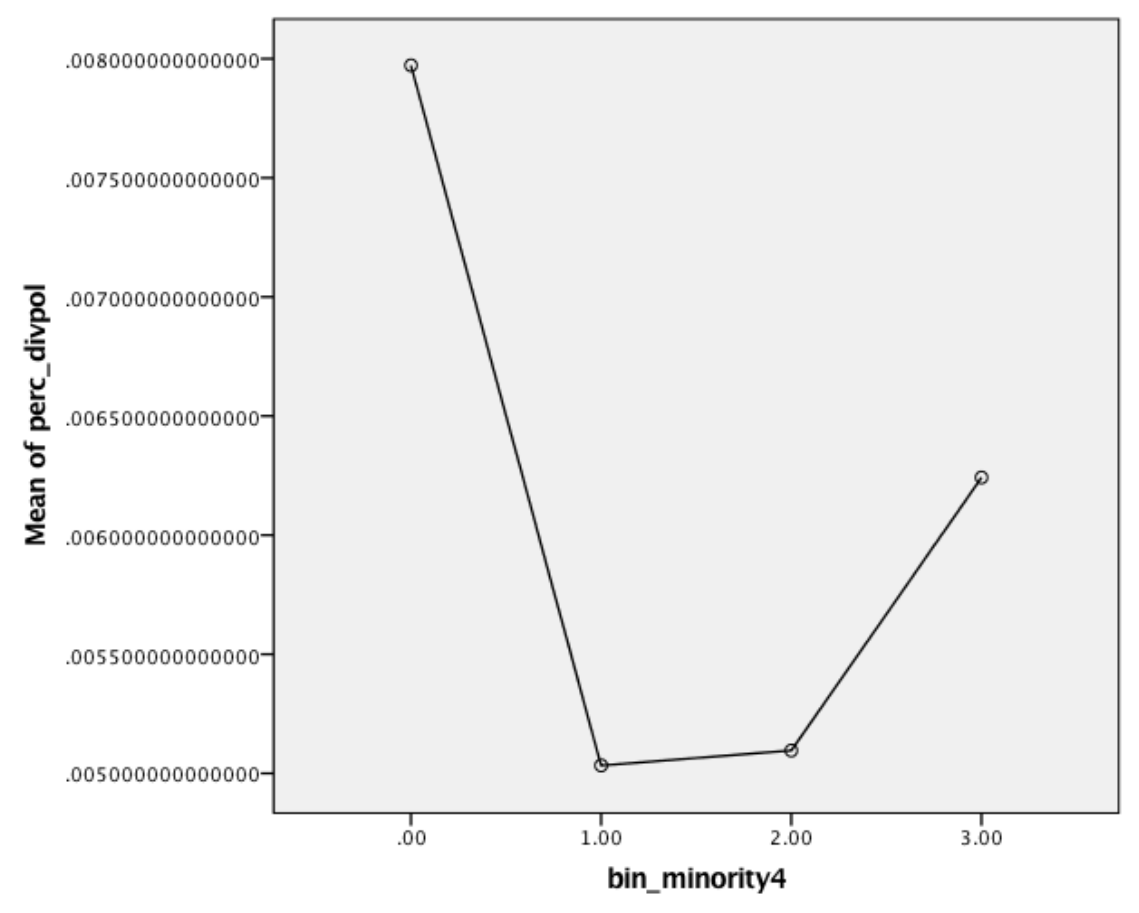

\section{Oneway}

\section{Descriptives}

\begin{tabular}{|c|c|c|c|c|c|c|c|c|}
\hline & \multirow[b]{2}{*}{$\mathrm{N}$} & \multirow[b]{2}{*}{ Mean } & \multirow[b]{2}{*}{$\begin{array}{c}\text { Std. } \\
\text { Deviation }\end{array}$} & \multirow[b]{2}{*}{ Std. Error } & \multicolumn{2}{|c|}{$\begin{array}{l}95 \% \text { Confidence } \\
\text { Interval for Mean }\end{array}$} & \multirow[b]{2}{*}{ Minimum } & \multirow[b]{2}{*}{ Maximum } \\
\hline & & & & & $\begin{array}{l}\text { Lower } \\
\text { Bound }\end{array}$ & $\begin{array}{l}\text { Upper } \\
\text { Bound }\end{array}$ & & \\
\hline .0 & 1 & .00797234 & .01148193 & .00331454 & .00067707 & .01526761 & .00000000 & .03947368 \\
\hline 0 & 2 & 5640000 & 6200000 & 9460000 & 1456000 & 9800000 & 0000000 & 4200000 \\
\hline 1. & 2 & .00741946 & .01152268 & .00251445 & .00217440 & .01266452 & .00000000 & .05172413 \\
\hline 00 & 1 & 3040000 & 1100000 & 5160000 & 1480000 & 4600000 & 0000000 & 7900000 \\
\hline 2. & 3 & .00464242 & .00678310 & .00108616 & .00244359 & .00684124 & .00000000 & .03750000 \\
\hline 00 & 9 & 0290000 & 6170000 & 6270000 & 1640000 & 8950000 & 0000000 & 0000000 \\
\hline 3. & 2 & .00624195 & .00649554 & .00132589 & .00349912 & .00898478 & .00000000 & .02564102 \\
\hline 00 & 4 & 6680000 & 4920000 & 7550000 & 8610000 & 4740000 & 0000000 & 5600000 \\
\hline
\end{tabular}




\begin{tabular}{l|r|r|r|r|r|r|r|r}
\hline T & 9 & .00606602 & .00857554 & .00087523 & .00432845 & .00780359 & .00000000 & .05172413 \\
ot & 6 & 3160000 & 9170000 & 8322000 & 5400000 & 0910000 & 0000000 & 7900000 \\
\hline al & & & & & & & \\
\hline
\end{tabular}

\begin{tabular}{lr|r|r|r|r}
\multicolumn{7}{c}{ ANOVA } \\
perc_divpol & \multicolumn{7}{c}{} & & \\
& Sum of Squares & df & Mean Square & F & \multicolumn{1}{c}{ Sig. } \\
\hline Between Groups & .000 & 3 & .000 & .727 & .538 \\
\hline Within Groups & .007 & 92 & .000 & & \\
\hline Total & .007 & 95 & & & \\
\hline
\end{tabular}

\section{Means Plots}

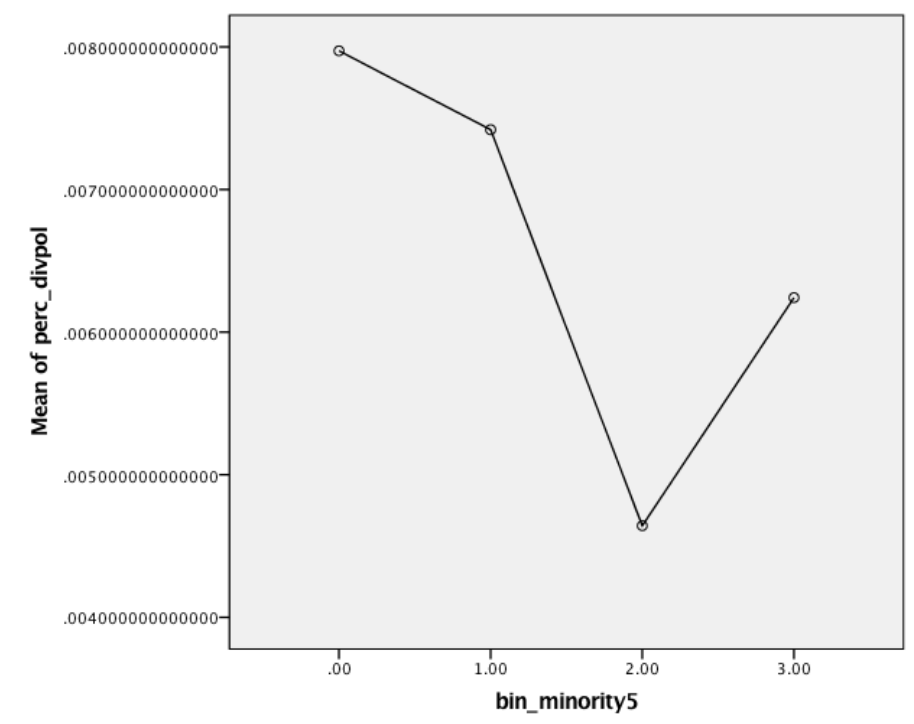

\section{Oneway}

Descriptives 


\begin{tabular}{|c|c|c|c|c|c|c|c|c|}
\hline \multirow{2}{*}{\multicolumn{2}{|c|}{$\mathrm{N}$}} & \multirow[b]{2}{*}{ Mean } & \multirow[b]{2}{*}{$\begin{array}{c}\text { Std. } \\
\text { Deviation }\end{array}$} & \multirow[b]{2}{*}{ Std. Error } & \multicolumn{2}{|c|}{$\begin{array}{l}95 \% \text { Confidence } \\
\text { Interval for Mean }\end{array}$} & \multirow[b]{2}{*}{ Minimum } & \multirow[b]{2}{*}{ Maximum } \\
\hline & & & & & $\begin{array}{l}\text { Lower } \\
\text { Bound }\end{array}$ & $\begin{array}{l}\text { Upper } \\
\text { Bound }\end{array}$ & & \\
\hline .0 & 1 & .00797234 & .01148193 & .00331454 & .00067707 & .01526761 & .00000000 & .03947368 \\
\hline 0 & 2 & 5640000 & 6200000 & 9460000 & 1456000 & 9800000 & 0000000 & 4200000 \\
\hline 1. & 4 & .00501659 & .00839855 & .00125198 & .00249338 & .00753979 & .00000000 & .05172413 \\
\hline 00 & 5 & 2890000 & 3420000 & 2420000 & 8110000 & 7670000 & 0000000 & 7900000 \\
\hline 2. & 3 & .00534402 & .00712234 & .00117090 & .00296931 & .00771873 & .00000000 & .03750000 \\
\hline 00 & 7 & 5200000 & 6430000 & 6540000 & 6670000 & 3730000 & 0000000 & 0000000 \\
\hline 3. & 1 & .00647124 & .00752313 & .00201064 & .00212751 & .01081497 & .00000000 & .02564102 \\
\hline 00 & 4 & 6070000 & 9480000 & 3600000 & 4660000 & 7500000 & 0000000 & 5600000 \\
\hline $\mathrm{T}$ & 1 & .00564575 & .00820952 & .00078996 & .00407974 & .00721175 & .00000000 & .05172413 \\
\hline ot & 0 & 1900000 & 4200000 & 1834000 & 4700000 & 9100000 & 0000000 & 7900000 \\
\hline al & 8 & & & & & & & \\
\hline
\end{tabular}

ANOVA

\begin{tabular}{lr|r|r|r|r} 
perc_divpol & Sum of Squares & df & Mean Square & F & \multicolumn{1}{c}{ Sig. } \\
\hline Between Groups & .000 & 3 & .000 & .466 & .707 \\
\hline Within Groups & .007 & 104 & .000 & & \\
\hline Total & .007 & 107 & & & \\
\hline
\end{tabular}

Means Plots 


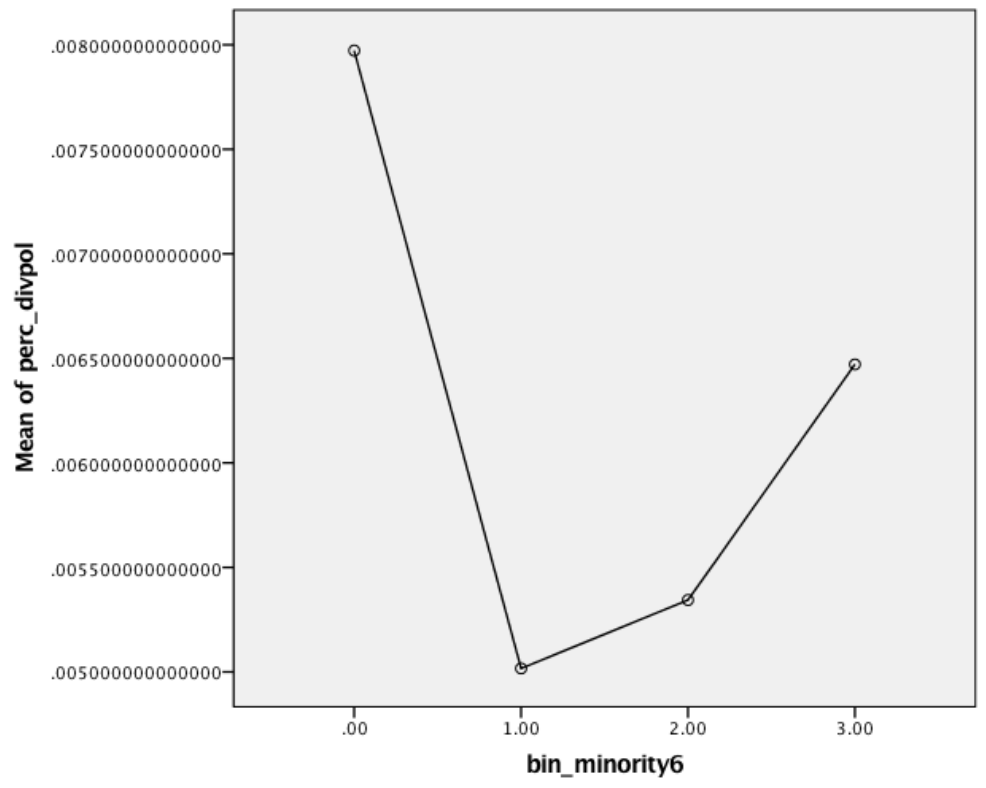

